\title{
3 Der anonyme Tractatus contra Graecos (1252)
}

\subsection{Aufbau und Methode}

Um dem Charakter des Tractatus contra Graecos gerecht zu werden, empfiehlt es sich, ihn mehr als Dossier denn als in sich geschlossene Abhandlung zu sehen. Der Aufbau des Gesamtwerkes gliedert sich in zwei Teile: Der erste ist der Hauptteil bzw. in der werkeigenen Terminologie der Tractatus maior ${ }^{410}$, der aus der Feder des Dominikaners stammt und aus insgesamt sechs Abschnitten bzw. in sich geschlossenen Textteilen besteht. Der zweite ist der umfangreiche Appendix: Hier kompiliert der Autor insgesamt neun Texte anderer Autoren bzw. Quellentexte der Tradition, die er ein- und ausleitet und zum Teil mit großem Textumfang kommentiert.

Gliederung des Tractatus contra Graecos:

\section{Tractatus maior}

0. Prolog / TcG Prol. 1-50 (p. 3-5)

1. Filioque: Prima distinctio de processione Spiritus Sancti / TcG I, 1-1134 (p. 6-54)

2. Purgatorium/Eschatologie: Secunda distinctio de animabus defunctorum / TcG II, 1- 326 (p. 55-68)

3. AzYMEn: Tertia distinctio de sacramento altaris / TcG III, 1-384 (p. 69-85)

4. PRIMAT Roms: Quarta distinctio in qua ostenditur quod papa sit summus pastor omnium ecclesiarum / TcG IV, 1-602 (p. 86-111)

5. DIE GRÜNDE DES SCHISMAS: De quatuor causis schismatis / TcG V, 1-55 (p. 112114)

\section{Appendix}

6. KonZILIEngeschichte: (A) De conciliis generalibus (B) et particularibus / TcG App. I, 1-422 (p. 115-135)

7. Interpretation Der CANONEs: (A) Canones Apostolorum und (B) Responsio Latinorum ad auctoritatem canonum / TcG App. II, 1-606 (p. 136-161)

8. ILLUSTRATION EINER FÄLSCHUNG des Quicumque vult durch einen griechischen Mönch: Augenzeugenbericht zweier Zisterzienser / TcG App. III, 1- 92 (p. 162-164)

9. Das Symbolum der 318 Väter von Nizäa / TcG App. IV, 1-16 (p. 165)

10. Die Exkommunikationen von 1054: Der Bericht des Pantaleo von Amalfi / TcG App. V, 1-40 (p. 166-167)

11. DiE Sicht DES 12. JhdTS.: (A) Hugo Eterianus: De heresibus quas in Latinos Greci devolvunt; und (B) Leo Tuscus: De heresibus et prevaricationibus Grecorum / TcG App. VI, 1-448 (p. 168-187) 
12. Dominikanische Quellen: (B) Die Syllogismen des Eustratios von Nikaia und refutationes der dominikanischen Autoren (A) Nicolaus de Syria und (C) Iacobus Mediolanensis / TcG App. VII, 1-277 (p. 188-196)

13. Konstantinopel: (A) Bilinguales Brieffragment des Patriarchen Germanos II. und (B) refutatio des anonymen Autors / TcG App. VIII, 1- 414 (p. 197-209)

14. TIFLIS: Brieffragment der Dominikaner aus Georgien / TcG App. IX, 1-62 (p. 210 211)

Die Qualifizierung des Tractatus contra Graecos als kontroverstheologisches Werk verlangt an dieser Stelle - noch vor der detaillierten Darstellung des Inhalts - eine Einordnung in jene Kriteriologie von Polemik, die in den Vorbemerkungen der vorliegenden Studie definiert wurde. ${ }^{411}$ Vor dem Hintergrund der drei Merkmale von Polemik innerhalb der Ost-West-Kontroverse - Auseinandersetzung in Form von Abgrenzung; keine Konsens- oder Kompromissorientierung; Anpassung der Mittel zur Erreichung der Ziele - soll eruiert werden, inwiefern der Tractatus contra Graecos jene Merkmale trägt und von daher unter das Stichwort Polemik zu stellen ist.

Zunächst gilt auch und besonders für den Tractatus contra Graecos, dass er sich mit seinem Gegenüber in klarer Abgrenzung auseinandersetzt. Für diese Auseinandersetzung kann der Autor eigenen Angaben zufolge zu einem großen Ausmaß auf schriftliche griechische Quellen aus den klösterlichen Archiven und Bibliotheken zurückgreifen, außerdem auf mündlich geführte Debatten, auf die er gelegentlich rekurriert und die er als mündliche Quellen heranzieht. Zweitens zielen polemische Werke nach oben genannter Definition nicht auf einen Konsens oder auf Kompromisslösungen, sondern sie konzentrieren sich auf die Verteidigung und/oder Vermittlung des jeweils eigenen Gedanken-, Glaubens- oder Traditionsguts. Im Fall des Tractatus contra Graecos bedeutet das, dass den Byzantinern Wege aufgezeigt werden sollen, die unerlässlich für die diesseitige Einheit der Kirche und für die jenseitige Erlangung des Seelenheiles sind, und dass diese Wege ident sind mit der lateinischwestlichen Tradition inklusive ihrer Hermeneutik bzw. deren Verständnis in den $\mathrm{Au}$ gen des anonymen Autors. Die diesseitige Einheit und das jenseitige Seelenheil stellen im Grunde sowohl die Vorzeichen als auch die Bedingungen aller weiteren Ausführungen dar. Der Dominikaner hat sein Werk expressis verbis als Handreichung für jene verfasst, die in direkter Auseinandersetzung und Konfrontation mit den griechischen Argumenten stehen. ${ }^{412}$ Dabei soll der Traktat dem Rezipienten als Modell und Muster dienen, wie ein solcher Disput im Idealfall zu verlaufen habe, und ihm Wege und Mittel aufzeigen, das Eigene argumentativ stichhaltig und plausibel dem Gegenüber zu präsentieren. Das dritte Merkmal, das den Traktat als polemisches Werk charakterisiert, ist der diffamierende Umgang mit der Person, der Meinung oder der Tradition

411 Vgl. dazu die Seiten 5-8 der vorliegenden Studie.

412 Als ein Beispiel sei TcG IV, 63-65 (p. 88) genannt: Super quo admonitum uolumus esse lectorem, ut habeat quid aduersariis ueritatis debeat respondere [...]. 
des Gegenübers. Die diesbezüglichen Stichworte im Tractatus contra Graecos stehen in der klassischen Tradition der Kontroverstheologie, wenn etwa die Zuschreibungen mendax/mendaciter (lügen, bewusst Falsches erfinden und verbreiten, betrügen), delirare/deliramentum (schwätzen, Unwahres faseln, im Wahn reden) und malitiosus/ malitia (arglistig, tückisch sein, hinterlistig und bewusst hintergehend handeln) verwendet werden. ${ }^{413}$ Mehr noch aber, als das Argumentum ad hominem in seinen verschiedenen Ausprägungen anzuwenden, bezeichnet der Dominikaner - ebenfalls in kontroverstheologischer Tradition stehend - die Byzantiner als blind oder verblendet, als vom bzw. von den Falschen verführt und zu kurzsichtig, um der Wahrheit entsprechend zu folgen oder sie auch nur erahnen zu können. Umso mehr bedürfe es der Anstrengung der Lateiner, allen voran des römischen Papstes als des Hauptes aller Kirchen, die griechische Kirche zurückzuführen und so die gravierende Verletzung, ja den Bruch der Kirche zu heilen. Von den Byzantinern erwarte man entsprechende Bereitschaft und Kooperation. Vor diesem Hintergrund mangelt es dem Tractatus contra Graecos nicht an Fingerzeigen und Hinweisen, die die griechische Kirche vermittelt durch das Bemühen der lateinischen - auf den richtigen Weg zurückbringen sollen.

\subsection{Inhalte, Argumente und theologischer Ertrag}

Im Folgenden werden die beiden Teile - Tractatus maior und Appendix - vorgestellt, indem ihre einzelnen Textteile der Reihe nach auf die Inhalte, die Argumentationsgänge und den theologischen Ertrag hin befragt werden. Auf diese Weise soll neben den überlieferungsgeschichtlichen Besonderheiten dieses Dossiers dargestellt werden, ob bzw. auf welche Weise sein Autor Neues oder Originelles bietet, das letztlich auch die inhaltliche bzw. theologische Sonderstellung des Traktats im literarischen Kanon der lateinisch-griechischen Kontroverse rechtfertigt.

\subsubsection{Tractatus maior}

\subsubsection{Prolog: Programm und Methode}

Zunächst ist festzuhalten, dass es sich beim Prologus des Werkes um einen Teilprolog handelt: Angekündigt werden die Inhalte und die Absicht des Verfassers nur, insofern sie den Tractatus maior und damit das eigene Werk des Dominikaners betreffen. Der Appendix hingegen wird weder der Sache noch seinem Umfang nach angekündigt, was den Revisor Bartholomeus Constantinopolitanus rund 50 Jahre später dazu veranlassen wird, eine entsprechend ergänzende Textpassage in den Prolog einzufü-

413 Vgl. etwa TcG I, 77-81 (p. 9); TcG I, 465 - 468 (p. 26); TcG II, $294-297$ (p. 67); TcG IV, 141-149 (p. 82); TcG IV, 562-569 (p. 110) usw. 
gen. ${ }^{414}$ Der verhältnismäßig kurze Prolog bietet zunächst Informationen zum unmittelbaren Anlass bzw. zum Entstehungsort des Traktats und gibt Hinweise auf das theologische wie methodische Programm seines Autors. Die bio- und bibliographischen Eckdaten, die auf diese Weise und ergänzt durch weitere Angaben im nachfolgenden Textverlauf preisgegeben werden, zeichnen den Traktat als Produkt der dominikanischen Gelehrsamkeit im Konvent von Konstantinopel, der im Jahr 1252 verfasst wurde ${ }^{415}-\mathrm{zu}$ einer Zeit also, in der der Konvent in der ehemals byzantinischen Hauptstadt bereits auf mehrere Jahre Bestand und Erfahrung im ost-westlichen Disput zurückblicken konnte. Wenn auch die Griechen, so der Dominikaner im Werkprolog, in Besitz und Verwaltung einer ungemein reichen und wertvollen kirchlichen Tradition sind und sich bis in seine Gegenwart in den Spuren dieser Tradition bewegen, so sei dennoch eine Gefahr zu beobachten, die die griechische Kirche in ihren Grundfesten schädigt: Die Griechen seien geschlagen von Blindheit, die sie getrennt von der hochheiligen römischen Kirche (sacrosancta ecclesia Romana) verharren und unzählbaren Irrtümern anhängen lässt. Diese Irrtümer seien letztlich auf eine einzige Quelle rückzuführen: auf Photius, den berühmten Patriarchen von Konstantinopel, der wie ein Sämann zu seiner Zeit unermesslich viele Keime der Häresie ausgesät habe, sodass man ihn ohne Zweifel als den ersten Begründer dieses Schismas (primus inuentor huius schismatis) bezeichnen müsse. Ihrem Mangel an Wissen und der bitteren Missgunst (propter defectum scientie [...] et invidie amaritudinem) sei es geschuldet, dass jene Keime seither kräftig und fortwährend sprießen. Unter den vielen Irrtümern seien es im Besonderen vier Themen, in deren Auffassung die griechische von der lateinischen Kirche abweicht: Dabei gehe es um den Ausgang des Heiligen Geistes (de processione Spiritus Sancti), um die Seelen der Verstorbenen (de animabus defunctorum), um das ungesäuerte oder gesäuerte eucharistische Brot (de azimo et fermentato) und um den Gehorsam gegenüber der römischen Kirche (de obedientia ecclesie Romane). Da sich die byzantinischen Zeitgenossen - ganz Kinder ihrer Vorfahren - weder von Vernunftargumenten noch durch die Heilige Schrift an sich von der Wahrheit überzeugen ließen, sondern sich zur Rechtfertigung ihrer Positionen ausschließlich auf die eigene griechisch-patristische Tradition stützen, liege - so der Dominikaner - die Entscheidung der methodischen Vorgehensweise des Tractatus maior auf der Hand: Die patristischen und zeitgenössischen theologischen Autoritäten der Griechen seien daraufhin zu prüfen, ob und inwiefern sie tatsächlich im Widerspruch zur lateinischen Position stehen, oder ob sie nicht vielmehr einer Hermeneutik unter falschen Voraussetzungen bzw. einer - bewusst oder unbewusst verkürzten Interpretation unterworfen seien. Letzteres aufzuzeigen sei die Absicht des

414 Vgl. dazu die Ausführungen auf Seite 204 der vorliegenden Studie.

415 Vgl. das Explicit des Tractatus maior und die Beständigkeit der Jahreszahl 1252 in den Varianten der handschriftlichen Überlieferung: Hec autem scripta sunt anno Domini $M^{\circ} C C^{\circ} L I I^{\circ}$ in ciuitate Constantinopoli a fratribus ordinis predicatorum, ad edificationem ecclesie et profectum animarum, ad laudem et gloriam Patris et Filii et Spiritus Sancti, cui est honor et gloria in secula seculorum. Amen. (TcG V, 51-55 (p. 114)) 
Traktats, das heißt zu erweisen, dass den Autoritäten der Griechen durch deren zeitgenössische Fehlverwendung bzw. -interpretation Gewalt angetan werde und dies letztlich sogar so weit führe, dass der Riss des Schismas die wahre Kirche Jesu Christi schwer verletze. Die Griechen aber seien starrsinnig, so der Autor, und von daher sei es notwendig, sie explizit und anhand ihrer eigenen Quellen (ex suis libris) ihres Starrsinns zu überführen und von der Wahrheit zu überzeugen, damit auf diese Weise der Riss geheilt und die Kircheneinheit wiederhergestellt werden könne. Der Prolog gibt am Ende einen Hinweis darauf, dass der Dominikaner seinen Traktat als Auftragswerk der Mitbrüder verfasst hat, und schließt mit der Captatio benevolentiae.

Was sich später auf der Agenda der einzigen beiden mittelalterlichen Konzilien wiederfinden wird, die sich unter verschiedenen Vorzeichen und Bedingungen der Union mit der griechischen Kirche widmen, ist hier als frühest auffindbare lateinische Quelle belegt: Der Kanon jener vier theologischen Konfliktthemen, die zu lösen zur Standardanforderung und -voraussetzung von Kircheneinheit bis hin zum Konzil von Ferrara-Florenz (1438/39) und inoffiziell weit darüber hinaus werden sollte. Die Methodenwahl des Dominikaners, sich (beinahe) ausschließlich auf die griechischen Quellen zu stützen, zeigt zunächst eine gewichtige Vorannahme des Autors: Die patristischen und konziliaren Autoritäten beider Seiten, der griechischen wie der lateinischen, sind die eine Grundlage und als solche - freilich neben der Heiligen Schrift - per se gemeinsames Erbe der Kirche Jesu Christi. Den hermeneutischen Schlüssel zu diesem gemeinsamen Erbe legt der Dominikaner in die Hand und Verantwortung der lateinischen, weil wahren Theologie und Kirche, deren und letztlich des Papstes Aufgabe es ist, die Griechen heimzuholen und sie so vor gravierenden Gefahren bis hin zum Verlust ihres Seelenheiles zu bewahren.

Im Prolog findet sich also die klassische Ankündigung des inhaltlichen Programms und seiner Methode, und beides zeichnet - aus der rückblickenden Perspektive - wesentlich für die Originalität und große Verbreitung des Werkes verantwortlich:

Contra quos errores pestiferos quamuis multorum iam fidelium desudauerit labor, et plurima scripta ad defensionem uere fidei catholicis dimiserint perlegenda : Quia tamen moderni Greci noui pariter et antiqui scismatici nec argumentis uel rationibus, nec sacre scripture testimoniis nisi suorum scriptis sanctorum, quibus plurimum innituntur tam apocrifis quam ueris, uolunt superari, fraternis quandoque precibus inclinatus, qualiter ex suis libris eorum conuincatur pertinacia, uirtute qua potero ostendere laborabo. (TcG Prol., 36-44 (p. 4-5))

Zwar wurde schon die Mühe vieler Gläubiger gegen diese schädlichen Irrtümer aufgebracht, und bereits viele Schriften wurden zur Verteidigung des wahren katholischen Glaubens zur detaillierten Lektüre geschrieben. Weil aber die griechischen Zeitgenossen genauso wie ihre schismatischen Ahnen sich weder von Argumenten noch von vernünftigen Beweisgängen und den Zeugnissen der Heiligen Schrift, sondern nur von den Schriften ihrer Heiligen überzeugen lassen wollen, denen sie - gleich ob apokryph oder wahr - sehr anhängen, beuge ich mich den mitbrüderlichen Bitten und werde mich nach Kräften zu zeigen bemühen, wie der Starrsinn der Griechen anhand ihrer eigenen Bücher erwiesen werden kann. 
Zwar stellt sich der Dominikaner in die Reihe und Tradition seiner gelehrten Vorgänger, die bereits Mühen und Aufwand zur Verteidigung des wahren katholischen Glaubens gegen die Griechen investiert hatten. Er betont aber, dass wegen des Starrsinns der Griechen (pertinacia) die bisherigen Mühen keinen Erfolg gebracht hätten und dass es deswegen nötig sei, einen neuen Weg einzuschlagen: Über Erfolg oder Scheitern entscheide letztlich, ob und inwieweit die lateinische Kirche es schaffe, auf die Spezifika und die Tradition der griechischen Kirche einzugehen. Überzeugungsarbeit sei daher nicht allein durch Argument und Vernunft bzw. durch Schriftund Traditionsbeweis zu leisten, sondern man müsse zunächst einen Schritt zurückgehen und sich die traditionellen wie neuen Argumentationsgänge der Byzantiner aneignen. Vor dem Hintergrund des gemeinsamen Erbes sei es schließlich das Ziel, diese davon zu überzeugen, dass die von ihnen selbst ins Feld geführten Quellen und Autoritäten der lateinischen Position nicht nur nicht widersprechen, sondern - im Gegenteil - diese sogar stützen und untermauern. Diesen neuen Weg, den der Dominikaner mit seinem Werk einschlägt, begründet er weiter: Die bereits lange andauernde ost-westliche Kontroverse habe gezeigt, dass die grundlegenden und gemeinsamen Autoritäten, das heißt in erster Linie die Heilige Schrift und die Beschlüsse der gemeinsam rezipierten Konzilien, von beiden Seiten immer wieder für ihre jeweils eigenen Zwecke interpretiert worden seien. Gegensätzliche Positionen und Wahrheiten seien so auf Basis derselben Quellen argumentiert worden. Dies habe letztlich nicht zur Annäherung, sondern im Gegenteil zu wiederkehrender Verhärtung der Fronten geführt. Ein weiteres Werk nach diesem Muster sei demnach nicht zielführend. Vielmehr gelte es - so die zweite Stufe im Begründungsgang seiner Methodenwahl -, die griechischen Autoritäten auf die lateinischen Positionen hin zu befragen und so den Starrsinn der Byzantiner mit deren eigenen Waffen zu schlagen (ex suis libris eorum convincatur pertinacia). Wenn ihnen vor Augen geführt werde, dass ihre eigenen Autoritäten der lateinischen Position nicht widersprechen, sondern dass sie im Gegenteil diese sogar befürworten und vertreten, dann gebe es keinen plausiblen Grund mehr, warum sich die griechische Kirche weiterhin der Bringschuld des Gehorsams gegenüber der römischen Kirche verweigere. Die lateinische Position könne so von den Byzantinern nicht mehr als einseitig entlarvt, sondern müsse von ihnen als Wahrheit anerkannt und als solche angeeignet werden. Damit aber sei schließlich das übergeordnete Ziel aller Bemühungen in der lateinisch-griechischen Kontroverse, nämlich die Rückführung (reductio) der griechischen Kirche unter römische Obödienz, erreicht.

In konkreter Umsetzung dieses Erfolg verheißenden Rezeptes zitiert der Dominikaner die Kirchenväter und Autoritäten der griechischen Tradition zur Untermauerung der lateinischen und geht kaum einen Schritt ohne griechisch-patristische Absicherung. Dabei ist interessant zu sehen, dass einige Themenbereiche runder und fundierter argumentiert sind, andere hingegen brüchig und mit unterschiedlich verankerter theologischer Substanz. Auf diese Aspekte und Tendenzen wird bei der Analyse der einzelnen Textteile eingegangen werden. Für die konkrete Struktur der Beweisgänge ergibt sich somit Folgendes: Dort, wo der Autor seiner eigenen Methodik in 
größtmöglicher Stringenz gerecht wird (dies ist vor allem in der ersten und der dritten distinctio über das Filioque und die Azymen der Fall), ergibt sich eine doppelte Beweisführung: Die Triebfeder jedes einzelnen Themas ist die zu widerlegende Meinung der Griechen. Der Dominikaner stellt zu diesem Zweck zunächst die griechischen Positionen der Reihe nach voran, um diese schließlich Schritt für Schritt mithilfe der griechischen Quellen zu den gängigen Schrift- und Konzilstexten zu korrigieren. In anderen Fällen weicht der Autor zwar der Gliederung, nicht aber dem Inhalt nach von seiner eigenen Methode ab. Dies ist vor allem in der zweiten und vierten distinctio über die Seelen der Verstorbenen und den Primat Roms der Fall. Im Bezug auf die zweite distinctio mag dies der Neuartigkeit des Inhalts und dem weitgehenden Fehlen von Vorlagen geschuldet sein. Im zweiten Fall dient dieser Befund zur Untermauerung der These, dass es sich bei der vierten distinctio um eine im Grunde eigenständige Abhandlung über die Vorrangstellung Roms handelt, die in den Duktus des Traktats integriert wurde. Auf beides wird im Einzelnen eingegangen werden.

Die Analyse des Prologs abschließend seien noch einmal die beiden Schlüsselbegriffe genannt, mit denen der Autor die griechische Kirche charakterisiert und mit deren Verwendung er sich in eine klassische und traditionelle Linie stellt: (a) pertinacia und (b) caecitas. (a) Durch die Zuschreibung von pertinax wird den Byzantinern nicht nur ein Fehlverhalten attestiert, sondern sie werden in weit größerem Ausmaß dessen beschuldigt, was durch die Theologiegeschichte hindurch - beginnend in patristischer Zeit - als Kriterium und Konstante von Häresie angesehen wurde: die Beharrlichkeit bzw. der Starrsinn, der eine Irrmeinung erst zur Häresie macht. Indem sich die byzantinischen Zeitgenossen beharrlich der Wahrheit verweigern, sei die Gefahr nicht nur für sie selbst und ihr eigenes Seelenheil, sondern für die Kirche als ganze offenkundig. Von daher sei es auch klar, dass es nicht eine nebensächliche, sondern eine drängende und in gewisser Weise lebensnotwenige Angelegenheit der Kirche sei, diese Beharrlichkeit der Byzantiner zu brechen und die Einheit wiederherzustellen. (b) Auf biblischem Boden und ebenfalls in der langen Tradition der Kontroverstheologie steht der Vorwurf der Blindheit: Das Begriffspaar caecitas und incredulitas aus dem Röm 11 verweist auf jene Blindheit bzw. Verstockung ( $\pi \omega \omega \rho \omega \sigma \iota \varsigma$ im griechischen Text), die dem Glauben im Weg steht und der Barmherzigkeit Gottes bedarf. Die caecitas cordis aus Eph 4,18 ist Ausdruck einer Gottfernheit (alienati a vita Dei), die einhergeht mit ignorantia und einem verdunkelten intellectus beides Begriffe bzw. Motive, die im Vorwurf des Dominikaners der griechischen Kirche gegenüber nicht nur mitschwingen, sondern an mehreren Stellen explizit zum Ausdruck kommen. ${ }^{416}$

416 Vgl. etwa TcG Prol., 2-10 (p. 3); TcG Prol., 38 - 44 (p. 4-5); TcG I, , 830 - 834 (p. 41); TcG IV, 541 - 543 (p. 109); TcG IV, 581-584 (p. 110). 


\subsubsection{Filioque: Prima distinctio de processione Spiritus Sancti}

Die erste distinctio über den Hervorgang des Heiligen Geistes aus dem Vater und dem Sohn, das heißt über das Filioque mitsamt seiner Theologie und dem Faktum seiner Einfügung in das Nicäno-Constantinopolitanum, nimmt etwas weniger als die Hälfte des Gesamtumfangs des Tractatus maior ein und ist somit die umfangreichste der vier distinctiones. In keiner der anderen drei arbeitet der anonyme Autor derart strukturiert und systematisch entlang seiner gewählten Methode wie hier über den Heiligen Geist. Den Ausgangspunkt seiner Erläuterungen stellen die Meinungen der Griechen dar, die er dem Leser am Beginn in neun Untergliederungen referiert. Anschließend nimmt er Punkt für Punkt darauf Bezug, indem er die aus lateinischer Perspektive korrekte Gegenposition darstellt und diese mit Väterstellen und Konzilstexten untermauert. Jede einzelne Widerlegung der griechischen Position ist in sich geschlossen komponiert, indem am Ende jeweils noch einmal der Bezug zur Ausgangslage hergestellt wird und die wichtigsten lateinischen Argumente zusammengefasst werden. Den Abschluss der distinctio bildet die probatio in Gestalt einer positiven Beweisführung dessen, dass die Griechen als exkommuniziert zu gelten haben, wenn sie weiterhin willentlich und bewusst an ihrer falschen Auffassung festhalten. Insgesamt bleibt der Dominikaner in der Darstellung der Filioque-Problematik auf traditionellem Boden, indem er die lange schon zum Standard gewordenen Polemiken der Griechen aufgreift, die seit den Mystagogien des Photius im Umlauf waren ${ }^{417}$ und nach ihm vor allem bei Niketas Byzantius ${ }^{418}$ und Nicolaus Methonaeus ${ }^{419}$ im Zentrum der Debatten standen. Im Folgenden werden die acht Einwände der Griechen gegen das Filioque zunächst im Wortlaut dargestellt; anschließend folgt die Paraphrase der Antwort bzw. Widerlegung des Dominikaners mit der Analyse seiner Argumentationsgänge und Quellen.

\section{Einwand 1: Superfluit secunda processio oder: Der zweite Hervorgang aus dem Sohn ist überflüssig}

Si Spiritus Sanctus, inquiunt, procedit a Patre secundum Euangelium, quod negare non potestis, aut procedit perfecte siue illa processio perfecta est aut non. Si perfecta, ut uos conceditis, quare necesse est ut etiam a Filio procedat Spiritus Sanctus? Ergo superfluit secunda processio. Sed nihil superfluum aut inconueniens in deitate, ergo etc. (TcG I, 6-11 (p. 6))

Wenn der Hl. Geist - so sagen die Griechen - gemäß dem Evangelium aus dem Vater hervorgeht, was auch ihr [Lateiner] nicht leugnen könnt, dann geht er entweder vollkommen bzw. in einem vollkommenen Hervorgang vom Vater aus, oder nicht. Wenn vollkommen, wie ihr zugesteht: Warum ist es dann notwendig, dass der Heilige Geist auch vom Sohn ausgeht? Daher: Dieser

417 Photius: Mystagogia, ed. PG 102, col. 279 A - 542 A.

418 Niketas Byzantius: Capita syllogistica, ed. J. A. G. HeRGENRÖTHER 1869, 84-138.

419 Nicolaus Methonaeus: Orationes, ed. A. Demetrakopoulos, Bibliotheca ecclesiastica, Hildesheim 1965 (`Leipzig, 1866), 199-380. 
zweite Hervorgang [aus dem Sohn] war überflüssig. Aber in Gott gibt es nichts Überflüssiges oder Unziemliches, daher etc.

Zwar geht, so der Dominikaner in seiner Antwort auf den ersten Einwand, auch aus lateinischer Sichtweise der Geist in einer vollkommenen und vollständigen Weise aus dem Vater hervor. Gleichzeitig aber ist es die lateinische Überzeugung in Glaube und Verkündigung, dass der Geist auch in vollkommener und vollständiger Weise aus dem Sohn hervorgeht. Dennoch sei daraus nicht zu folgern, dass es zwei Hervorgänge in Gott gibt, von denen einer überflüssig bzw. redundant wäre. Denn Vater und Sohn sind zwar unterschieden hinsichtlich ihrer hypostatischen Eigentümlichkeiten, eins aber hinsichtlich ihres Wesens bzw. ihrer Natur. Daraus folgt ein Zweifaches: Dass Vater und Sohn, Augustinus zitierend, das eine Prinzip des Heiligen Geistes sind; und dass sich in der einen Natur Gottes jeder Zeit- oder Ortsunterschied verbiete, jeder Schnitt, Zwischenraum und jede Wandelbarkeit. Da es in der Natur Gottes kein früher oder später gibt, ist der Hervorgang des Geistes ein einziger Hervorgang aus dem Vater und dem Sohn. Dass der Geist aber überhaupt auch aus dem Sohn hervorgehen kann, dafür ist einzig der Vater verantwortlich: Der Sohn, der sein Wesen und alles, was sein ist (omne suum), dem Vater verdankt, hat auch dieses vom Vater, dass der Geist auch aus ihm hervorgeht. Die Väter (sancti doctores) hätten versucht, diesem Umstand gebührend Rechnung zu tragen, indem sie den Hervorgang des Geistes als principaliter a patre oder per filium bzw. mediante filio qualifizierten. Die Griechen hingegen hätten, bezugnehmend auf diese Väterstellen, schlicht falsche Schlussfolgerungen gezogen: Der Geist gehe mehr aus dem Vater als aus dem Sohn hervor; sein Hervorgang erfolge zuerst aus dem Vater, und dann erst aus dem Sohn. Beides sei nicht folgerichtig, ja eine grobe Fehlinterpretation dessen, was die Väter mit solchen Termini gemeint und bezweckt haben und was die Lateiner bis heute vertreten.

Der Dominikaner führt zwar in seiner ersten Widerlegung zunächst Augustinus und damit den locus classicus der zitierten principaliter-Lehre $\mathrm{an}^{420}$, die die westliche Position nicht nur prägt, sondern begründet. Im Anschluss aber und weit mehr Raum einnehmend widmet er sich der klassischen östlichen Interpretation mithilfe der

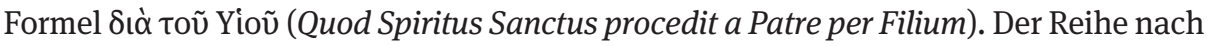
führt er die griechisch-patristischen Belegstellen bei Gregor von Nazianz, Dionysius Exiguus, Basilius, Tarasius (am II. Nicaenum) und Athanasius an und verwendet sie noch einmal in Ergänzung durch Augustinus und (Ps.-)Hieronymus - als Beleg für einen doppelten Ausgang des Geistes aus dem Vater und dem Sohn. 


\title{
Einwand 2: Duae causae - duo principia oder: Der Sohn als Grund und Quelle des Heiligen Geistes
}

Item cum una sit causa et fons deitatis scilicet Pater, tam Filius quam Spiritus Sanctus existunt a Patre: ille per generationem, iste per processionem. Sed si a Filio existit aut procedit Spiritus Sanctus, etiam Filius erit causa et fons Spiritus Sancti, et ita due cause et per consequens duo principia in deitate. Sed hoc est inconueniens, ergo etc. (TcG I, 12-17 (p. 6))

\begin{abstract}
Und weiter: Weil es einen einzigen Grund und eine Quelle in Gott gibt, nämlich den Vater, existieren sowohl der Sohn als auch der Heilige Geist aus dem Vater; der Sohn durch Zeugung, der Heilige Geist durch Hervorgang. Wenn nun aber der Heilige Geist auch aus dem Sohn existiert oder hervorgeht, dann wäre auch der Sohn Grund und Quelle des Heiligen Geistes, und damit gäbe es zwei Gründe und folglich zwei Prinzipien in Gott. Das aber anzunehmen ziemt sich nicht, daher etc.
\end{abstract}

Die Bezeichnung des Sohnes als causa et fons des Heiligen Geistes findet sich ebenso wie das entsprechende Bild des Geistes als imago Filii bei den Vätern belegt. Dies schickt der Dominikaner voraus, bevor er sich zunächst den Belegstellen der ersten Frage im Einzelnen zuwendet (Quod Filius dicitur causa et fons Spiritus Sancti). Die Väter hätten diese Qualifizierung des Sohnes als causa et fons des Geistes im Bemühen erarbeitet, die Art der Existenz des Geistes aus dem Sohn bzw. das Verhältnis zwischen ihnen zu verdeutlichen. Erneut in direkter Anlehnung an Augustinus stellt der Autor als ersten Grund dieser Bezeichnung den Geist als die Liebe zwischen Vater und Sohn - und somit als beidseitige Gabe - vor (tamquam donum amborum et amor utriusque). Grund und Quelle des Geistes sind nach Augustinus also beide: Vater und Sohn. Und wieder widmet sich der Dominikaner im Anschluss den griechischen Autoren in weit größerem Umfang und zitiert der Reihe nach Gregor von Nyssa, Athanasius und Kyrill. Dass bzw. auf welche Weise der Heilige Geist umgekehrt imago Filii genannt werden müsse (Quomodo Spiritus Sanctus dicatur ymago Filii), erklärt der Autor mit Gregor Thaumaturgos, Athanasius, Basilius, Kyrill und Gregor von Nazianz.

Das Geist-Sohn-Verhältnis aber bezeichneten die patristischen Autoritäten mit den Formulierungen per filium oder mediante filio, um klar darauf hinzuweisen, dass der Sohn dies - das heißt das ,Grund-und-Quelle-Sein` - vom Vater hat. Da das Wesen Gottes, immanent trinitarisch gedacht, nur zwei Arten des Seins von einer Person her kennt, nämlich das Gezeugtwerden des Sohnes (generatio) und den Hervorgang des Geistes (processio), müsse folglich auch der Hervorgang des Geistes aus dem Sohn nach Art des Hervorgehens (per modum processionis) geschehen, da andernfalls gänzlich falsch und häretisch von zwei Söhnen und einem Enkel die Rede sein müsste (nisi forsan nouam uelit fingere heresim, ut dicat quod isdem Spiritus generetur a Filio, et sint in deitate duo filii et unus eorum nepos). Mit Athanasius, Basilius, Gregor von Nyssa und Epiphanius weist der Dominikaner auf diesen letztgenannten Befund hin (Quod Spiritus Sanctus accipiat a Filio). Der kluge Leser (prudens lector), an den er sich im Duktus des Werkes gelegentlich explizit wendet, sei nun unzweifelhaft in der Lage, die angeführten patristischen Belege als Untermauerung der rechtgläubigen und wahren Lehre gegen die Einwände der Griechen zu erkennen. 


\title{
Einwand 3: Non est scriptum in evangelio oder: Das Filioque ist nicht heilsnotwendig
}

Item in Iohanne dicit Veritas discipulis suis: Omnia quecumque audiui a Patre meo, nota feci uobis, ubi dicit Glossa „omnia necessaria ad salutem“, ergo omnia necessaria ad salutem scripta sunt in Euangelio. Sed istud non est scriptum in Euangelio, ergo non est de necessariis ad salutem, ergo non tenemur credere. Sed que uera sunt tenemur credere et uenerari maxime, que diuinam essentiam uidentur predicare. Sed istud non tenemur credere, ergo non est uerum. (TcG I, 18-25 (p. 7))

\begin{abstract}
Und weiter: Im Johannesevangelium sagt Christus zu seinen Jüngern: Alles, was ich von meinem Vater gehört habe, habe ich euch mitgeteilt. Die Glosse kommentiert: alles zum Heil Notwendige. Im Evangelium steht demnach alles geschrieben, was zum Heil notwendig ist. Dies aber [scil. der Hervorgang des Geistes aus dem Sohn] steht nicht im Evangelium geschrieben und gehört folglich nicht zu den heilsnotwendigen Dingen, weswegen es zu glauben für uns nicht verbindlich ist. Alles Wahre aber glauben wir verbindlich, und wir verehren hoch, was über das göttliche Wesen zu verkündigen scheint. Dies [scil. siehe oben] zu glauben aber ist für uns nicht verbindlich, deswegen ist es nicht wahr.
\end{abstract}

Zwar beinhaltet das Evangelium auch aus Sicht der Lateiner alles zum Heil Notwendige, allerdings sei manches explizit, manches nur implizit enthalten. Beides nach Art hermeneutischer Regeln anzuerkennen sei wichtig, um der Offenbarung gerecht zu werden. Das Implizite ist, so der Dominikaner, dem magisterium des Heiligen Geistes von Christus her anvertraut, auf dass er die Menschen in Christi Wahrheit unterweise. Der Heilige Geist als der Paraklet ist und bleibt auf diese Weise Lehrer und ,Verstehensschlüssel' der biblischen Wahrheit. Denn die Schrift birgt die Wahrheit nicht nur dem Wortlaut nach (secundum vocem), sondern an vielen Stellen ist sie verborgener, das heißt dem Verständnis bzw. dem Sinn nach (secundum intellectum) enthalten. Was nun den Hervorgang des Heiligen Geistes betrifft, spricht die Schrift davon nicht im Wortlaut, wohl aber dem Sinn nach: Sie nennt den Heiligen Geist den Geist des Sohnes (Spiritus Veritatis). Der Wortbefund lasse auf sprachlich-grammatikalischer Ebene (je nach Verwendung des Genitivus als subiectivus oder obiectivus) zwei Deutungen zu, nämlich dass der Geist vom Sohn (als Urheber) ist oder dass der Sohn (als Objekt) vom Geist ist (quia Spiritus est a Veritate, aut quia Veritas est a Spiritu), wobei die zweite Bedeutung anzunehmen ein Irrtum und somit häretisch wäre. Der Heilige Geist ist also der Geist des Sohnes, und damit ist er a Filio. Zur Untermauerung dieses Bekenntnissatzes dienen dem Dominikaner anschließend Kyrill, Gregor von Nazianz, Athanasius, Basilius, Epiphanius und Anastasius Antiochenus, außerdem und basierend auf dem dargelegten hermeneutischen Prinzip des impliziten Schriftverständnisses ein kommentierter biblisch-exegetischer Streifzug durch das Alte und das Neue Testament. Am Schluss dieser dritten Widerlegung resümiert der Dominikaner, dass beiden ,Gefäßen der Wahrheit' - das heißt dem impliziten wie dem expliziten - auf gleicher Ebene begegnet werden müsse, weil beide einander ergänzen und für ein umfassendes Verständnis der biblischen Wahrheit unerlässlich sind. 


\section{Einwand 4: A Patre tantum oder: Christus selbst hat nicht vom Hervorgang aus dem Sohn gesprochen}

Item cum Veritas faceret mentionem de processione Spiritus Sancti ait: qui a Patre procedit, non dixit 'et a Filio'. Quod si Veritas aliud intellexisset, aliud dixisset. Ego autem addere uerbis eius non audeo nec presumo. (TcG I, $26-29$ (p. 7))

Und weiter: Als Christus über den Hervorgang des Heiligen Geistes sprach, sagte er: der aus dem Vater hervorgeht, und er fügte nicht hinzu: und aus dem Sohn. Hätte es Christus anders gewusst, dann hätte er es auch anders gesagt. Ich aber [scil. der Grieche] wage es nicht und maße es mir nicht an, den Worten Christi irgendetwas hinzuzufügen.

Die Griechen seien einer falschen Schlussfolgerung hinsichtlich des Zeugnischarakters der Heiligen Schrift erlegen: Dass eine der trinitarischen Personen nicht genannt sei, heiße nicht, dass sie deswegen dem Verständnis nach ausgeschlossen ist. Wäre das der Fall, hätte Christus selbst uns in vielerlei Irrtümer gestürzt (isto modo in multos errores precipitasset nos ipsa Veritas). Oder umgekehrt formuliert: Die Bibel bezeugt eine Reihe von Herrenworten, die bisweilen den Vater oder den Heiligen Geist nicht nennen, obwohl sie dem theologischen und heilsgeschichtlichen Sinn nach jeweils mitzudenken sind. In knappem trinitätstheologischen Aufriss verweist der Dominikaner auf die einzigen drei Gegebenheiten, die nicht allen drei Personen gemeinsam sind: zunächst auf die hypostatischen Eigentümlichkeiten der Personen, die freilich nur diesen jeweils alleine zukommen (ingenitus, inprincipiatus et genitor in Bezug auf den Vater, genitus et principiatus in Bezug auf den Sohn und procedens in Bezug auf den Heiligen Geist); dann auf das, was dem Vater und dem Sohn allein gemeinsam ist, nämlich dass sie den Heiligen Geist hervorbringen; und schließlich darauf, was dem Sohn und dem Heiligen Geist allein gemeinsam ist, dass nämlich beide von Ewigkeit her (eternaliter) aus dem Vater sind: der Sohn durch Zeugung, der Heilige Geist durch Hervorgang. Alles Übrige kommt, sofern damit nicht die Eigentümlichkeit der Personen aufgehoben und der Unterschied verwischt wird, allen drei Personen gemeinsam zu.

\section{Einwand 5: Sub anathematis uinculo oder: Die Konzilien haben jede Hinzufügung zum Symbolum verworfen}

Item non solum Christus hoc tacuit, sed nec aliquis Apostolorum tale aliquid dixit, nullus sanctorum hoc predicauit, immo quod plus est, in editione uere fidei sancta concilia super hoc nil diffinierunt. Sed ponentes in symbolo, que necessaria sunt ad salutem, omnem additionem expositionem declarationem sub anathematis uinculo excluserunt et reiecerunt. (TcG I, $30-35$ (p. 7))

Und weiter: Nicht nur Christus hat darüber [scil. über den Hervorgang aus dem Sohn] geschwiegen, sondern keiner der Apostel und der Heiligen hat solches gesagt und verkündigt. Und was noch gewichtiger ist: Die heiligen Konzilien haben im Glaubensbekenntnis nichts darüber festgeschrieben. Im Gegenteil: Die heilsnotwenigen Dinge im Symbolum nennend haben sie jede Art von Hinzufügung, Auslegung und Erklärung ausgeschlossen und zurückgewiesen und unter die Strafe der Exkommunikation gestellt. 
Dass sich bei den Aposteln und Heiligen keinerlei Andeutung oder explizite Erwähnung des Hervorgangs des Geistes aus dem Sohn finde, widerlegt der Dominikaner zunächst, indem er - zum Teil die Sentenzen des Petrus Lombardus referierend erneut auf die biblischen und für den Ausgang des Geistes relevanten patristischen Belege eingeht. Er führt damit allein schon durch seine Methode vor Augen, dass sowohl die Schriftzeugnisse (und damit die Apostel!) als auch die auf sie rekurrierenden Kommentare (und damit die Heiligen!) den Ausgang des Heiligen Geistes aus dem Sohn thematisieren.

Umfassender fällt die Antwort des Dominikaners in Bezug auf das Verbot des Konzils von Ephesos aus, dem Symbolum etwas hinzuzufügen. Zunächst stellt er in aller Schlichtheit fest: Das Filioque sei deswegen nicht im Symbolum enthalten, weil es zur Zeit der ersten Konzilien nicht zur Debatte bzw. in der Kritik stand. Das Wesen eines Konzils ist es, Antwort und Klärung hinsichtlich innerer und äußerer Herausforderungen zu bieten und Konflikte zu lösen. Gerade weil das Filioque in diesem Sinn nicht bezweifelt oder in Frage gestellt wurde, konnten die Konzilien darüber schweigen. Erst infolge des Aufkommens von Infragestellungen, ja von Kritiken am Ausgang des Heiligen Geistes aus dem Sohn vor allem in der westlichen Welt musste die Kirche reagieren: Zunächst wurde nur in den betreffenden Gebieten und unter Zustimmung des Papstes der Beschluss gefasst, diese Glaubenswahrheit zu ihrem Schutz auch verbaliter in das Symbolum aufzunehmen. Aus zwei Gründen habe man die Griechen und die übrigen Ostkirchen in diese Entscheidung nicht involviert (Greci uero et ceteri Orientales uocati non sunt): Erstens, weil sie allzu weit entfernt waren (nimis distabant); und zweitens, weil sie keine Bedenken an der Sache hegten (non dubitant talequid adducere in questionem).

Das zweite Argument des Autors ist ein Argumentum ex negativo (Quod liceat ueritatem fidei addere in symbolo): Die Konzilien von Ephesos 341 bis Nizäa 787 legten verschiedene Bestimmungen fest, die jeweils die volle universalkirchliche Gültigkeit beanspruchen und dennoch nicht im Symbolum von Nizäa-Konstantinopel enthalten sind. Es sei daher plausibel, dass heilsnotwendige Glaubenswahrheiten auch außerhalb des klar definierten Symbolums der ersten beiden Konzilien zu finden sind. Konsequenterweise müssen solche Glaubenswahrheiten, die der notwendigen Klärung eines Konfliktfalls entstammen, in den Rang des Symbolums erhoben werden. Dies sei umso leichter zu argumentieren, als die altera fides, wie sie vom Konzil von Ephesos verboten wurde, nicht als Hinzufügung an sich zu verstehen sei, sondern als Glaubensinhalt, der gegen die Wahrheit steht (contraria uere fidei et ueritati). Als solche erfährt sie zu Recht die Strafe des Anathems. Eine Wahrheit aber, die im Symbolum noch nicht ausreichend zum Ausdruck kommt (minus expressa olim in symbolo), müsse geradezu verpflichtenderweise von der Kirche erhellt und expressis verbis verdeutlicht werden. Andernfalls hätte ein Konzil das jeweils nachfolgende Konzil exkommuniziert, weil Glaubenswahrheiten definiert wurden, die im Vorgängerkonzil noch nicht zum Thema gemacht worden waren. Das aber anzunehmen gezieme sich nicht und sei letztlich Unsinn. 
Die lateinische Fassung des Symbolums inklusive Filioque sei daher nicht Ausdruck eines anderen oder gar falschen Glaubens, sondern erhelle schlicht das im Symbolum, was zuvor minus expressum war. Im Umkehrschluss sei also gerade durch die Einfügung des Filioque in den Wortlaut des Symbolums verhindert worden, dass sich dem Glauben und der Wahrheit Widersprechendes verbreiten konnte. Das Verbot des Konzils von Ephesos aber sei gegen die Unverschämtheit der Häretiker gerichtet und habe dort seine Berechtigung und Notwendigkeit, wo diese alles daransetzen, die Wahrheit zu pervertieren (contra hereticorum importunitates, qui ueritatem peruertere nituntur).

\section{Einwand 6: Intellectus - verbum/vox - spiritus/vehiculum oder: Die Autorität des Johannes von Damaskus}

Item multi doctorum nostrorum, quorum scripta auctentiquissima apud nos usque hodie perseuerant, ut Theodoritus et quidam alii, contrarium huius opinionis uestre scripserunt et mandauerunt. Damascenus quoque, cuius scriptis certe contradicere non potestis, uolens ostendere, quod tam Filius et Spiritus Sanctus existunt a Patre, et quod Spiritus Sanctus non procedat a Filio, methaphoram uocis et intellectus adducens in medium ait: „Primo est intellectus, deinde uerbum exterius scilicet uox, spiritus autem uehiculum est uerbi. Intellectus ergo format uocem, et in ipsa uoce spirata ostenditur intellectus. "Ecce intellectus Patri, et uerbum Filio, spiritus Spiritui Sancto attribuitur. Sicut ergo uidemus, quod ab intellectu procedit spiritus et uox, et non spiritus a uoce, sic a Patre procedit Filius et Spiritus Sanctus, et non Spiritus Sanctus a Filio. (TcG I, 36-49 (p. 7-8))

Und weiter: Viele unserer Gelehrten, deren altehrwürdige Schriften bis heute bei uns bewahrt werden, wie Theodorit und einige andere, schrieben und überlieferten das Gegenteil zu eurer Meinung. Auch Johannes von Damaskus, dessen Schriften ihr mit Sicherheit nicht widersprechen könnt, wollte zeigen, dass auf dieselbe Weise, wie der Sohn und der Heilige Geist aus dem Vater sind, der Heilige Geist nicht aus dem Sohn hervorgeht. Die Metapher der Stimme und des Gedankens verwendend schreibt er: „Zuerst ist der Gedanke; dann das äußere Wort, d.h. die Stimme; der Hauch aber ist das Gefährt des Wortes. Der Gedanke formt die Stimme, und in der gehauchten Stimme selbst zeigt sich der Gedanke." Und so ist der Gedanke dem Vater, das Wort dem Sohn und der Hauch dem Heiligen Geist zuzuteilen. Wie wir aber sehen, dass vom Gedanken die Stimme und der Hauch ausgehen, nicht aber der Hauch von der Stimme, so gehen auch Sohn und Heiliger Geist vom Vater aus, nicht aber der Heilige Geist vom Sohn.

Auf zwei griechische Zeugen gegen das Filioque nimmt der Dominikaner als Antwort auf den sechsten Einwand konkreter Bezug. Zunächst auf Theodoret von Kyros und das II. Konzil von Konstantinopel (553): Ihn unter die zitierten doctores zu reihen disqualifizierte die Griechen insgesamt, denn ihn müsse man als gesamtkirchlich verurteilten Häretiker wie die Pest fliehen und verwerfen (tamquam pestem fugimus et tamquam hereticos reprobamus). Da Theodoret sich gerade in der Frage des Ausgangs des Heiligen Geistes aus dem Sohn gegen die ,Säule der Rechtgläubigkeit“ Kyrill von Alexandrien zu wenden gewagt habe, sei ex negativo und der Tradition der Kirche gemäß seine falsche und verwerfliche Position in Sachen Filioque erwiesen. Anders bei Johannes von Damaskus: Seiner Interpretation des angeführten Belegs stellt der Dominikaner eine Differenzierung der damaszenischen Begrifflichkeiten voran. Ge- 
nauso wie das Wort zweifach (duplex) sei, nämlich das innere Wort als Gedanke und das äußere Wort als Stimme oder Rede, sei auch der spiritus zweifach: Der innere ist die Liebe, der äußere ist Hauch oder Luft. Während nun die Griechen auf das verbum exterius (die Rede) und den spiritus exterius (den Hauch, mit dem die Rede ausgeht) Bezug nehmen, gehen die Lateiner auf die innere Ebene und vergleichen - Augustinus gemäß - das ungezeugte Wort mit dem ungeschaffenen Geist, der - innertrinitarisch gesprochen - die Liebe ist (exemplificantes de Verbo incarnato et Spiritu increato): Die Liebe geht von beiden, Vater und Sohn, gleichermaßen aus, und die einseitige Liebe des Vaters zum Sohn anzunehmen, wie die Griechen es konsequent weiterdenken müssten, ist falsch und führt Viele in den Irrtum. Dass die Griechen nach eigenen Aussagen das Filioque nicht bekennen (nos non dicimus), präzisiert der Dominikaner mit ,sie singen bzw. beten es nicht' (non cantamus) und verwirft dies als irrtümliches Festhalten an einer falschen liturgischen Tradition, die mit der kirchlichen Dogmatik nicht übereinstimme.

\title{
Einwand 7: Non ergo mediante Filio oder: Mitten unter Vater und Sohn
}

\begin{abstract}
Item sanctus Epiphanius Cipri in libro de una deitate, qui Anguiroton dicitur, de Spiritu Sancto sic testatur: „Spiritus Sanctus Deus est, et Spiritus Christi est, non secundum aliquam compositionem, quemadmodum in nobis anima et corpus, sed in medio Patris et Filii." Non ergo mediante Filio, ut uos deliratis, procedit Spiritus a Patre, cum secundum patris huius uocem medius inter Patrem et Filium ordinetur Spiritus. (TcG I, 50 - 56 (p. 8))

Und weiter: Der Heilige Epiphanius von Zypern bezeugt in seinem Werk über den einen Gott mit dem Titel Ancoratus über den Heiligen Geist Folgendes: „Der Heilige Geist ist Gott, und er ist der Geist Christi, nicht gemäß irgendeiner Zusammenstellung wie in uns [i.e. Menschen] Seele und Leib, sondern mitten unter Vater und Sohn." Nicht also vermittelt durch den Sohn, wir ihr faselt, geht der Sohn vom Vater aus. Sondern Epiphanius zufolge ist er mitten unter Vater und Sohn angeordnet.
\end{abstract}

In dieselbe augustinische Kerbe schlägt der Dominikaner zunächst zur Widerlegung einer auf Epiphanius basierenden Argumentation der Griechen: Als die Liebe ist der Geist das Verbindende und Gemeinsame von Vater und Sohn, deswegen geht er communiter von beiden hervor. Umso mehr sei dies erwiesen, als die Griechen den weiteren Satzverlauf des Epiphanius unterschlagen: ... ex Patre et Filio tertius [...], der dem Sinn nach auch bei Gregor von $\mathrm{Nyssa}^{421} \mathrm{zu}$ finden sei.

421 Dem Dominikaner scheint das Werk unter dem Namen des Basilius vorzuliegen; vgl. dazu TcG I, 953-958 app. crit. (p. 46). 


\title{
Einwand 8: De meo, hoc est de Patre meo oder: Bei uns ist Wahrheit
}

Item quis hoc uobis reuelauit? Unde habuistis? Quare etiam nobis non fuit reuelatum? Quare in symbolo tale quid intrusistis, quod nusquam positum fuit a sanctis patribus? Si uero occasione quorumdam uerborum diuine Scripture, dicentium Spiritum Filii uel quod Spiritus mittatur a Filio, hoc habuistis, sciatis uos uel non intelligere Scripturas, uel intellectas studiose peruertere, aut certe per ignorantiam multum a ueritate et sanctorum expositionibus deuiare. Unde ad nos, qui fontes sumus, redeuntes audire poteritis ueritatem. Dicitur igitur Spiritus Filii non quia procedat ab eo, sed quoniam ratione diuine essentie est consubstantialis ei. Item dicitur mitti uel dari a Filio Spiritus, quia ab ipso mittitur ad sanctificandas creaturas, sicut in Iohanne ipse testatur dicens: Nisi ego abiero etc., si autem abiero, mittam etc. Quod uero alibi dicit ipse Filius: Ille me clarificabit, quia de meo accipiet etc. Intelligendum est, de meo', hoc est, de Patre meo'. Omnia enim, que Patris sunt, exceptis personalibus proprietatibus, communia sunt utrique. Proprium enim dicimus esse Patri, ut ab ipso tantum, et non ab alio procedat Spiritus. (TcG I, 57-75 (p. 8-9))

\begin{abstract}
Und weiter: Wer hat euch dies geoffenbart? Woher habt ihr dies genommen? Warum wurde es uns nicht geoffenbart? Warum habt ihr solches in das Symbolum eingefügt, was nirgendwo bei den heiligen Vätern geschrieben steht? Wenn ihr dies freilich aus einigen Schriftworten entnehmt, dass er der Geist des Sohnes ist oder dass der Geist vom Sohn gesandt wird, dann sollt ihr wissen, dass ihr entweder die Schrift nicht versteht, oder das richtige Verständnis eifrig verdreht oder durch Unwissenheit weit von der Wahrheit und den Erklärungen der Heiligen abweicht. Kehrt ihr also zu uns, die wir die Quellen sind, zurück, könnt ihr die Wahrheit hören: Geist des Sohnes wird er nicht deswegen genannt, weil der Geist vom Sohn ausgeht, sondern aufgrund seines göttlichen Wesens und der Wesensgleichheit mit ihm. Und weiter: Es heißt vom Geist, dass er vom Sohn gesandt oder gegeben wird, weil er vom Sohn selbst gesandt wird zur Heiligung der Geschöpfe, wie Christus selbst im Johannesevangelium bezeugt: „Denn wenn ich nicht fortgehe usw., gehe ich aber, so werde ich senden usw.“ Was aber anderswo der Sohn selbst sagt: „Er wird mich verherrlichen, denn er wird von dem, was mein ist, nehmen usw.“, ist zu verstehen als „von meinem Vater“. Alles nämlich, was des Vaters ist außer die hypostatischen Eigentümlichkeiten, ist allen Dreien gemeinsam. Wir nennen es also das Proprium des Vaters, dass von ihm allein und nicht von einem anderen der Geist hervorgeht.
\end{abstract}

Den ersten Teil des achten Einwands der Griechen, der in Form von suggestiven Fragen formuliert ist (woher die Lateiner solches hätten und warum so eine wichtige Wahrheit nur einseitig, nämlich den Lateinern und nicht den Trägern der wahren Tradition, d. h. den Griechen (qui fontes sumus) geoffenbart worden sei), sieht der Dominikaner als hinreichend durch alles Vorhergehende beantwortet bzw. widerlegt. Er widmet diesen Fragen daher keine eigene Abhandlung mehr und geht sofort $\mathrm{zu}$ den beiden biblisch begründeten procedat-Argumenten der Griechen über: An der Frage, ob auch der Heilige Geist von Ewigkeit her der Geist des Sohnes ist, entscheide sich die richtige Lehre. Verneinen dies die Griechen, so stehen sie der Meinung des Gregor Thaumaturgos in dessen Auslegung des Symbolums und des Epiphanius in einer seiner Reden entgegen. Bejahen sie aber und stehen damit in der Tradition ihrer eigenen Väter, wie können die Griechen dann den Ausgang des Geistes aus dem Sohn auf die Heilsökonomie (ad sanctificandas creaturas) begrenzen? Umso mehr gelte, dass der Geist von Ewigkeit her aus dem Sohn existiert (eternaliter existit ab eo). Den griechischen Einwand der Wesensgleichheit als Grund der Bezeichnung „Geist des Sohnes“verwirft der Dominikaner als Unsinn (deliramentum), denn andernfalls müsste dieses Schema 
auf alle drei Personen angewandt werden und etwa der Vater a Spiritu Sancto sein. Die Antwort auf den achten Einwand beschließt der Dominikaner mit dem Fingerzeig auf klassische Häretiker wie Makedonius und Sabellius, um die Tendenz der Griechen in ähnliche Richtungen zu markieren, und auf die häretisch vorgezeichnete via perditionis, auf der sie sich bewegen und die Gegenstand des folgenden letzten Abschnitts der ersten distinctio ist.

\section{Probatio: Jeder, der das Filioque ablehnt, ist ipso facto et iure exkommuniziert}

[...] restat nunc ostendere, qualiter ipsi in laqueum, quem nobis parauerant, inciderint, et utrum dicendi sunt heretici uel tantum excommunicati, uel quod magis dolendum est utrum simul utrumque. (TcG I, 1029-1032 (p. 50))

[...] bleibt nun zu zeigen, auf welche Weise sie [scil. die Griechen] selbst in die Schlinge traten, die sie uns bereitet hatten, und ob sie Häretiker oder nur exkommuniziert zu nennen sind oder beides, was beklagenswerter wäre.

In der Probatio am Ende der acht Widerlegungen geht der Dominikaner in zwei Schritten vor: Zunächst zeigt er auf, (a) warum die Griechen der Sache geschuldet, das heißt automatisch exkommuniziert sind (in canonem late sententie inciderint), wenn sie an der Leugnung des Filioque mitsamt seiner Theologie festhalten; im zweiten Schritt (b) führt er die historischen bzw. kirchenrechtlich bindenden Gründe an, warum die Griechen bereits als exkommuniziert anzusehen sind.

Ad (a): Der Heilige Geist ist gemäß den authentischen und von der Kirche als Tradition bewahrten Schriften seinem Wesen nach vom Sohn und geht von ihm aus (essentialiter sit a Filio et procedat $a b$ eo). Dies wurde von den Generalkonzilien bestätigt und definiert. Daraus folgt im Umkehrschluss, dass jeder ipso facto et iure exkommuniziert ist, der sich dagegen wendet, sich auf bereits verurteilte Positionen stützt (der Dominikaner führt hierbei die Verurteilungen des II. Konzils von Konstantinopel 553 an) und sich beharrlich (obstinato animo) gegen die Wahrheit stellt. (b) Dass die Griechen bereits ausdrücklich (nominatim), das heißt kirchenrechtlich bindend exkommuniziert sind, führt der Dominikaner anhand zweier Daten vor Augen - und beide Daten sind aufschlussreich und aussagekräftig vor dem Hintergrund der heutigen Frage, wann man das definitive Schisma zwischen Ost- und Westkirche, zwischen Lateinern und Byzantinern anzusetzen habe: Erstens rekurriert der Dominikaner auf die Bannbulle des Jahres 1054 der päpstlichen Gesandten gegen die Griechen (excommunicationis sententia contra eos), deren Triebfeder die griechische Nichtanerkennung des Filioque unter anderen Irrtümern gewesen war. Zweitens nimmt er Bezug auf die zeitgenössische lateinische Kirchenpolitik und auf das Symbolum, das Papst Innozenz III. als Vorsitzender auf dem Vierten Laterankonzil 1215 den Beschlüssen vorangestellt hatte. Demnach - und unter explizitem Rückbezug auf das Symbolum Quicumque - ist jeder exkommuniziert, der leugnet, dass der Vater ohne Ursprung, der Sohn vom Vater allein ist und der Heilige Geist von beiden gleichermaßen hervorgeht (pariter ab utroque). Der Dominikaner fasst abschließend die 
Rechtgläubigkeit der Lateiner im Gegensatz zu den Griechen in eine Bekenntnisformel, die den nachfolgenden Wortlaut umso schärfer erscheinen lässt, mit dem er im nächsten und für diese distinctio letzten Satz die Meinung und Haltung der Griechen tamquam heretice verwirft:

Nos autem sanctorum grecorum et latinorum sententias secuti credimus et confitemur, cantamus, scribimus et docemus Patrem a se, non ab alio, Filium a Patre solo genitum, Spiritum Sanctum a Patre et Filio pariter et equaliter procedentem, tres quidem discretas et distinctas et perfectas ypostases, sed unam essentiam et unam deitatem, unam potentiam, unum Deum omnipotentem, eternum, incommutabilem, unum principium, unam causam, a quo omnia, per quem omnia, in quo sunt omnia, et ipsi est gloria, honor et imperium in secula seculorum. Amen.

Illos uero qui dicunt, quod Spiritus Sanctus procedit quidem a Patre sed non a Filio, uel 〈quod) aliter aut plus a Patre procedit quam a Filio, aut prius a Patre, postmodum a Filio, et similia recte fidei aduersantia, et hoc asserendo credunt, predicant et scribunt, sicut iam dudum diffinitum est a sanctis patribus, tamquam hereticos a catholica ecclesia abicimus, uitamus, maledicimus et reprobamus. (TcG I, $1119-1134$ (p. 53-54))

Wir aber - den Worten der lateinischen und griechischen Heiligen folgend - glauben und bekennen, singen, schreiben und lehren, dass der Vater aus sich und aus niemand anderem ist, dass der Sohn vom Vater allein gezeugt ist, und dass der Heilige Geist gleich und auf gleiche Weise aus dem Vater und dem Sohn hervorgeht - drei unterschiedene, getrennte und vollkommene Hypostasen, aber ein Wesen und eine Gottheit, eine Macht, ein allmächtiger Gott, ewig, unveränderlich, ein Prinzip, ein Ursprung, aus dem und durch den und in dem alles ist. Ihm ist Ruhm, Ehre und Macht in alle Ewigkeit. Amen.

Jene aber, die behaupten, dass der Heilige Geist freilich aus dem Vater, nicht aber aus dem Sohn hervorgeht, oder dass er anders oder mehr aus dem Vater als aus dem Sohn hervorgeht, oder früher aus dem Vater und später aus dem Sohn, oder ähnliche Dinge, die dem rechten Glauben entgegenstehen, und die das behauptend glauben, verkünden und schreiben, diese wollen wir wie es schon von den heiligen Vätern bestimmt worden ist - wie Häretiker aus der Kirche verstoßen, meiden, schmähen und verwerfen.

Rückblickend auf den Duktus der ersten distinctio sind zwei Beobachtungen und eine Schlussfolgerung hervorzuheben, die die Einordnung des theologischen wie auch des originell-kontroverstheologischen Gehalts der ersten distinctio betreffen: (a) Theologisch gesehen reagiert der Dominikaner auf die klassischen photianischen Anfechtungen mit den ebenfalls klassischen augustinischen Antworten: Der Heilige Geist als die Liebe zwischen Vater und Sohn durchbricht das östliche Prinzip einer klaren Unterscheidung zwischen immanenter und heilsökonomischer Trinität, die ja letztlich bis in die Gegenwart ökumenischer Debatten den Brennpunkt des noch ungelösten Konflikts um das Filioque darstellt. Neu und im Hinblick auf die Methode originell ist (b), dass die augustinischen Positionen mit griechisch-patristischen oder gemeinsamen konziliaren Autoritäten untermauert werden. Die letzte und äußerste Argumentation aber, dass nämlich die Griechen der via perditionis folgen und in Gefahr sind, der Häresie zu verfallen bzw. darin bereits verharren, durchbricht überraschenderweise die eigenen methodischen Vorgaben. Denn schlussendlich sind es zwei genuin lateinische Autoritäten, die diesen Nachweis erbringen sollen: Die Bannbulle des Jahres 1054 und das Symbolum des IV. Lateranums bzw. Papst Inno- 
zenz' III. Für die kirchenrechtliche Dimension der griechischen beharrlichen Leugnung des Filioque führt der Dominikaner also keine griechischen Belegquellen an, sondern kehrt in die ihm eigenen Begründungsstrukturen zurück. Dies impliziert theologisch gesehen - allerdings interessanterweise auch, dass der Autor die Bestimmungen des Vierten Laterankonzils als für die Griechen durchaus gültig erachtet, dass sie also - wenn auch auf historisch-theologisch bedingten Abwegen - zum Corpus der Kirche zählen und dass das IV. Lateranum in diesem Sinn ein ökumenisches, weil universalkirchlich gültiges Konzil darstellt.

\subsubsection{Purgatorium/Eschatologie: Secunda distinctio de animabus defunctorum}

Die zweite distinctio über das Schicksal der Seelen der Verstorbenen bis zum Tag des Jüngsten Gerichts - verkürzt zusammengefasst als Konflikt um das Purgatorium weist sowohl inhaltlich als auch stilistisch einige Besonderheiten auf. Zwar beanspruchen die Ausführungen über die Seelen der Verstorbenen (de animabus defunctorum) nur etwa ein Fünftel des Gesamtumfangs des Tractatus maior. Dennoch ist dieser kurze Text vor allem aus zwei Gründen ein hochinteressantes Zeugnis mittelalterlicher lateinisch-griechischer Kontroverstheologie, das zu untersuchen Erträge auf mehreren Ebenen verspricht: Zum einen ist es beachtlich, dass ein vergleichsweise junger, noch nicht in der ost-westlichen Kontroverse etablierter Konfliktpunkt bereits derart prominent in den Rang traditioneller Problemstellungen und Diskussionsthemen aufgenommen wurde. Die zweite distinctio des Traktats ist die erste bekannte lateinische Quelle, die den eschatologischen Konfliktpunkt behandelt und ihn in jenes Ensemble aufnimmt, wie es später zum Standard der ,Griechenfrage‘ auf den mittelalterlichen ,Unions'-Konzilien werden sollte. Daher ist zum anderen die Arbeitsweise des Autors gerade in diesem Punkt hochspannend zu analysieren, weil er sich - anders als bei den etablierten Konflikten - auf keine traditionellen Vorlagen oder Argumente stützen kann - so die Annahme. Was hier vorliegt, ist nicht nur methodisch, sondern auch inhaltlich-theologisch neu. ${ }^{422}$

Die zweite distinctio ist ein wichtiges Zeugnis und beredtes Beispiel dafür, dass das Purgatorium nicht den Brennpunkt, sondern nur einen Teilbereich im größeren eschatologischen Konflikt zwischen Ost- und Westkirche darstellte. Ähnlich wie im Fall des Filioque nennt der Dominikaner auch hier zunächst den Einwand der Griechen, den es im Anschluss zu kommentieren und zu korrigieren gelte. 


\section{Einwand: Citra diem iudicii oder: Kein Urteil über die Seelen vor dem Jüngsten Gericht}

Opinio enim eorum est, sicut supradiximus, quod neque in paradisum bone, neque in infernum citra diem iudicii uadunt anime reproborum, sequentes quemdam huius hereseos inuentorem archiepiscopum quondam Cesaree Capadocie Andream nomine, qui dicit eas propria corpora prestolari, ut cum eis, cum quibus bona et mala commiserunt, retributionem simul factorum recipiant. (TcG II, $13-19$ (p. 55))

Wie oben bereits vorgestellt lautet die Meinung der Griechen, dass vor dem Tag des Jüngsten Gerichts weder die guten Seelen in das Paradies, noch die Seelen der Verdammten in die Hölle kommen. Darin folgen sie dem Erfinder dieser Häresie, einem gewissen Andreas, einst Erzbischof von Caesarea in Kappadokien, der behauptet, dass die Seelen ihrer eigenen Körper harren, auf dass sie mit diesen Körpern, mit denen sie Gutes und Schlechtes begangen haben, den Lohn gemäß ihren Taten empfangen.

Als den Kern des Problems nennt der anonyme Autor die Leugnung der Griechen, dass es ein individuelles Urteil über die Seelen der Verstorbenen noch vor dem Tag des Jüngsten Gerichts gebe. Bereits am Beginn überrascht der Dominikaner, indem er nicht auf die loci classici der östlichen Eschatologie wie etwa Origenes oder Kyrill von Alexandrien zurückgreift. Statt dessen taucht - als Ursprung dieser Irrmeinung - der Name eines Autors auf, der der Nachwelt vor allem durch seinen in mehrerer Hinsicht einzigartigen Kommentar zur Johannes-Apokalypse bekannt ist: Andreas von Caesarea, Erzbischof und Theologe in Kappadokien, dessen hauptsächliche Schaffensperiode auf die Jahre zwischen 563 und 614 datiert werden kann. ${ }^{423}$ Ihn beschuldigt der Dominikaner als Häresiarchen, das heißt als Geburtshelfer bzw. gar Begründer der östlichen häretischen Auffassung zum Zustand der Seelen nach dem individuellen Tod des Menschen bis zum Jüngsten Gericht. Der Lehre des Andreas, die er am Ende der distinctio ausführlicher und im Wortlaut zitiert, stellt der Dominikaner drei lateinische Positionen entgegen, die er durch die Schrift und die griechische Tradition zu untermauern beabsichtigt und die gleichzeitig das Gliederungsprinzip der zweiten distinctio sind: (1) In der responsio Latinorum antwortet er zunächst direkt auf den Einwand der Griechen und argumentiert für ein erstes Urteil über die Verstorbenen unmittelbar nach dem individuellen Tod. (2) Über die vier Aufenthaltsorte der Seelen (De quatuor receptaculis defunctorum) spricht er im zweiten Abschnitt und präzisiert damit die Topographie des Zwischenzustandes: Himmel, Hölle, Limbus und Fegefeuer. (3) Das Purgatorium, das Namensgeber dieses eschatologischen Konfliktpunktes werden sollte, ist Gegenstand des dritten Abschnittes der zweiten distinctio. Diese drei Untergliederungen sind nicht nur im Hinblick auf ihre Verortung in der lateinischgriechischen Kontroverse interessant, sondern sie geben auch Aufschluss über den Status quo der lateinischen eschatologischen Konzepte in der Mitte des 13. Jahrhun-

423 Andreas Caesariensis: Commentarius in Apocalypsin, ed. ScHMID 1955; vgl. auch die neuere Studie von Constantinou 2013, die allerdings bzgl. des theologischen Gehalts des Kommentars wenig in die Tiefe geht. 
derts, das J. Le Goff in seiner prominenten Studie als die Geburtsepoche des Fegefeuers bezeichnet und dem A. Merkt mit patristischer Expertise widersprochen hat. ${ }^{424}$ $\mathrm{Zu}$ den Positionen und ihren Argumenten im Einzelnen:

\section{Urteil vor dem Urteil}

Die wichtigste griechische Autorität, die der Dominikaner in der zweiten distinctio ins Feld führt, ist der Konstantinopler Patriarch und Prediger Johannes Chrysostomus. Diese Beobachtung stützt den Befund J. Ratzingers, der in seinem Handbuch zur Eschatologie Johannes Chrysostomus als den Vater nennt, bei dessen theologischem Konzept der griechische Osten bis heute stehengeblieben ist. ${ }^{425}$ Der Dominikaner zeigt auf, dass gemäß dem Glauben und der Hoffnung der römischen Kirche jetzt schon (etiam nunc) die Seelen der Heiligen mit Christus regieren, die Seelen der Verdammten jetzt schon und auf ewig in der Hölle bestraft werden und so den gerechten Lohn erhalten. Die Ausgangsfrage dieser zweiten distinctio, nämlich was mit den Seelen im Zwischenstadium zwischen Tod und Jüngstem Gericht geschieht, ist daher zunächst im Hinblick auf die Gerechten und auf die Verdammten beantwortet und es wurde grundsätzlich geklärt, dass überhaupt von einem aktiven (Urteils-)Prozess noch vor dem Jüngsten Gericht ausgegangen werden müsse: Die Gerechten gehen unmittelbar nach dem Tod bereits in das Paradies ein, die Verdammten gleichermaßen in die Hölle. Zur Untermauerung und mit Bezug auf (Ps.-)Athanasius und Johannes Chrysostomus liegt der Fokus auf der Interpretation der Schriftworte, wobei die Stelle vom Schächer (latro) und der Paradiesestür, die Christus für ihn heute noch (hodie), das heißt noch vor dem Tag des Jüngsten Gerichts öffnet, am meisten Raum erhält. Christus habe das Paradies nicht nur für den Schächer allein geöffnet, sondern für alle Heiligen, während umgekehrt die Verdammten ebenfalls schon vorher dort sind, wo kein Menschengedenken sie mehr erreicht und keine Fürbitte mehr für sie wirksam ist.

Der Dominikaner bietet im Anschluss zwei zusätzliche Argumentationsgänge, die hinsichtlich der Quellenart und seiner persönlichen Involviertheit vor Ort einigen Ertrag liefern: (a) Nicht nur bei den griechischen Kirchenvätern finde sich das Urteil vor dem letzten Urteil belegt, sondern auch an ihren Kirchenwänden (in parietibus ecclesiarum suarum), das heißt in Motiven der byzantinischen Sakralikonographie. Zu sehen seien unter anderem herabsteigende Engel des Lichts, die die Seelen der Heiligen in den Himmel geleiten, und Engel des Satans, die die Seelen der Verdammten mit Gewalt aus ihren Körpern reißen und mit sich in die Hölle zerren. (b) Auch die byzantinische Liturgie biete ihren Gläubigen genügend Anknüpfungspunkte an ein Urteil vor dem letzten Urteil: Der Dominikaner zitiert exzessiv aus den entsprechenden liturgischen Texten, die die anzurufenden Märtyrer als im Himmel seiend bezeugen. Da nun also die Griechen immer schon in Literatur, Liturgie und Ikonographie Zeugnis

424 LE GOFF 21991; vgl. MERKT 2005.

425 RATZINGER ${ }^{6} 1990,179$. 
für ein erstes Urteil abgelegt hätten, könne es sich freilich nicht um Unwissenheit (ignorantia) handeln, wenn sie dagegen argumentieren, dass den Menschen nach seinem Tod ein individueller Urteilsspruch erwartet, der noch vor dem endgültigen Gericht am Ende der Zeiten den Aufenthaltsort seiner Seele bis dahin bestimmt.

\section{Die vier Aufenthaltsorte der Seelen}

Die daran anschließende Darlegung der vier Aufenthaltsorte der Seelen impliziert eine Kategorisierung der Verstorbenen je nach Verdienst und Verhalten zu ihren Lebzeiten, die ausschlaggebend für ihre Zuteilung zum jeweiligen receptaculum - Himmel, Hölle, Limbus oder Fegefeuer - ist. Man könnte auch hier zunächst einen augustinischen Einschlag vermuten, der aber spätestens bei der Darlegung des Limbus nicht gilt, da Augustinus der Sündenfreiheit ungetaufter Kinder (sunt enim expertes peccati) nicht zustimmen würde, wie der Dominikaner sie bei (Ps.-)Athanasius findet und verwendet. Die Vorstellung von den Kammern, wie sie im äthiopischen Henoch-Buch (um 150 v.Chr.) und im 4. Esra-Buch (um 100 n.Chr.) ihren Ausgang und ihre Prägung gefunden hat, liegt der griechischen Position zugrunde, die der Dominikaner in diesem zweiten Abschnitt etwas unstrukturiert(er) dar- und widerlegt. Die vier receptacula, die die Seelen bis zum jüngsten Gericht beherbergen, seien in den eigenen Büchern der Griechen (legant et intelligant libros suos) beschrieben: Neben Paradies und Hölle berichtet (Ps.-)Athanasius über das dritte receptaculum, das die Seelen der ungetauften Kinder und der Kinder ungläubiger Eltern (non baptizati autem et etiam gentilium pueri) beherbergt. Diesen locus tertius finde man in der Tradition der Griechen zwar nicht benannt, aber die lateinischen Väter wie Augustinus und Gregor der Große bezeichnen denselben Ort als sinus Abrahae bzw. limbus. Das seit der Frühscholastik neu aufgekommene Konzept eines Limbus puerorum ${ }^{426}$ wird hier also mit dem Schoß Abrahams, oft auch als Limbus patrum bezeichnet, kombiniert ${ }^{427}$ als jener Ort, den man sich unter Bezug auf die biblische Gestalt des Lazarus (Lk 16,22) als

\footnotetext{
426 Zur mittelalterlichen Vorstellung des Limbus puerorum bis zum Umgang des 20. Jahrhunderts mit diesem umstrittenen eschatologischen Teilbereich vgl. SchwaRZ 2006; vgl. BAUN 1994, 115-125; vgl. SCHEFFCZYK 1997, 936-937.

427 Ein vergleichender Blick auf das Werk des berühmten Zeitgenossen und Ordensbruders des anonymen Dominikaners, Albertus Magnus, zur Eschatologie (das J. Le Goff als die wohl „,beste Definition des geographischen Jenseitssystems, die im 13. Jahrhundert erarbeitet wurde“ bezeichnet (LE GofF $\left.{ }^{2} 1991,318\right)$ ), zeigt ein dem späteren Tractatus contra Graecos ähnliches Muster, unterscheidet allerdings den Limbus puerorum von dem der Väter: Auf die Frage, ob es Wohnungen für die Seelen gebe, nachdem sie den Körper verlassen haben, erläutert Albertus Magnus (Kommentar zum IV. Sentenzenbuch, dist. 44, art. 45) die drei Regionen des jenseitigen Zwischenstadiums Paradies, Hölle und Fegefeuer. Die Hölle ist in sich unterteilt in die Gehenna als unterer Höllenteil für die Verdammten und den Limbus puerorum als oberer Höllenteil. Ein Teil des eigentlichen Fegefeuers ist der als geschlossen und unbewohnt gedachte Limbus patrum.
} 
Beherbergung der Gerechten des Alten Bundes bis zur Auferstehung Christi und danach als leer und geschlossen, weil von Christus erlöst, vorstellte. ${ }^{428}$

\section{Das Purgatorium}

In der daran anknüpfenden Probatio quod sit purgatorium zeichnet der Autor schließlich ein Bild jenes Reinigungsortes, den die Lateiner - anders als die Griechen - mit einem ersten Urteilsspruch unmittelbar nach dem individuellen Tod und mit einem aktiven Prozess der Reinigung von Sünden in Verbindung brachten. Diese Probatio, die als dritter Teil eingebettet ist in den größeren eschatologischen Kontext, ist letztlich das ausschlag- und namensgebende Element im Hinblick auf die Aufnahme und Rezeption dieses Konflikts in der lateinisch-griechischen Debatte. Für die Existenz dieses vierten Ortes lassen sich, so die Einführung in diesen Abschnitt, viele Zeugnisse aus der Tradition finden, wovon das erste und grundlegende das biblische ist: Dass die Errettung durch Feuer bei Paulus in 1 Kor 3,11-15 das Feuer als ignis

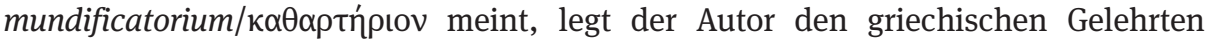
(quidam doctorum suorum) selbst in den Mund, wobei das konkrete und nicht namentlich angeführte Zitat Theodoret von Kyros entnommen ist. ${ }^{429}$ Makrina die Jüngere bezeugt als zweite das Reinigungsfeuer (ignis purgatorii) nach dem Tod und vergleicht es mit der Gabe einer Medizin, die je nach Schwere der Krankheit entsprechend bemessen werde. Zur Stütze der Autorität Makrinas und unter Vorwegnahme dessen, dass die Griechen der Meinung einer Frau möglicherweise kein Gewicht zugestehen, zitiert der Dominikaner anschließend ihre beiden Brüder Gregor von Nyssa und Basilius, die er beide für den reinigenden Aspekt heranzieht. Mit (Ps.-)Johannes von Damaskus schwenkt er dann zum zweiten großen Themenkomplex in Bezug auf das Purgatorium, nämlich auf die Fürbitte der Lebenden für die Toten. Mit dem aus den Vitae patrum stammenden Bild des Purgatoriums als Fluss aus Feuer, in dem der Alte den verstorbenen Jüngling sieht und dem er mit seinem inständigen Gebet nach und nach Linderung verschafft, belegt der Dominikaner die Wirksamkeit des Gebets und den positiven Einfluss der lebenden Gläubigen auf den Läuterungsprozess der Verstorbenen. Mit Basilius und Athanasius antwortet der Dominikaner auf den diesbezüglichen griechischen Einwand, dass es sich hierbei nicht um ein Fegefeuer gleich welcher Art, sondern bereits um das Feuer der Hölle handle, wie die Befreiung des heidnischen Kaisers Trajan durch Gregor den Großen bezeuge: Die Höllenstrafe sei im Gegensatz zum Purgatorium fruchtlos (infructuosa); und es handle sich um die einfachen und leichten Sünden (subtilia et leuia), nicht um die schweren oder schändlichen (grauia vel turpia), die zu läutern die Lebenden betend unterstützen können, auf dass ihnen selbst einmal diese Unterstützung zuteil werde.

428 Vgl. Le GofF ${ }^{2} 1991,63$ et passim.

429 Vgl. Dondaine 1951, 347-348. 
Aus der lateinischen Darstellung der griechischen Position ergibt sich ein Zweifaches: Erstens stoßen sich die Griechen daran, dass das lateinische Fegefeuer einer Rehabilitierung der Sünder noch vor dem Jüngsten Gericht Tür und Tor öffnet. Zweitens bestätigen sie zwar die Existenz eines Zwischenstadiums bzw. einer Art Warteposition, die allerdings mehr einer neutralen Aufbewahrungsstätte gleicht und keinerlei Einfluss auf den Schiedsspruch und das Schicksal der Seele nach dem Endgericht hat. Beidem widerspricht der anonyme Autor unter Zuhilfenahme der Schrift und der griechischen patristischen Tradition und kommt schließlich zum ersten Argument des paulinischen Schriftwortes in 1 Kor 3,15 zurück, um eine letzte, sprachlich-grammatikalisch motivierte Beweisführung zugunsten der lateinischen Position zu präsentieren: Die Wahl des paulinischen Vokabulars $\sigma \omega \theta \eta \dot{\sigma \varepsilon \tau \alpha \iota ~ z u r ~}$ Wirkweise des Feuers lasse die Übersetzung mit dem lateinischen Begriff conservatio (Aufbewahrung/Bewahrung) nicht zu, sondern müsse vielmehr mit salvatio (Rettung/ Heilung) wiedergegeben werden, womit eine Interpretation des Zwischenstadiums als neutraler Aufbewahrungsort ausgeschlossen sei. Mit einem so verstandenen Reinigungsprozess sei vielmehr ein Ort der Heilung bzw. der Befreiung von Lasten bezeichnet. Deswegen müsse auch - und damit greift er das erste Argument der Griechen auf - die Präposition per [ignem] in ihrer Bedeutung genau beachtet werden, da nicht das Feuer selbst in kausaler Verwendung die befreiende Wirkung leiste, sondern instrumental als Hilfsmittel Gottes wirke, womit die Reinigung auf Geheiß Gottes (Deo iubente) geschehe. Der Autor veranschaulicht seine Ausführungen mit der Metapher eines Steines, der ins Feuer geworfen wird: Dass der Stein im Feuer bestehen kann und unbeschadet (illesus) bleibt, ist ihm nicht durch das Feuer, sondern durch seine von Gott geschenkte Natur gegeben. So ist auch im Falle des Menschen nicht das Feuer das wirkmächtige und entscheidende Element, sondern der Plan Gottes mit dem Menschen, dem das Feuer als Werkzeug dient. Der anonyme Autor resümiert seine Ausführungen schließlich mit folgenden Worten:

Saluari ergo hominem per ignem dicimus, id est a peccatorum uenialium maculis mediante illo igne temporali et purgatorio liberabitur, ut sic uidelicet anima purificata propriis piaculis digna conspectui Iudicis quandoque presentetur. (TcG II, 309-313 (p. 68))

Wir behaupten daher, dass der Mensch durch das Feuer gerettet wird, das heißt, dass er von den Makeln der lässlichen Sünden mithilfe jenes zeitlichen und reinigenden Feuers befreit wird, auf dass so die von den eigenen Sünden gereinigte Seele einst in Würde dem Angesicht des Richters vorgestellt werde.

Anders als im vorangegangenen Artikel über das Filioque und in den nachfolgenden beiden Artikeln über die Azymen und den Primat Roms fehlt in der zweiten distinctio formal betrachtet die Klarheit und Systematik der Vorgehensweise des Autors. Sein sonst übliches Schema, die Meinungen der Griechen voranzustellen, um sie nacheinander zu behandeln und zu widerlegen, kommt hier nur bedingt zur Anwendung. Die Behauptung der Griechen, vor dem Tag des Jüngsten Gerichts gebe es keinen individuellen Urteilsspruch, der bereits das Paradies oder die Hölle zur Folge habe, 
nimmt der Autor zum Anlass einer Belehrung über die Aufenthaltsorte der Seelen in diesem Zwischenstadium von Tod und Jüngstem Gericht, darunter am ausführlichsten über das Purgatorium. In der Mitte der distinctio kehrt er noch einmal zurück zum biblischen Fundament, um erneut die verkehrte Lehre (praua expositio) des Häresiarchen Andreas in die Waagschale zu werfen und sie im Anschluss auf einer neuen Ebene, nämlich der sprachlich-exegetischen, zu bekämpfen. Vieles deutet im Vergleich mit den anderen distinctiones auf ,work in progress ‘ hin: Die weniger klare bzw. stringente Gliederung; das kompetente Heranziehen neuer Quellen aus der Ikonographie und der Liturgie, die die Anwesenheit des Dominikaners vor Ort und seine sprachlich-theologischen Fähigkeiten unterstreichen; das Gewicht, das der Dominikaner dem eschatologischen Konfliktpunkt im Ensemble der lateinisch-griechischen Kontroverse zumisst: Am Beginn der folgenden dritten distinctio über die Azymen blickt er noch einmal wertend zurück auf die beiden ersten Themen. Während das Filioque von den Griechen ausdrücklich geleugnet wird (negant), ist der Zustand bzw. Aufenthaltsort der Seelen eine theologische Frage, über die die Griechen lediglich schlechtes Urteilsvermögen besitzen (male sentiunt) - eine Qualifizierung, die letztlich auch auf den (durchaus gegenseitigen) Wissensstand schließen lässt und auf das noch junge Alter der Kontroverse hindeutet.

\subsubsection{Azymen: Tertia distinctio de sacramento altaris}

Im Gegensatz zur eschatologischen Frage ist die dritte distinctio einem Konflikt gewidmet, der dem Filioque vergleichbar alt und bereits tief verankert ist. Es überrascht daher nicht, dass der Dominikaner hier auf Vorlagen zurückgreift. Die Art der Vorlagen ist es eher, die Beachtung verdient und insofern hervorgehoben werden muss, als ihre Verwendung aus mehreren Gründen nicht zum Standard lateinischer Rezeption gehört. Doch zunächst zum Aufbau und zur Inhaltsübersicht:

Vor der bewährten Auflistung der griechischen Meinungen über das gesäuerte und ungesäuerte Brot in der Liturgie, die seinen eigenen Ausführungen programmatisch vorangestellt sind, findet sich eine Art Vorspann. Der Dominikaner lenkt den Blick auf seine Interpretation der Ereignisse des Jahres 1054, weil er darin den Ursprung des Azymenkonflikts verortet: ${ }^{430}$ Der Konstantinopler Patriarch Michael Kerullarios, den er als Gefolgsmann und Schüler des Photius vorstellt ${ }^{431}$, sei für den

430 Dreimal insgesamt nimmt der Tractatus contra Graecos Bezug auf 1054: Am Ende der ersten distinctio über das Filioque (TcG I, 1092-1101 (p. 52-53)), zu Beginn der dritten distinctio über die Azymen (TcG III, 15-34 (p. 69-70)) und durch die Aufnahme des Berichtes des Pantaleon von Amalfi in den Appendix des Traktats (TcG App. V, 1-40 (p. 166-167)). Angesichts des Befundes von A. Bayer, dass die Rezeption der Ereignisse von 1054 in den kontroverstheologischen Werken bis zum 15. Jahrhundert nur äußerst marginal stattfinde, nimmt der anonyme Dominikaner verhältnismäßig häufig Bezug darauf; vgl. BAYER 2014.

431 Michael folgt, so der Dominikaner, Photius insofern, als Photius als Allererster sein hochmütiges Haupt (wörtl.: den Nacken) gegen den höchsten Papst zu erheben wagte (... secutus per omnia pre- 
Ausbruch des Azymenstreites verantwortlich zu machen, da er den ansässigen Lateinern seines Herrschaftsgebietes den eucharistischen Gebrauch des gesäuerten Brotes aufgezwungen habe mit dem Ziel, sie so zur Annahme des griechischen Ritus zu führen. Rom habe mit der Exkommunikation durch den päpstlichen Legaten Humbert von Silva Candida reagiert, woraufhin die Griechen sich in vielen Schriften und Stellungnahmen wehrten und das Sakrament der Lateiner umso mehr verunglimpften. Der Streit habe daher zusätzlich zur liturgisch-kirchenrechtlichen Dimension massive gesellschaftliche, den Lateinern zum Nachteil gereichende Implikationen wie die öffentliche Beschimpfung als ,Azymiten ${ }^{6}$ mit sich gebracht. ${ }^{432}$ Dieser Vorspann am Beginn der dritten distinctio deutet bereits in die Richtung der späteren Argumentation, dass die Griechen in dieser Thematik eine Härte an den Tag legten, die keineswegs der Sache geschuldet, sondern unangemessen sei und theologisch nicht schlüssig argumentiert werden könne.

Was die Meinungen der Griechen und die theologische Gegenargumentation betrifft, stützt sich der anonyme Autor im Fall der dritten distinctio weitgehend auf etablierte theologische Lehre und in der „Forschungslandschaft“ hinreichend Aufbereitetes: ${ }^{433}$ Große Textpassagen übernimmt er, zum Teil wortgetreu, aus zwei Werken bzw. von zwei nicht namentlich genannten Autoren, von denen der erste Schulmeinung ist und der zweite überrascht: aus dem Tractatus de sacramento Eucharistie der Summa Aurea des Wilhelm von Auxerre, der den Azymenkonflikt zwischen Lateinern und Griechen als letztes Kapitel unter dem Titel De discordia quae est inter Graecos et Latinos in confectione eucharistiae seinen sakramententheologischen Ausführungen beifügt; ${ }^{434}$ und aus dem Werk Adversus Graecorum calumnias des Humbert von Silva Candida, der letztlich weniger wegen seines literarisch-theologischen Schaffens, sondern wegen seines hochpolitischen Aktes der Exkommunikation des Michael Kerullarios in die (Theologie-)Geschichte eingegangen ist. ${ }^{435}$ Die Gliederung der distinctio betreffend lässt sich beobachten, dass der Autor nach dem Vorspann über 1054 insgesamt vier Einwände der Griechen zwar auflistet, dass die lateinische Reaktion darauf allerdings mehr zur beantworten scheint, als es die griechische Provokation verlangt. Der Dominikaner greift nicht vorher ins Spiel gebrachte Argumente der Griechen auf und widerlegt sie, was darauf hindeuten könnte, dass er seine Vorlagen ohne oder mit nur geringer weiterer Anpassung herangezogen und sich auf bisherige Argumentationen gestützt hat. Freilich muss man die Möglichkeit einräumen, dass die handschriftliche Tradition einen ursprünglich zusam-

decessorem suum Fotium patriarcham, qui primus superbam ceruicem suam contra summum pontificem erigere attentauit; TcG III, 17-20 (p. 70))

432 In diesem Kontext erwähnt der Dominikaner das Martyrium der zypriotischen Mönche; vgl. dazu die Ausführungen auf den Seiten 31-33 der vorliegenden Studie und die weiterführenden Angaben in Anmerkung 119.

433 Vgl. dazu AvvaKumov 2002, bes. 117-159.

434 Wilhelm von Auxerre: Summa Aurea, lib. 4, tract. 7, cap. 8, ed. RIBAILLIER, 185-193.

435 Humbertus de Silva Candida: Adversus Graecorum calumnias, ed. PL 143, col. 929 A - 974 A. 
menhängenden inhaltlichen Duktus zerrissen hat (vgl. etwa den Einschub im Kontext des dritten Einwandes Oppositio Grecorum TcG III, 150 - 168 (p. 75-76) und Responsio Latinorum TcG III, 169-209 (p. 76-78)). Inhaltlich ist dieser Teil auf die beiden ersten Einwände bezogen, und der Dominikaner flicht hier ein weiteres Mal Wilhelm von Auxerre ein). Da sich dafür aber in den erhaltenen Abschriften keine belegbaren Gründe finden, wurden in der kritischen Edition der Einschub im dritten Einwand und die beiden unangekündigten patristischen Paraphrasen am Ende beibehalten. Das Argument, der Autor habe hier in der dritten distinctio formal weniger stringent gearbeitet, ist von daher nur mit einiger Vorsicht zu verwenden und lässt sich letztlich nur insofern stützen, als es sich hier großteils nicht um die eigenen Ausführungen des Dominikaners, sondern weitgehend um bereits existente Vorlagen handelt.

\section{Einwand 1: Pascha Christianorum oder: Mit welchem Brot feierte Jesus selbst das letzte Abendmahl?}

[...] Dominus noster, qui in sui memoriam hoc facere mandauit, non in azimo, sed in fermentato pane tradidit discipulis suis. Constat enim, dicunt, quod secundum legem Moysi quartadecima luna fiebat immolatio agni et esus azimorum, sicut scriptum est in Leuitico, qui dies Pascha proprie uocabatur. Sed Dominus iuxta Euangelium Iohannis ante diem festum Pasche celebrauit cenam cum discipulis suis, et misterium corporis et sanguinis sui tradidit. Sed in tali die erat XIIIa luna, ergo XIIIa luna celebrauit Pascha. Sed tunc utebantur fermentato, ergo de pane fermentato tradidit corpus suum. (TcG III, 49-58 (p. 71))

[...] dass unser Herr, der [uns] aufgetragen hat, dies zu seinem Gedächtnis zu tun, dies seinen Jüngern nicht in ungesäuertem, sondern in gesäuertem Brot überlieferte. Es steht nämlich fest, dass gemäß dem Mosaischen Gesetz zum 14. Mond [scil. Nissan] die Opferung des Lammes und das Mahl der Azymen stattfand, wie es in Lev beschrieben und mit dies Pascha, Tag des Paschafestes, bezeichnet ist. Der Herr aber feierte gemäß Joh am Tag vor dem Paschafest das Mahl mit seinen Jüngern und ließ sie teilhaben am Mysterium seines Leibes und Blutes. An jenem Tag aber war der 13. Nissan, also feierte er zum 13. Nissan das Paschamahl. An diesem Tag aber wurde gesäuertes Brot verwendet, von daher überlieferte er seinen Leib in gesäuertem Brot.

Die Griechen untermauern zunächst mit biblischen Belegen, dass das letzte Abendmahl Jesu mit seinen Jüngern kein klassisches und den Regeln entsprechendes Paschamahl (Pascha tempore et modo debito) war. Jesus sei vielmehr am Vortag des 14. Nissan mit seinen Jüngern zusammengekommen, weswegen die Regel, man müsse alles Gesäuerte aus dem Haus verbannen, noch nicht in Kraft war. Die Antwort des Dominikaners ist die Antwort Humbert von Silva Candidas, die mit Ausnahme der kurzen patristischen Belege am Beginn wörtlich übernommen wurde. Wenn die Griechen behaupten, das letzte Abendmahl sei kein Paschamahl gewesen, dann widersprechen sie Johannes Chrysostomus: Nach Mt 5,17 beabsichtigte Jesus gerade nicht, sich gegen die jüdischen Gesetze und Gebote zu stellen oder aufzulehnen. Daher müsse davon ausgegangen werden, dass das biblisch bezeugte letzte Abendmahl Jesu ein jüdisches Paschamahl war, das nach den entsprechenden Regeln - und folglich auch mit ungesäuertem Brot - gefeiert wurde. Diese These stützt der anonyme 
Autor mit einem ebenfalls auf der Schrift basierenden Argumentum ex silentio: Die Juden im Umkreis des Tempels, die Jesus im Visier hatten und ohnehin nach Gründen suchten, ihn belasten zu können, äußerten sich gemäß dem biblischen Befund nicht über ein falsches Prozedere Jesu hinsichtlich des Paschamahles. Hätte Jesus die Regeln gebrochen, hätten sie ihn deswegen angeklagt bzw. dagegen polemisiert. Auf den referierten Einwand der Griechen hin, dass Jesus womöglich heimlich die Regeln des Paschamahles gebrochen und auf diese Weise das Pascha Christianorum initiiert habe, antwortet der Dominikaner, dass das eucharistische Sakrament, das bis zu seiner Zeit in griechischer und lateinischer Übereinkunft das fundamentum totius ecclesie darstellt, wohl kaum mit einem Unrecht, einer Überschreitung der Gebote Gottes begonnen habe, was allein anzunehmen unwürdig sei. „Wohl einmalig in der lateinischen Literatur“436, so Y. Avvakumov, werde hier die „Grundproblematik des [Azymen-]Streites angesprochen“, nämlich die Frage, ob das letzte Abendmahl ein jüdisches Paschamahl oder eine neue, christliche Grundsteinlegung war. Gegen einen zweiten, untergeordneten Einwand der Griechen, der in gewisser Weise eine Kompromisslösung darstellt, wendet sich der Dominikaner weiter: Jesus habe, weil allmächtig (si creditur omnipotens), die Azymen des Paschamahles in gesäuertes Brot verwandelt. So sei nach Meinung der Griechen gewahrt, dass das letzte Abendmahl ein Paschamahl war, es ist so aber nicht notwendigerweise an die Verwendung des ungesäuerten Brotes gebunden. Die Evangelisten hätten von solch einem Wunder in jedem Fall berichetet, kommentiert der Dominikaner lapidar, und der Herr sei gerade wegen seiner Allmacht kein Übertreter des Gesetzes.

\section{Einwand 2: In die Parasceve oder: Karfreitag ohne Azymen}

Item: „Non introierunt in pretorium, ne contaminarentur, sed manducarent Pascha." Sed constat, quod tunc erat dies Parasceues, ergo in die Parasceue comederunt Pascha. Sed tunc fuit quartadecima luna, ergo in precedenti, quando Dominus tradidit corpus suum, fuit XIII ${ }^{a}$ luna, et inde ut prius. (TcG III, 59-63 (p. 71))

Und weiter: „Sie gingen nicht in das Praetorium, um nicht unrein zu werden, sondern das Paschalamm essen zu können. “ Aber es steht fest, dass dies der Freitag war, also aßen sie am Freitag das Paschalamm. Dies aber war am 14. Nissan, deswegen war am vorhergehenden Tag, an dem der Herr seinen Leib hingab, der 13. Nissan, etc.

Auf den zweiten, in dieselbe Kerbe schlagenden Einwand der Griechen antwortet der Dominikaner mit Wilhelm von Auxerre, ohne ihn - wie oben Humbert von Silva Candida - als seine Quelle offenzulegen. Skizziert werden die biblischen Verwendungen und Kontexte des Wortes Pascha (Zeit des Paschamahles; Paschalamm; das Fest der ungesäuerten Brote; die Azymen selbst) und die scheinbaren Widersprüche in 
den Evangelien, um davon ausgehend schlüssig zu zeigen, dass Pascha in der zitierten Schriftstelle Joh 18,28 mit Azymen gleichzusetzen sei.

In die Beantwortung des nachfolgenden dritten Einwandes eingeschoben ist schließlich ein weiteres Argument, das inhaltlich die Frage des Datums des letzten Abendmahls als Paschamahl oder als Pascha Christianorum berührt: ${ }^{437}$ Die Wahrheit müsse der Figur entsprechen, so die Griechen. Der Dominikaner widerspricht und führt dazu unter Rückgriff auf Wilhelm von Auxerre den Vergleich aus, dass auch das Zeichen nicht in allem dem Bezeichneten (nec signum signato) entsprechen müsse.

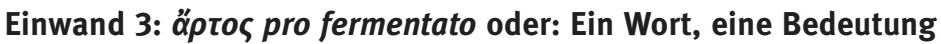

Item cum Euangelista de materia illius panis faceret mentionem, non dixit accepit Iesus azima, sed „accepit Iesus arton“. Sed arthos supponit pro fermentato, ergo etc. (TcG III, $64-66$ (p. 71))

Und weiter: In der Formulierung des Evangelisten über die Materie jenes Brotes heißt es nicht: Jesus nahm das ungesäuerte Brot, sondern es heißt: Jesus nahm das [gesäuerte]Brot. Deswegen steht das griechische Wort arthos für das gesäuerte Brot, etc.

Dass der griechische biblische Begriff öptoৎ ausschließlich für das gesäuerte Brot steht, wie die Griechen behaupten, sei schlichtweg falsch. Er bezeichne im Gegenteil jede Art von Brot (pro quolibet pane sumitur), wie der Dominikaner - wiederum gestützt auf Wilhelm und Humbert - anhand von fünf Beispielen aus dem AT und dem NT zeigt: An der Emmaus-Erzählung des nachösterlichen Brotbrechens Christi im Kreis der Jünger wird deutlich, dass hier mit dem Wort arthos konkret die Azymen gemeint sein müssen, da die sieben gebotenen Tage der ungesäuerten Brote (dies azimorum) noch nicht vorbei waren. Mose wird in Ex das Wort arthos in den Mund gelegt, wo der Kontext klar und dem Gesetz entsprechend auf die Azymen hinweist. Wenn in Weish vom Manna, das heißt vom Brot des Himmels die Rede ist, steht in der LXX das Wort arthos; ebenso verwenden die Ps und Spr arthos für das Brot in verschiedenen Kontexten. Der Begriff ő $\rho \tau$ то werde demnach, so das erste Resümee, für beide Formen des Brotes verwendet: für das Brot, das den Magen füllt, wie auch für jenes, das den Geist sättigt (accipitur tam pro azimo, quam pro fermentato, et tam pro eo quod replet uentrem, quam pro eo quod satiat mentem). Daher lasse der griechische Begriff flexible Übersetzungen und vor allem hermeneutische Implikationen $\mathrm{zu}$ - ein Potential, dessen man den Begriff nicht berauben dürfe.

\section{Einwand 4: Das gesäuerte Brot symbolisiert die zwei Naturen Christi}

Item cum scriptum sit, quod stando et cum lactucis agrestibus et festinanter deberet comedi agnus Pascalis, nullum tale quid in Euangelio reperitur. Unde constat quod illa cena non fuit esus agni siue Pascha Iudaicum, sed potius cena et Pascha Christianorum: Non cum azimis, sed cum fermentato 
pane, quod significat Christi perfectionem, fuit celebratum. Nam Christus Dominus noster duas naturas in unam personam sibi uniuit. Et sicut diuina simplicissima, ita humana est composita ex anima rationali et carne. Sicut ergo in Christo fuit et est diuinitas, anima et corpus, ita in misterio sacramenti nostri, quod ex perfecto pane scilicet fermentato perficitur, tria similiter reperiuntur: hoc est farina, fermentum et aqua. Vestrum autem sacramentum non solum non est uerum sacramentum, sed nec sacramentum quidem, cum tantum discrepet a ueritate. (TcG III, 67-80 (p. 71-72))

Und weiter: Obwohl geschrieben steht, dass das Paschalamm stehend, mit Bitterkräutern und in Eile gegessen werden soll, findet sich nichts davon im Evangelium. Von daher steht fest, dass jenes Abendmahl nicht das Mahl des Lammes oder das jüdische Pascha war, sondern vielmehr das Mahl und Pascha der Christen: Gefeiert wurde es nicht mit Azymen, sondern mit gesäuertem Brot, das die Vollkommenheit Christi symbolisiert. Denn unser Herr Jesus Christus vereinte in sich zwei Naturen in einer Person. Und so wie die göttliche Natur eine einzige ist (simplicissima), so ist die menschliche Natur zusammengesetzt aus (Vernunft-)Seele und Leib. Wie daher in Christus Göttlichkeit, Seele und Körper waren, so finden sich im Geheimnis unseres Sakramentes, das aus dem vollkommenen, d.h. gesäuerten Brot gewandelt wird, gleichsam diese drei: Mehl, Sauerteig und Wasser. Euer Sakrament aber ist nicht nur kein wahres Sakrament, sondern es ist überhaupt kein Sakrament, weil es so sehr von der Wahrheit abweicht.

Als Altweibergeschwätz (fabula uetularum) bezeichnet der anonyme Autor die bildhafte Redeweise der Griechen, die ausgehend von der Zwei-Naturen-Lehre drei Komponenten im eucharistischen Sakrament herleiten. Wenn schon dieses Bild, dann müsse man zugestehen, dass im Brot neben den drei genannten Komponenten auch noch zwei andere zu finden seien: Salz und Feuer bzw. Hitze, wobei letzteres das Brot erst in die ihm entsprechende Form (ad essentiam suam) bringt. So finde sich also nicht die Dreizahl, sondern die Vier- oder gar Fünfzahl, die sich im Sakrament spiegeln müsste, wenn man das Argument der Griechen konsequent weiterdenkt. Die Dreizahl könne aber dennoch aufrechterhalten werden, und zwar in ihrer lateinischen Interpretation: Das Brot in seiner vollkommenen Form besteht aus Mehl, Wasser und Feuer bzw. Hitze. Mithilfe des Feuers verbinden sich Wasser und Mehl zum Brot, wobei das Mehl das Fleisch (caro) symbolisiert, das Wasser für die Seele (anima) steht und das Feuer die Göttlichkeit (diuinitas) zum Ausdruck bringt, die das Bindeglied darstellt und Leib und Seele zur Einheit der Person vereint.

Die letztlich entscheidende argumentative Wende in der Azymen-Thematik vollzieht der Autor in der letzten Passage, die somit den Charakter einer Probatio erhält, ohne als solche betitelt zu sein. Entlang zweier patristischer Autoritäten, die sich letztlich beide als unecht herausstellen ${ }^{438}$, plädiert der Dominikaner für die Gleichwertigkeit beider Traditionen und damit für die dem lateinischen Westen eigene und übliche Sichtweise: Das gemeinsame Glaubensbekenntnis eine die einzelnen Teilkirchen. Der Ritus aber sei jeweils unterschiedlich, und das aufgrund jeweils eigener,

438 Vgl. Theorianus Philosophus / Theodorus Prodromos (= Ps. Iohannes Chrysostomus), Epistola ad sacerdotes in monte degentes (rec. latina), ed. LoENERTZ 1970, 55-66; ed. PG 94, col. 405-407, inter Dissertationes Damascenicae, VI, 42-43; vgl. DondaINE 1951, 352-357; und vgl. Ps. Gregorius Magnus, fragmentum, ed. PG 94, col. 404-405, inter Dissertationes Damascenicae, VI, 42; vgl. DondAINE 1951, $357-362$. 
aber nicht ausschließender theologischer Begründung. Denn im Grunde ist es unerheblich, ob das Brot vor der eucharistischen Konsekration gesäuertes oder ungesäuertes Brot ist, weil das entscheidende Kriterium der eine Leib unseres Herrn Jesus Christus nach der Wandlung ist (neque azimus neque fermentatus dicitur uel est, sed corpus et caro Domini). Denn nach der Wandlung sind die Merkmale ,gesäuert‘ oder ,ungesäuert', ja das Brot an sich ohnehin irrelevant, wie auch die Sorte des Weines oder ob es sich um Rot- oder Weißwein handelt keine Rolle mehr spielt. In diesem Zusammenhang tadelt der Autor die allzu große und dem Mysterium unangemessene Neugierde (stultas curiositates) der Griechen; ein Tadel, der gewöhnlich eher umgekehrt von Seiten der Griechen an die den Lateinern zugeschriebene Rationalität, oft mit dem Argument der apophatischen Theologie, adressiert ist.

Die Gesamtintention des Traktats widerspiegelnd resümiert der Autor am Ende der dritten distinctio über die Azymen, dass er anhand dieses Beispiels erneut hinlänglich gezeigt habe, dass die Kirchenväter beider Traditionen mit dem übereinstimmen, was die römische Kirche bewahrt hat, lehrt und vertritt. Die Griechen aber wollten das „Joch des Gehorsams gegenüber der hochheiligen römischen Kirche auf ungebührliche Weise abschütteln“ (ugum obedientie sacrosancte dicte ecclesie a collo suo indebite excutere uoluerunt) und beschuldigen sie daher einer Reihe von Irrtümern. Ihren eigenen beharrlichen Protest (rebellionem pertinacem) aber kleiden sie in Vernunftargumente, weswegen es umso wichtiger sei, diese Argumente zu prüfen und dabei ihre wahren Motive, d.h. den Ungehorsam gegenüber der römischen Kirche, offenzulegen.

\subsubsection{Primat Roms: Quarta distinctio in qua ostenditur, quod papa sit summus pastor omnium ecclesiarum}

Die vierte distinctio über die Vorrangstellung der römischen Kirche und mit ihr des Papstes stellt sich in einiger Hinsicht - formal und inhaltlich - anders dar als die ersten drei distinctiones. Zunächst fällt an ihrem Aufbau auf, dass sie zwar wie üblich die Meinungen der Griechen jedem einzelnen Argumentationsgang voranstellt, dies aber mehr nach Art eines Aufhängers für die lateinischen probationes, die in sich geschlossen eine eigene Abhandlung über den Primat darstellen, die problemlos aus dem Kontext der anderen drei distinctiones genommen werden könnte. Die Vorrangstellung (potestas) der römischen Kirche als Gegebenheit annehmend, ist diese Abhandlung anhand dreier Fragen komponiert:

Sciendum uero, quod ad probandam obedientiam et debitam reuerentiam ecclesie Romane oportet nos querere primo a quo habuerit ecclesia istam potestatem, secundo quando, tertio utrum super omnes uniuersaliter an particulariter super aliquos. (TcG IV, 5-8 (p. 86))

Man muss wissen, dass wir für den Nachweis des Gehorsams und der geschuldeten Ehrerbietung gegenüber der römischen Kirche drei Fragen stellen müssen: erstens, von wem die Kirche diese Macht erhalten hat; zweitens, wann sie diese Macht erlangt hat; und drittens, ob sie diese Macht über die Gesamtheit aller Kirchen oder über einige Teilkirchen ausübt. 
(a) Wer hat der römischen Kirche diese Vorrangposition bzw. diese Macht verliehen? (b) Seit wann hat die römische Kirche diese Stellung inne? (c) Hat diese potestas universal- oder partikularkirchliche Gültigkeit? Anders als davor hat der Dominikaner eine (stilistische?) Einzelperson als Adressaten bzw. Leser im Blick, die er gelegentlich mit dem Imperativ anspricht. Eine weitere Besonderheit der vierten distinctio besteht im Charakter des patristischen Quellenfundus, den der Dominikaner hier verwendet: Neben Johannes Chrysostomus (und - nicht namentlich - Theophylact von Bulgarien) als Hauptbezugsquelle der griechischen Patristik sind es in erster Linie die Konzilsdokumente und konzilsbezogene Briefkorrespondenz, wobei das Konzil von Chalcedon (451) und Papst Leo I., dessen Predigten als erstmaliger systematischer Ausdruck des typisch römischen Petrusamtes gelten ${ }^{439}$, in Person und Werk den Dreh- und Angelpunkt der Argumentation bilden. Schließlich erscheint die vierte distinctio anders als die drei vorhergehenden Themenbereiche als Ziel- und Endpunkt einer Dynamik, die der Autor bis dahin vorangetrieben hat: Die Bearbeitung der drei Konfliktpunkte Filioque, Purgatorium und Azymen und mit ihnen die Thematisierung von Dogmatik/Trinitätstheologie, Eschatologie und Ritus/Liturgie hatte, so der Autor im Prolog zum Tractatus maior ${ }^{440}$, das Ziel, die Griechen von der Notwendigkeit römischer Obödienz zu überzeugen bzw. sie der römischen Kirche wieder einzugliedern um der Einheit der Kirche und des Seelenheils ihrer Gläubigen willen. Die vierte distinctio nutzt der Autor nun ausführlich zugunsten dieser inhaltlichen Klammer seines ganzen Tractatus maior, indem er die Bringschuld des Gehorsams und der Verehrung gegenüber der römischen Kirche nachweist (ad probandam obedientiam et debitam reuerentiam ecclesie Romane), worin er das Ziel und die Bemühungen seiner bisherigen Ausführungen exponiert verdeutlicht.

Schritt für Schritt und ineinander übergehend legt der Autor im Folgenden ausführlich dar, woher und seit wann die römische Kirche jene potestas besitzt, die den Gehorsam ihr gegenüber rechtfertigt, und ob sie diese Macht universal oder partikular ausübt. Einwände der Griechen ähnlich dem Schema der vorhergehenden drei Themen finden sich zwar auch hier eingewoben, allerdings eben nach Art einer Triebfeder der lateinischen probationes, wie der Dominikaner sie hier bezeichnet, denn als Ausgangspunkt eines Argumentationsgangs.

Quantum ad primum distingue, quia aut habuit a Deo mediante Petro, aut a principibus secularibus, aut a conciliis generalibus, aut simul ab istis tribus, aut a nullo istorum, sed usurpato honore utitur ecclesia uiolenter et indigne. Et istam ultimam concedunt Greci et dicunt, quod nullus Apostolorum fuit maior altero, sed omnes fuerunt fratres et pares iuxta illud: Vos omnes fratres estis, et patrem nolite uocare uobis super terram etc. (TcG IV, 9-15 (p. 86))

439 Vgl. PRÜGL 2004, 745-769, hier: 762.

440 Hiis itaque - fide scilicet, spe, et caritate - uirtutibus a cordibus fidelium dicto studio et ordine deletis, ultimo in totius consummationem nequitie quartus articulus eam, ad quam horum et similium errorum spectat correctio, id est sanctam Romanam ecclesiam, canino dente lacerat eamque non esse capud ecclesiarum nec ei oediendum communiter asserendo predicat, moribus affirmat, et factis ostendit. (TcG Prol., $28-35$ (p. 4)) 


\begin{abstract}
Was die erste Frage betrifft, musst du unterscheiden, ob sie diese Macht von Gott und vermittelt durch Petrus erhalten hat, oder von den weltlichen Herrschern, oder von den Generalkonzilien, oder gleichsam von all diesen dreien, oder von niemandem dieser drei Instanzen, sondern ob sie sie - im Gegenteil - unrechtmäßig ausübt und sie durch Gewalt und unwürdig erlangt hat. Letzteres behaupten die Griechen und sagen, dass keiner der Apostel höhergestellter war als ein anderer, und dass alle Brüder und gleichen Ranges waren gemäß dem Schriftwort: „Ihr alle aber seid Brüder, und ihr sollt niemanden euren Vater nennen auf Erden usw.“
\end{abstract}

Zunächst geht es um die Vorrangstellung des Apostels Petrus im Apostelkollegium, um davon ausgehend die Position des römischen Papstes als Stellvertreter Christi (uicarius Christi), Vater der Väter (pater patrum) und höchster Pontifex (summus pontifex) sowie sein Verhältnis zu den Patriarchen des Ostens darzulegen. Mt 23,8-9 sei kein Beleg für die Gleichrangigkeit der Apostel, indem das Vorsteheramt (officium prelationis) abgeschafft wird, sondern stehe gegen die Begierde des (Be-)Herrschenwollens (libido dominandi). Es ist nämlich nicht die Kirche selbst, die sich ihren Vorsteher bestimmt, sondern Gott, der ihn für ein solches Amt beruft. Dem Apostel Petrus kommt in diesem Kontext und entgegen der Auffassung der Griechen der Ehrenvorrang (prerogatiua dignitatis super Apostolos) und die Fülle der Macht (plenitudo potestatis) zu, was der Dominikaner im Folgenden ausführlich darlegt. Er zieht Johannes Chrysostomus ${ }^{441}$ heran, um anhand Joh 21,17 den Apostelfürsten Petrus als den Inhaber des Vorsteheramtes (praepositura) zu nennen, weil er vor allen anderen stehe (praecipuus omnium) und der Mund, das heißt Sprecher des Apostelkollegiums (os totius chori) ist. Jede gegenteilige Auslegung des Johannes Chrysostomus beweise, dass die Griechen sogar zu Fälschungen ihrer eigenen Autoritäten bereit sind: Anhand einiger ChrysostomusOriginale aus den griechischen Klöstern habe der Dominikaner zeigen können, dass Fälschungen des Theophylact von Bulgarien im Umlauf seien, die Johannes Chrysostomus die Gleichrangigkeit aller Apostel in den Mund legen. ${ }^{442}$ Des Weiteren bezeichne Germanos II., der ,jüngst verstorbene Erzbischof von Nizäa“, in einem seiner Briefe auch Paulus als coripheon ton Apostolon, was allerdings vonseiten seines eigenen Klerus nur belächelt und als Unsinn quittiert worden sei. ${ }^{443}$ Und weiter in der Argumentation: Joh schreibt in den daran anschließenden Versen Petrus die Verantwortung für alle Gläubigen zu (praelatio omnium fidelium). Wenn auch den Patriarchen des Ostens territoriale Befugnisse zukommen, indem sie in partibus potestatis berufen sind, so ist Petrus dagegen in plenitudine potestatis berufen, den Thron des ganzen Erdkreises innezuhaben. Dies belege Mt 16,18-19, indem die Schlüsselübergabe exklusiv (tibi discretiue ab aliis) interpretiert wird. ${ }^{444}$ Aus dem Schriftwort $T u$

441 Vgl. TcG IV, 38-46. 47-51. 53-56 (p. 87-88).

442 TcG IV, 61-78 (p. 88-89).

443 TcG IV, $96-101$ (p. 90).

444 Quod autem Petrus habuerit prerogatiuam dignitatis super Apostolos et plenitudinem potestatis super omnes homines, probatur sic: In Euangelio Iohannis, cum Dominus ter requisisset a Petro singulariter et specialiter, an se diligeret, audiuit: Pasce oues meas etc. Super quem locum dicit Iohannes Cristostomus: „Quia igitur finis erat cene, Petro preposituram orbis ouium committit, non alteri hanc dat, 
vocaberis cephas lasse sich zudem deutlich ableiten, dass die lateinische Übersetzung dieses griechischen Wortes mit caput legitimerweise zu caput ecclesiarum führt, wobei

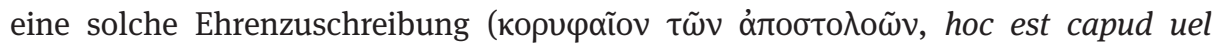
uerticem siue apicem Apostolorum) ohnehin niemand anderem als Petrus zuteil wird, wie aus liturgischen Quellen der Griechen deutlich wird. ${ }^{445}$ Alle Apostel haben die potestas übertragen bekommen, aber Petrus als einziger unter ihnen die Fülle der Macht, die ihn dazu befähigte, die Apostel in Teilverantwortung (in partem sollicitudinis) einzusetzen. Von daher wird deutlich, dass - anders als der Nachfolger Petri die Nachfolger der übrigen Apostel nicht summi pontifices, sondern archipraesules oder archiepiscopi sind und genannt werden. Einzig der Nachfolger des Petrus, des Stellvertreters Christi, darf summus pontifex et papa, das bedeutet pater patrum, heißen und entsprechend seiner Stellung die Nachfolge des Petrus ausüben. ${ }^{446}$

Dass Petrus die Apostel in Teilverantwortung eingesetzt habe, nimmt der Dominikaner zum Ausgangspunkt der Erläuterung des Verhältnisses zwischen Rom und den östlichen Patriarchaten: Die biblisch belegte oder rekonstruierbare Anwesenheit des Petrus selbst oder eines Stellvertreters an einem gewissen Ort legitimierte durch die Geschichte hindurch bis in die Gegenwart des Autors die Sonderstellung der östlichen Patriarchate und die Bezeichnung ihres jeweiligen Bischofs als princeps patrum. ${ }^{447}$ Dass die Patriarchatswürde tatsächlich von Petrus abhängig ist, dass also nicht die Apostel und Apostelschüler unabhängig von ihrer Sendung durch Petrus eine Sedes begründen konnten, erklärt der Autor im Analogieschluss schlicht damit,

sed huic tantum. Quare? Quia omnium precipuus et os totius chori [...].“ Et post aliqua dicit [i.e. Dominus] ei: Sequere me: „Commisit quidem Petro prelationem omnium fidelium, quia etsi Iacobus Ierosolimorum sedem suscepit, Petrus tamen totius orbis, quasi dicat: Sanctus uocatus est Iacobus in partem sollicitudinis, sed Petrus Apostolus in plenitudinem potestatis." Unde in Mattheo: Tibi dabo claues, tibi discretiue scilicet ab aliis dabo claues etc. (TcG IV, 34-52 (p. 87-88)).

445 TcG IV, $79-83$ (p. 89).

446 Item Dominus de Petro in Euangelio: Tu uocaberis cephas, quod de Greco in Latinum redditum sonat ,capud', ut etiam ex ipsa impositione nominis capud ecclesie eumdem demonstraret. Quod sacri doctores fidei considerantes ubicumque de Petro mentionem aliquam faciunt, 'coripheon ton Apostolon', hoc est capud uel uerticem siue apicem Apostolorum, nominauerunt. Quam prerogatiuam nominis nusquam de aliquo alio Apostolorum legi uel audiui. [...] Et licet omnes Apostoli claues ligandi atque soluendi a Domino susceperint, nullus tamen sibi potestatis plenitudinem aliquo tempore uendicauit. Sunt enim uocati in partem sollicitudinis sicut archiepiscopi a papa, et episcopi ab archiepiscopis, et ab episcopis sacerdotes. Unde factum est, ut successores aliorum Apostolorum non summi pontifices, sed archipresules uel archiepiscopi nuncupantur. Romanus uero pontifex, quia uicario Christi, id est Petro, in omnibus successit, non immerito summus pontifex et papa, hoc est pater patrum, singulariter nominatur. (TcG IV, 83-115 (p. 89-90)).

447 Aliorum etiam locorum episcopi, in quibus personaliter ipse [i.e. Petrus] prefuit ut Antiochie, uel aliquem uicarium suum misit ut Alexandrie Marcum, et etiam Cesaree Palestine, ubi ordinauit Cornelium et uices suas commisit, propter Petri reuerentiam speciale priuilegium et dignitatem pre ceteris ecclesiis habere meruerunt, ut dictarum ecclesiarum episcopi non modo archiepiscopi, sed patriarche, hoc est patrum principes siue principales, appropriato uocabulo a cunctis nominentur. (TcG IV, 116-123 (p. 90-91)). 
dass ansonsten mehr als jene fünf Patriarchate - Rom, Konstantinopel, Alexandrien, Antiochien und Jerusalem - existieren müssten. ${ }^{448}$ Dass auch Jerusalem den Status eines Patriarchats besitze, sei der Ehrerbietung (reuerentia) geschuldet, die dem Ort aufgrund der Präsenz und des Opfers Christi zukommt. ${ }^{449}$ Anders verhält es sich, so der Dominikaner, mit dem Patriarchat von Konstantinopel, da Konstantinopel aus den vorher genannten Gründen eigentlich über keine Sedes verfügen dürfte. Durch eine Intervention des Kaisers Theodosius am Konzil von Konstantinopel (381) seien die Konzilsväter dazu gezwungen worden, hinter dem Rücken des Papstes und ohne seine Zustimmung (clam summo pontifice sine cuius consensu) Konstantinopel zum Patriarchat zu erheben und seinem Bischof den Rang eines Patriarchen zuzuerkennen, den dieser vorher nicht besessen hatte. Für die erheblichen Vergünstigungen und Erweiterungen der Privilegien des Patriarchen von Konstantinopel am Konzil von Chalcedon (451) macht der Dominikaner in polemischer Absicht drei Faktoren verantwortlich: Die größer gewordene Zeitspanne zu den unrühmlichen Ausgangsereignissen (processus temporis), das mit der Zeit unbekümmerter werdende und bewusst hintergehende Handeln der Griechen (Grecorum crescente malitia) und das faktische Anwachsen ihrer machtpolitischen Einflüsse (potentia inualescente). Trotz des Widerspruchs der päpstlichen Legaten am Konzil von Chalcedon sei durchgesetzt worden, dass Konstantinopel ähnliche Privilegien wie Rom zukamen, dass dem Patriar-

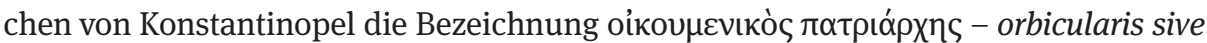
universalis patriarcha zuerkannt wurde, und dass diesem der zweite Platz in der kirchlichen Rangfolge nach Rom zustehe, der bis dahin und auf den ersten drei ökumenischen Konzilien Alexandrien wegen der Verehrung des Petrusschülers Markus zugekommen war. ${ }^{450}$ Der Autor referiert im Folgenden die Briefkorrespondenz mit

448 Hiis sic se habentibus multum uidetur opinio quorumdam nostrorum Latinorum infirmari qui dicunt, quod patriarche dicti sunt, quia in locis hiis Apostoli presiderunt. Si esset positum,Apostolus presedit;, id est Petrus uel per se uel per uicarium suum, ualeret quod dicitur. Sed si simpliciter de omnibus intelligi uolunt, quomodo stare possit non uidemus, quoniam essent plures quam quinque, nec omnia supra nominata loca patriarchali honore decorarentur. Nullus enim Apostolorum sedit Constantinopoli, nec Alexandrie nisi Petri discipulus beatus Marcus. Sedit hoc secundum Grecos etiam Mediolani Barnabas, electus Apostolus gentium cum beato Paulo, et aliqui de Apostolis quibusdam regionibus specialiter prefuerunt. Sed si quorumlibet Apostolorum et discipulorum Domini sessio faceret sedem, necesse esset, sicut diximus, quod essent plures quam quinque patriarche in mundo. Sed cum hoc non uideamus, sequitur quod gratia Petri predictarum ciuitatum sedes honorem huiuscemodi pre ceteris ecclesiis habere meruerunt. Suscepit igitur Petrus plenitudinem potestatis a Christo, et eam suis posteris successiuo iure dimisit, ut qui in ea sede, quam, ut ita dicam, martirio crucis pro Domino consecrauit, is qui secundum canones fuerit electus, Christi uicarius non immerito cognoscatur. (TcG IV, 213-233 (p. 95-96)).

449 Si uero queritur, unde ergo Ierusalem et Constantinopolis habuerint patriarcham, respondemus: In primo generali concilio patres sancti, qui intererant, considerantes loci reuerentiam Ierusalem, scilicet quam redemptor omnium sua presentia et suo cruore piissimo dignatus est consecrare, honorem huiuscemodi, id est patriarchatus, eiusdem loci episcopo dispensatiue concesserunt. (TcG IV, 123-129 (p. 91).

450 Constantinopolis proprie sedem non habet, sed Theodosius imperator in secundo concilio coegit CL patres clam summo pontifice, sine cuius assensu fieri non potuit, prout legentibus hunc libellum patebit, 
Papst Leo I. anlässlich des Konzils von Chalcedon und der Privilegien des Patriarchen von Konstantinopel, um zu zeigen, dass (a) eine Entscheidung des Konzils ohne die eingeholte Zustimmung des Papstes, der ja nicht vor Ort war, oder seiner Gesandten, die am Konzil vertreten waren, als unabgeschlossen und daher ungültig angesehen werden müsse (quia sine confirmatione pape uel legatorum eius infectum negotium habeatur), und dass (b) dies in der Geschichte der Kirche auch niemals von den Griechen angezweifelt worden war.

Als autoritativen Beleg für die umfassende, das heißt auch weltliche Macht des Papstes verweist der Autor auf die sogenannte Konstantinische Schenkung, jene Dokumentensammlung, die schon im 13. Jahrhundert eine stark diskutierte und in der neu entstehenden Disziplin der kirchlichen Kanonistik an den Universitäten aktuelle Autorität war. ${ }^{451}$ Das im Traktat so genannte „Privilegium Constantini““452 rechtfertigt die weltlichen Machtansprüche des Papsttums, da es in der mittelalterlichen Vorstellung ,die erste Schenkungsurkunde eines christlichen Kaisers für die römische Kirche“453 darstellt, mit der Kaiser Konstantin I. Papst Silvester I. sowie sämtlichen Nachfolgern auf unbestimmte Zeit kaiserliche Privilegien zuerkannte. ${ }^{454}$ Der Autor des Traktats betont, dass Kaiser Konstantin I. die in der Schenkung gewährten Privilegien nicht von sich aus und damit nicht aus bloßer Eigeninitiative, sondern erfüllt vom Geist des Konzils gewährt habe. Die Konzilsväter waren es demnach, die schließlich die praerogativa der römischen Sedes und die Stellung des Papstes als Haupt aller

ut Constantinopolitanam sedem sublimarent nomen ei patriarche attribuentes, quod ante non habebat. Processu etiam temporis, Grecorum crescente malitia et potentia inualescente, patres, qui conuenerant in quarto concilio, suasu nihilominus principis Martialis quedam priuilegia Romane sedis similia et hoc nomen ,ycoumenicos patriarchis', quod sonat orbicularis siue uniuersalis patriarcha, eidem Constantinopolitano episcopo contradicentibus apostolice sedis legatis contulerunt, et ut habeat primum locum post papam, cum Alexandrinus primitus in primo et secundo et tertio concilio hanc dignitatem habuerit propter reuerentiam Marci discipuli beati Petri. (TcG IV, 136-149 (p. 91-92)).

451 Seit Ende des 12. Jhdts. und besonders seit dem 13. Jhdt. erhält die Konstantinische Schenkung neue Schubkraft in den Diskursen und wird - nicht zuletzt wegen der neu entstehenden wissenschaftlichen Disziplin des Kirchenrechts an den Universitäten - radikal neu ausgelegt und verstanden. Die Diskussion um die Rechtsbedeutung der Schenkung hatte aber spätestens 1228 mit Accursius in Bologna begonnen, und der Nachweis, dass es sich um eine Fälschung handelt, wurde im 15. Jahrhundert beinahe zeitgleich von drei Seiten erbracht: Von Nikolaus von Kues in seiner Concordantia catholica (1434), von Lorenzo Valla in seiner Schrift De falso credita et ementita Constantini donatione (1440) und von Reginald Pecock (1449) in seinem Repressor of over much blaming of the clergy. Edition der Konstantinischen Schenkung bei FuHRmann 1968; zur Textgeschichte vgl. FuHRmann 1966, 63178; vgl. Miethke 2008, 35-109, hier: 45-49; vgl. Fried 2007; vgl. FuHRMAnN 1981, 196-202; vgl. Henderson 2008, 283-305; vgl. PRÜGL 2012, 148 - 174, hier: 140 -141; vgl. jüngst MureŞAN 2019, 139 206; zur byzantinischen Rezeption der Schenkung vgl. ANGELov 2009.

452 Zur griechischen Vorlage des Dominikaners vgl. TcG introd., XI; vgl. auch ANGELov 2009, 98-99.

453 FuHRMANn 1966, 64.

454 Das Constitutum Constantini spielte später im Rahmen des Konzils von Ferrara-Florenz eine entscheidende Rolle in der lateinischen Argumentation des päpstlichen Primats gegenüber den Griechen; vgl. dazu SieBEN 1996, 345-355. 
Kirchen (caput omnium ecclesiarum) beschlossen, die schließlich auch von Seiten der griechischen Herrscher expressis verbis anerkannt wurde.

Seine Abhandlung über die Stellung des römischen Papstes abschließend fasst der Autor die Antworten auf die drei am Beginn gestellten Fragen in aller Kürze zusammen: ${ }^{455}$ Die römische Kirche habe die potestas von Christus her vermittelt durch Petrus inne, dem allein die Obsorge aller Gläubigen von Christus anvertraut worden war (cui cura ouium spiritualium specialiter singulariterque fuit commissa); die Ausübung dieser Macht (executionem tamen potestatis uel auctoritatis) gründet auf den Beschlüssen des ersten gesamtkirchlichen Konzils von Nizäa 325, das jeder Sedes Privilegien und Rangfolge je nach apostolischer Würde zuteilte. Die weltliche bzw. zeitliche Macht und Würde (dignitatem uero et potentiam temporalem) wurde ihr von den gläubigen weltlichen Herrschern übertragen, die zu ihren Gunsten zur Zeit des Papstes Silvester I. öffentliche Gesetze erließen. Im Hinblick auf das Ziel seiner Argumentationen schließt der Autor mit dem Ertrag seiner Ausführungen und der Exkommunikationsandrohung für alle, die gegenteiliger Meinung sind:

Constat ergo ex hiis, que dicta sunt, quod Romanus pontifex capud est ecclesiarum omnium siue uniuersalis ecclesie, cum una sit et non plures, successorque Petri et uicarius Dei in terris, et ei tamquam ipsi Domino oporteat fideles in hiis, que secundum Deum sunt, deuote et humiliter obedire. Eos uero, qui contumaciter repugnant et ipsam sedem non esse capud ecclesie asserunt, sicut iam a pontificibus eiusdem sedis decretum est, anathematis gladio percussos cum Datan et Abiron scismatis incursuros dicimus dispendium dampnationis eterne. (TcG IV, 594-602 (p. 111))

Aus dem Gesagten lässt sich schließen, dass der römische Pontifex das Haupt aller Kirchen bzw. der Gesamtkirche ist, weil sie ja die eine Kirche und nicht mehrere Kirchen ist; dass er der Nachfolger Petri und Stellvertreter Gottes auf Erden ist, dem die Gläubigen so wie dem Herrn selbst ergeben und demütig gehorchen sollen in allem, was gottgemäß ist. Jene aber, die auf schändliche Weise widersprechen und behaupten, der Papst sei nicht das Haupt der Kirche, wie es lange schon von den Päpsten auf eben jenem Thron festgeschrieben ist, nennen wir als vom Schwert der Exkommunikation geschlagen und gemeinsam mit den Schismatikern Datan und Abiron dem Unheil der ewigen Verdammung entgegeneilend.

455 Que cuncta, si diligens lector discutere uoluerit, inueniet illa tria, que in principio istius quarte partis quesita fuerant, esse soluta, uidelicet quo tempore Romana ecclesia habuerit istam potestatem, uel a quo, et utrum super omnes uniuersaliter an particulariter super aliquos. Quod tamen iterum breuiter repetentes, dicimus quod auctoritatem habet ecclesia a Christo mediante Petro, cui cura ouium spiritualium specialiter et singulariter fuit commissa; Executionem tamen potestatis uel auctoritatis sue habet ecclesia a primo concilio Nicee celebrato, in quo unaqueque sedes, secundum quod plus et minus honoris ab Apostolis receperat, magis et minus fuit priuilegiata et exaltata; Dignitatem uero et potentiam temporalem recepit a fidelibus imperatoribus, qui a tempore beati Siluestri pro ea publicas leges promulgantes ei pacem dederunt. (TcG IV, 513-526 (p. 108)). 


\subsubsection{Die vier Gründe des Schismas: De quatuor causis scismatis}

Im Prolog am Beginn des Traktats, in dem der Autor sein methodisches und inhaltliches Programm vorstellt, werden weder der umfangreiche Appendix ${ }^{456}$ noch der kurze Text über die vier Gründe des Schismas erwähnt, der dem handschriftlichen Befund nach aber noch zum Corpus des Tractatus maior gehört. Es handelt sich bei diesem Text um eine wiederum in sich geschlossene kurze Abhandlung über die Gründe bzw. Anlässe, die zur Trennung zwischen der griechischen und der lateinischen Kirche geführt haben. Im Gegensatz zu den im Hauptteil vorgestellten theologischen deviationes, das heißt den Abweichungen der Griechen und ihren theologisch-kirchlichen Implikationen, referiert der Autor nun seine Sicht auf die vier Gründe (cause) bzw. Anlässe (occasiones) des Schismas bzw. darauf, inwieweit dieses zu rechtfertigen sei, wobei er in diesem Text dezidiert nicht-theologisch argumentiert.

Als ersten der vier Gründe nennt der Autor die Reichsteilung (divisio imperii), die an die Person Karls des Großen und die Etablierung des Karolingischen Reiches geknüpft war, womit das römische Reich seit Beginn des 9. Jahrhunderts neben dem byzantinischen Kaiser einen Kaiser im Westen hatte. Der Autor legt Wert darauf, die römische Kirche in der Mitverantwortung für das politische Auseinanderbrechen des Reiches zu entlasten, indem er das Entstehungsszenario des ,westlichen Kaiserreichs als politischen Zwang durch Verweigerung östlicher Hilfeleistung in kriegerischen Auseinandersetzungen zeichnet.

Dass die griechische Kirche nicht eingebunden worden war in den Entscheidungsprozess der Einfügung des Filioque im Zuge des concilium ultramontanum, womit vermutlich die von Kaiser Karl dem Großen einberufene Synode von Aachen im Jahr 809 gemeint ist, führt der Autor als zweiten Grund des Schismas an.

Als dritten Grund, der dem Autor in einer persönlichen Unterhaltung mit seinen griechischen Zeitgenossen angedeutet worden sei, nennen sie die allzu übertriebenen Geldforderungen der päpstlichen Legaten, die diese zur Zeit der lateinischen Herrschaft an Klerus und Volk in Konstantinopel anlässlich der jährlichen Übergabe des Chrisam-Öls stellten und die Unruhe im Hinblick auf die lateinisch-griechischen Beziehungen stifteten. ${ }^{457}$

Als vierten Grund und gleichsam Zündfunken der drei vorhergehenden, insofern es den Klerus betrifft, bezeichnet der Autor die Absetzung des Konstantinopler Patriarchen Photius, jenes von den Lateinern als inuentor huius scismatis bewerteten Bischofs und Kirchenpolitikers, der für alle Folgen und Ausprägungen des Schismas

456 Zum Redaktor Bartholomeus, der diese Notiz im Prolog ergänzt, vgl. TcG Prol., 44 app. crit. (p. 5); vgl. TcG introd., XLIX und die Seiten 200 - 208 der vorliegenden Studie.

457 J. S. Vaquero vermutet hinter dieser Begründung die Unzufriedenheit gegenüber den verschärften Bestimmungen Innozenz' III. und seines Nachfolgers Honorius III., die die Hierarchie des lateinischen Klerus in Konstantinopel und die Unterordnung des griechischen Klerus unter die lateinischen Hierarchen betrafen; vgl. VAQUERO 1955, 350-401, hier: 363-365 mit den Angaben der entsprechenden päpstlichen Briefkorrespondenz. 
verantwortlich zu machen sei. Die Griechen wiederum sahen in seiner Absetzung und der weiterer Welt- und Ordenskleriker einen Affront.

Die Analyse dieses kurzen Textes unmittelbar vor dem Schlussteil des Tractatus maior ist insofern aufschlussreich, als die hier aufgelisteten Gründe (causae bzw. occasiones bzw. excusationes ${ }^{458}$ ) für den Dominikaner offenbar von anderer Qualität sind als die vier vorhergehenden und theologisch abgehandelten. Er listet sie auf und anerkennt damit das ,Stolperstein-Potential', das die Griechen ihnen beimessen, verwirft sie aber letztlich als griechischen Vorwand. ${ }^{459}$ Wichtiger als die punktuellen Verletzungen in der gemeinsamen Geschichte der beiden Kirchen und als das Stellen der Schuldfrage seien die Implikationen, die ebendiese Verletzungen auf das theologische Grundgerüst der Kirche (im Singular!) hatten. Dort müsse der Heilungsprozess ansetzen, und dort gelte es zu investieren, da diese Verletzungen eine Gefahr für Wesen und Auftrag der Kirche Jesu Christi und für das Heil der Seelen darstellen. Dennoch zeigen gerade die Ausführungen über diese vier Gründe des Schismas, dass der Dominikaner über ein reiches historisches Wissen verfügt und dieses zwar nicht als Argument, wohl aber als Demonstration der Kenntnis der Gegenseite, der altera pars, einbringt.

Der Tractatus maior endet hier mit dem Explicit und informiert über das Datum und den Ort der Entstehung des Werkes, womit die Informationen des Incipits bzw. diejenigen, die im Text verstreut zu finden sind, ergänzt werden:

Hec autem scripta sunt anno Domini MoCCoLIIo in ciuitate Constantinopoli a fratribus ordinis predicatorum, ad edificationem ecclesie et profectum animarum, ad laudem et gloriam Patris et Filii et Spiritus Sancti, cui est honor et gloria in secula seculorum. Amen. (TcG V, 51-55 (p. 114))

All das wurde im Jahr 1252 in Konstantinopel von Brüdern des Dominikanerordens geschrieben; zur Auferbauung der Kirche und zum Heil der Seelen; zum Lob und Ruhm des Vaters und des Sohnes und des Heiligen Geistes, dem Ehre und Ruhm gebührt in alle Ewigkeit. Amen.

\subsubsection{Appendix}

Unter bestimmten Voraussetzungen lässt sich argumentieren, dass der eigentliche Ertrag, das eigentlich Neue und Originelle des Werkes des anonymen Dominikaners nicht im theologischen ersten Teil, sondern im Appendix besteht. A. Dondaine, der 1951 die erste und bislang einzige umfassende Studie zum Tractatus contra Graecos verfasst hat, ist ein beredtes Beispiel für diese Sichtweise, widmet er dem Appendix doch den umfassendsten Teil seiner Studie unter dem Titel „Documentation mineu-

458 Vgl. TcG V, 1-2 app. crit. (p. 112).

459 Sed numquid ista sufficiunt ad excusationem tanti scismatis et tantarum perditionem animarum? Minime. Sed occasiones querit, qui uult recedere ab amico. (TcG V, 33-35 (p. 113)); vgl. dazu auch die Seiten 230-231 der vorliegenden Studie. 


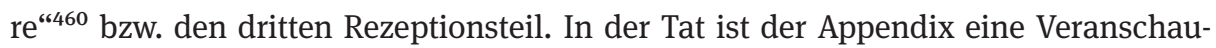
lichung des, wenn man so will, Forschungsstandes in der lateinisch-griechischen Kontroverse zur Zeit des Dominikaners. Die handschriftliche Überlieferung variiert stark hinsichtlich der Zahl der Textteile und ihrer Anordnung, es konnte allerdings begründet für einen ursprünglich chronologischen Aufbau von insgesamt neun in sich geschlossenen und großteils voneinander unabhängigen, aber motivisch durchaus stringenten Texten plädiert werden. ${ }^{461}$ Während die Originalität des Tractatus maior vor allem in der Methodik und in der theologischen Aktualität seines Autors liegt, kann man den Appendix anhand zweier Grundmerkmale charakterisieren: Er ist (a) eine Art Reader, eine Leseliste für den Kontroverstheologen auf lateinischer Seite, um noch besser auf die zeitgenössischen Argumente der Byzantiner vorbereitet zu sein. (b) Trotz seiner Komposition als Text-Sammlung greift der Dominikaner gelegentlich inhaltlich ein, wie am besten anhand der beiden ersten Texte über die General- und Partikularsynoden gezeigt werden kann. ${ }^{462}$ Aus diesem Grund handelt es sich nicht um eine reine Anthologie. Die Chronologie der Appendix-Texte reicht von den ersten General- und Partikularkonzilien im vierten Jahrhundert bis in die Gegenwart des Dominikaners. Dass die Anzahl und Anordnung der Texte in der Handschriftentradition derart variiert, weist einmal mehr darauf hin, dass der Appendix ein gewachsenes Textcorpus ist. Dank seiner Zusammenstellung sind einige Texte und Werke bislang singulär überliefert, die so zum Fundus der literarisch-theologischen Kontroverse des Mittelalters beitragen.

Man hat in der Sekundärliteratur darauf hingewiesen, dass im Unterschied zum Tractatus maior der Fokus des Appendix darauf liege, die kulturelle Entfremdung und die praktischen Stolpersteine zwischen den beiden Kirchen darzustellen bzw. nachzuzeichnen. ${ }^{463}$ Bei dieser Einschätzung ist es wichtig zu bedenken, dass sie auf der falschen und unvollständigen Appendixanordnung einer Handschriftenfamilie basiert, die durch einen Zufall der Forschung zum Grundlagen- und Referenztext wurde, weil er - wie oben dargelegt - durch die Aufnahme in Mignes Patrologia Graeca zugänglich wurde. ${ }^{464}$ Die Chronologie der Texte ist dort ebensowenig erkenn- oder nachvollziehbar wie die Tatsache, dass der Appendix weit umfangreicher ist, als es dieser Überlieferungszweig vermuten lässt. Dass es dem Dominikaner nicht mehr um die inhaltlich-theologische Ebene gehe, lässt sich etwa anhand der beiden Appendixteile VIII.2. (die Widerlegung des Germanos-Briefes) und II.2. (die Auslegung der Canones) entkräften, wo er das Schema des Tractatus maior wieder aufgreift und die griechischen Meinungen zum Teil unter Rückverweis auf den Hauptteil theologisch widerlegt. Eine Einordnung in den Reigen der kontroverstheologischen Schriften seiner Vorgänger mag durchaus mit Absicht angedacht sein, zumal der Sinn des Ap-

460 Vgl. Dondaine 1951, $350-446$.

461 Vgl. TcG introd., XLVII-LVI.

462 Vgl. dazu ausführlicher die Seiten 132-134 der vorliegenden Studie.

463 Vgl. etwa RIEBE 2005, 292-293.

464 Vgl. dazu ausführlicher die Seiten 77-79 der vorliegenden Studie. 
pendix das Anliegen im eigenen Tractatus maior unterstreicht und auf anderer Ebene fortführt.

Der Darstellung des Inhalts des Tractatus maior entsprechend werden im Folgenden die neun chronologisch angeordneten Textteile des Appendix präsentiert und kontextualisiert. Für die Details zur handschriftlichen Überlieferung sei auf die Einleitung zur kritischen Edition verwiesen. ${ }^{465}$

\subsubsection{Konziliengeschichte: De conciliis generalibus et particularibus}

Die erste Textgruppe und gleichsam die Eröffnung der Appendix-Sammlung ist eine Darstellung der General- und Partikularkonzilien nach Art einer griechischen Konzilssynopse. De conciliis generalibus et particularibus wurde zunächst - weil auf Basis der fehlerhaften Traktat-Version in der Patrologia Graeca - zumindest zum Teil für das Werk des Hugo Eterianus gehalten, dessen Schrift bzw. Übersetzung den Konzilien in der PG-Version vorgereiht ist. Mit zunehmendem Forschungsinteresse an den griechischen Konzilssynopsen, den „resümeeartige[n] Zusammenfassungen über die Reihe der Konzilien“466, konnten Textpassagen aus dem Appendix identifiziert und so die vormalige Zuschreibung als nicht haltbar erwiesen werden. ${ }^{467}$ Dies ist ein Befund, der sich mit den Argumenten aus der Textüberlieferung deckt. Zudem wurde gezeigt, dass der Feder des anonymen Dominikaners selbst eine wesentliche Rolle in der die Konzilien betreffenden Textsammlung zukommt. ${ }^{468}$ In einem kurzen Prolog wird das Gliederungsprinzip der folgenden Ausführungen vorgestellt, das der griechischen Vorlage folgt:

Consequenter post predicta uidendum est de conciliis generalibus et particularibus, uidelicet ubi, quando, et a quibus, et pro quibus causis fuerunt celebrata, et qui sunt, qui in dictis conciliis fuerunt condempnati. (TcG App. I, 4-7 (p. 115))

Im Anschluss an das Gesagte liegt der Fokus nun auf den General- und Partikularkonzilien, nämlich wo, wann, von wem und aus welchen Gründen sie gefeiert worden waren und wer diejenigen sind, die auf den Konzilien verurteilt worden waren.

Und bereits im Prolog ist eine der wichtigen Bezugsquellen genannt, die der Dominikaner hier in Teil I (und auch in Teil II, wie zu zeigen sein wird) verwendet: die im christlichen Osten wichtigste Kirchen- und Kaiserrechtssammlung Nomokanon XIV titulorum. Die Griechen würden darin nur fünf Konzilien als Generalkonzilien mit universaler Zuständig- und Gültigkeit anerkennen, da die anderen Konzilien die Kriterien dafür nicht erfüllten: die Präsenz und Intervention der auctoritas der römischen Bischöfe; dass alle Bischöfe geladen sind; und dass die verabschiedeten Canones den

465 TcG introd., XLVII-LXXIII.

466 SiEBEN 2000, 49-64, hier: 49.

467 Vgl. dazu den Beitrag von Sieben 2000; vgl. DondaIne 1951, 366-370.

468 Vgl. Dondaine 1951, 369 und vor allem SiEBEN 2000, 55-64. 
Glauben und nicht nur die Tugend und die Sitten betreffen. ${ }^{469}$ Aber ungeachtet ihrer Betitelung sind, so der Dominikaner, die Beschlüsse der Konzilien von allen zu rezipieren und ihre Autorität ist von allen anzuerkennen, wenn sie auf der Beteiligung der Gläubigen und der Bestätigung des Papstes basieren (que in ipsis a fidelibus gesta sunt et a papa confirmata).

Der erste Text dieser Sammlung mit dem Titel De conciliis generalibus (in der Edition I.1) behandelt die sieben General-, das heißt Ökumenischen Konzilien Nizäa (325), Konstantinopel (381), Ephesos (431), Chalcedon (451), II Konstantinopel (553), III Konstantinopel (690/681) und II Nizäa (787) und schließt eine kurze Erörterung über die Einreihung des achten Konzils in diese Rubrik an bzw. die Weigerung der griechischen Kirche, dies zu tun. ${ }^{470}$ Danach folgt der zweite Text De conciliis particularibus (in der Edition I.2), der sich mit den aus griechischer Perspektive nichtuniversalen Synoden beschäftigt. Darunter sind - gemäß den Erklärungen in den Vorlagen der griechischen Konzilssynopsen ${ }^{471}$ und der vorangestellten kurzen Einleitung des Dominikaners - entweder Lokalsynoden zu verstehen, an denen nur die Bischöfe eines Teilgebietes teilnahmen, oder solche, die keine glaubensrelevanten Canones hervorgebracht, sondern sich ausschließlich mit Disziplinarfragen beschäftigt haben. ${ }^{472}$ Die Auflistung des Dominikaners enthält neben den sieben Ökumenischen Konzilien, die auch hier integriert sind und auf zwei verschiedene griechische Synopsen als Vorlage hindeuten, insgesamt zehn Partikularsynoden: Antiochien (268), Ankyra (314), Neocaesarea (315), Sardica, Gangra (340 oder 355) ${ }^{473}$, Antiochien, Laodicea (ca. 363), Konstantinopel gegen Eutyches (448), Konstantinopel gegen Severus (536) und Karthago.

H. J. Sieben hat - anschließend an die Erkenntnisse A. Dondaines - der Vorlage des anonymen Autors zu den General- und Partikularsynoden eine ausführliche Studie gewidmet: Den Ausführungen zu den Konzilien komme vor allem deswegen besondere Bedeutung zu, weil der Dominikaner einer der wenigen lateinischen $\mathrm{Au}$ toren ist, der die Bedeutung des griechischen Textgenres der Konzilssynopsen erkannt und darauf reagiert hat. Er habe damit dem Rechnung getragen, dass die Griechen „den Konzilien eine viel zentralere Rolle für die Überlieferung des wahren Glaubens zuerkannten, als das derzeit im Westen der Fall war, wo das lebendige Lehramt des Papstes schon sehr entfaltet war und als Interpret der geoffenbarten Wahrheit galt““474.

469 Sciendum ergo est, quod licet VII uel VIII dicantur generalia concilia, tamen apud sapientes Grecorum prout in libro, qui Nomocanon uocatur, inuenimus quinque tantum ex ipsis generalia habentur concilia et non plura. Et hoc ideo contigisse tradunt, quia non intercessit in eis Romani pontificis auctoritas, et episcopi non fuerunt uniuersaliter citati, uel certe quia non ediderunt canones doctrinam fidei continentes, sed tantummodo illa, que ad honestatem et mores ecclesie pertinebant. (TcG App. I, 7-15 (p. 115))

470 De octaua synodo (TcG App. I, 301-319 (p. 129)).

471 Vgl. SIEBEN 2000, 59.

472 Vgl. Dondaine 1951, 367.

473 Zur Datierung der Synode von Gangra vgl. BARNES 1989, 121-124.

474 SIEBEN 2000, 58. 
Die Konzilssynopsen dienten dem Dominikaner vor diesem Hintergrund als Informationsquellen über die Zahl der autoritativen Konzilien aus griechischer Perspektive, und gleichzeitig stellte er sie in dieser Form dem Leser zur Verfügung, um aufzuzeigen, woraus „die Griechen einen Teil ihrer Argumentation gegen die Lateiner bezogen.“475 Als Vorlage, die er verwendete und aus der er seine konkreten Informationen schöpfte, hatte er wohl zwei griechische Konzilssynopsen vor Augen: eine, die die Ökumenischen Konzilien auflistete, und eine andere, die General- und Partikularsynoden gemeinsam behandelte. ${ }^{476}$ Er tat dies allerdings nicht nur kompilierend, indem er seine Quellen zugänglich machte, sondern er griff aktiv in seine Vorlagen ein, sodass daraus ein „Text aus der Feder und der Verantwortung des Anonymus selbst““477 entstand.

\subsubsection{Interpretation der Canones: Canones Apostolorum und responsio Latinorum ad auctoritatem canonum}

Der nächste Teil in der Chronologie des Appendix ist eine Darstellung und Reaktion auf eine Reihe von Canones, womit dieser Appendix-Teil II inhaltlich eng an den vorhergehenden über die Konzilien gebunden ist. Die den Apostolischen Canones oder den Konzilien entnommenen Rechtsbestimmungen werden - entsprechend dem Schema in den distinctiones des Tractatus maior - zunächst in ihrer griechischen Auslegung vorangestellt, insofern sie den Byzantinern als Beleg gegen die falsche und irreführende Praxis der Lateiner dienen (in der Edition II.1.). Daraus ergibt sich eine Liste von elf Canones, die der Dominikaner anschließend kommentiert und zugunsten der lateinischen Sichtweise korrigiert (in der Edition II.2.).

Für diesen Teil II des Appendix trifft am ehesten zu, dass es sich hierbei inhaltlich um Leitthemen handelt, die vor allem liturgische und sakramentale Bräuche und Gewohnheiten in den Fokus stellen. Folgende praxisbezogene und thematisch nicht aufeinander abgestimmte oder gruppierte Kontroversen werden damit angesprochen:

- Lebensformen des Klerus und damit verbundene Rechte und Pflichten

- Disziplinarmaßnahmen der Kirche gegenüber dem Klerus

- Fastengebote

- Verknüpfung weltlicher und geistlicher Macht

- Umgang mit Bi- oder Polygamie sowohl in Bezug auf den Klerus als auch auf Laien

- Umgang mit Frauen (Menstruation/Unreinheit und Zugangsbeschränkungen im Kirchenraum)

- Die Kirche als einziger liturgischer Raum, d.h. Umgang mit privaten Gottesdiensten

475 Ebd.

476 Es ist der Forschung bislang, so Sieben, keine griechische Vorlage bekannt, die beide Elemente zuerst die Ökumenischen Konzilien und anschließend die General- und Partikularsynoden zusammen - in einer Auflistung behandelt (vgl. SieBEN 2000, 58).

477 Ebd., 59. 
- Die Patriarchatswürde Konstantinopels

- Eucharistiefeier während der Fastenzeit

Seinen gezielten Antworten, die hier allerdings nicht im Detail dargelegt werden, stellt der Dominikaner einige allgemeine Bemerkungen voran, die den Grundtenor des Folgenden festlegen:

Respondentes igitur in primis generali modo loquendi dicimus quod omnis scriptura, quam Grecus pro se contra Latinum preter textum Biblie adducit, suspecta est et esse debet cuilibet uiro sanum sapienti, eo quod ab initio nascentis ecclesie in tantum excreuit peruersum dogma hereticorum in gente predicta, quod eorum studium et intentio fuit semper dicta sanctorum uera remouendo aut falsa inserendo corrumpere, destruere et dilacerare. (TcG App. II, 117-124 (p. 141))

Wir antworten zunächst allgemein und sagen, dass mit Ausnahme des Bibeltextes jedes Werk, das der Grieche zu seinen Gunsten gegen den Lateiner heranzieht, verdächtig ist - ja jedem vernünftigen Menschen verdächtig sein muss. Denn von Geburt der Kirche an wuchs das verkehrte Dogma der Häretiker im genannten Volk derart stark an, dass es zu ihrem dauerhaften Eifer und ihrer dauerhaften Absicht wurde, diese Werke durch das Eliminieren wahrer Worte der Heiligen oder durch das Einfügen falscher Worte zu verfälschen, zu zerstören und zu zerreißen.

Mit diesem generellen Misstrauen nicht nur der griechischen Interpretation gegenüber, sondern mehr noch mit einem dezidierten Fälschungsvorwurf geht der Dominikaner daran, Beispiele aus der Geschichte anzuführen, die die Unredlichkeit der Byzantiner diesbezüglich belegen sollen. Aus einem weiteren, daran anknüpfenden Grund seien die Canones in ihrer griechischen Auslegung mit Vorsicht zu bewerten:

Constat enim, sicut ipsi dicunt, canones, qui Apostolis inscribuntur, de Latino in Grecum a beato Clemente papa fuisse translatos. Cum ergo omnis aqua fluens in suo fonte et origine naturalior et uerior quam in riuulis, qui procedunt ab ea, inueniatur, supponendum et credendum est, quod in ecclesia Latinorum, a quibus tamquam a fonte riuuli dicti canones processerunt, ueriores et puriores sint quam in ecclesia Grecorum, presertim cum per ora quam plurium hereticorum et scismaticorum a CCC et LXXX annis et citra transierint, qui multas alias soliti sunt corrumpere scripturas. (TcG App. II, 141-150 (p. 142))

Zunächst ist es offensichtlich, dass - wie sie selbst sagen - die den Aposteln zugeschriebenen Canones vom seligen Papst Clemens aus dem Lateinischen ins Griechische übersetzt worden waren. Weil aber jedes Wasser an seiner Quelle und seinem Ursprung reiner und wahrhaftiger ist als in den Flüssen, die der Quelle entspringen, müssen wir unterstellen und glauben, dass besagte Canones in der Kirche der Lateiner, aus der sie wie Flüsse direkt aus der Quelle hervorgegangen sind, wahrhaftiger und reiner sind als in der Kirche der Griechen, zumal sie aus dem Mund vieler Häretiker und Schismatiker vor mehr als 380 Jahren hervorgegangen sind, die viele andere Schriften zu fälschen pflegten.

Sowohl das antiquitas-Argument, das heißt die Höherbewertung des Älteren vor dem Jüngeren oder Neuen, als auch das auctoritas-Argument, das heißt eine qualitative Wertung der Glaubwürdigkeit der Quelle, sind althergebrachte und etablierte patristische Kategorien, Orthodoxie von Häresie zu unterscheiden. Indem der Dominikaner die Klemens-Sammlung ins Spiel bringt, das heißt die Weitergabe der Apostolischen 
Konstitutionen von den Aposteln an Papst Klemens von Rom, liegen beide Argumente mit einigem Gewicht in der Waagschale. In Zusammenhang mit dem Fälschungsvorwurf an die Byzantiner zieht der Dominikaner daraus den Schluss, dass Vieles in Bezug auf die vorliegenden Canones von der griechischen Kirche - allen voran von Photius $^{478}$ - hinzugefügt oder wissentlich verändert wurde, auf dass es sich ihrem Argumentationsschema beuge. Dies alles gelte es freizulegen und aufzudecken, damit den Canones und damit der lateinischen Interpretation Gerechtigkeit widerfahre.

Ausgehend von diesem Vorspann, dass es sich bei den von den Griechen genannten Canones um unrechtmäßiges, weil nicht der (gemeinsamen) Tradition der Kirche entsprechendes griechisches Sondergut handle, betrifft das zweite Argument des Dominikaners die synchron/diachron-Ebene: Untermauert durch biblische und patristische Argumente verdeutlicht er, dass Bestimmungen, die zu einer gewissen Zeit und in einem gewissen Kontext erlassen worden waren, nicht notwendigerweise diachron und damit permanent gültig seien. Mit einer gewissen Leichtigkeit und Flexibilität ${ }^{479}$ entlastet er damit die Gläubigen bezüglich der Einhaltung rigoroser Vorschriften und weist im selben Argumentationsgang nach, dass die griechische Anschuldigung gegen die Lateiner, sich nicht adäquat an kirchliche Bestimmungen zu halten, in Vielem gegenstandslos - weil aus dem historischen Sitz im Leben gerissen sei.

Am Ende seiner detaillierten Stellungnahme zu den vorgebrachten elf Canones weist der Dominikaner darauf hin, dass sich eine Diskussion ihrer Auslegung im Grunde allein deswegen verbiete, weil die Autorität des Papstes darüber ohnehin nicht in Zweifel gezogen werden darf. Einzig zur Bekämpfung derjenigen, die solche Irrtümer anheizen und nähren (qui hunc errorem fouent et nutriunt), sei sie legitim und notwendig, was der Dominikaner mit dem Kampfaufruf gegen Babylon in Jer 50,14 debellate eam! - abschließend in Szene setzt.

\subsubsection{Illustration einer Fälschung des Quicumque vult durch einen griechischen Mönch: Augenzeugenbericht zweier Zisterzienser}

Der nächste und III. Teil des Appendix knüpft motivisch an den vorherigen an und scheint chronologisch in die Gegenwart des Autors zu springen. Mit ihm liefert der Dominikaner dem Leser eine Demonstration bewusster Quellenfälschung der Griechen in Form eines Augenzeugenberichts zweier Zisterzienser, die demnach kein historischer Mythos, sondern eine hochaktuelle und brisante Angelegenheit sei. ${ }^{480}$ Das Chronologie-Argument des Appendix bleibt aber letztlich auch hier gültig, wenn man nicht den zisterziensischen und damit zeitgenössischen Bericht an sich in den

478 Vgl. TcG App. II, 162-167 (p. 143).

479 Vgl. etwa TcG II, $199-208$ (p. 145).

480 Vgl. dazu Laurent 1936, 385-404, hier: 396-397. Laurent transkribiert den Text aus Vat. lat. 4066, fol. 45v-46v auf den Seiten 403-404. 
Fokus stellt, sondern das Symbolum Quicumque/Athanasianum ${ }^{481}$, das der Quellentext und somit der Dreh- und Angelpunkt dieses Berichtes ist. Im Text heißt es:

„Nicht lange vor unserer Zeit, das heißt vor dem Jahr des Herrn 1252“ ereignete sich die Begegnung zweier Zisterziensermönche aus dem Konstantinopler Umkreis mit einem griechischen Mönch-Schreiber in der Stadt Nizäa, wohin die beiden aus kirchenpolitischen Beweggründen gereist waren. Im Kontext kontroverstheologischer Debatten blieben sie länger in Nizäa und trafen in einem Kloster auf besagten griechischen Mönch, als er gerade dabei war, eine Handschrift zu kopieren. Einer der beiden Zisterzienser, der des Griechischen kundig war, identifizierte den kopierten Text als das Glaubensbekenntnis Quicumque des Athanasius. Der Zisterzienser erbat sich gezielt, die kopierte Abschrift zu lesen, und erkannte gleich den Skandal, dass die Kopie des Mönches das Filioque - das heißt im Fall des Quicumque das griechische Pendant zum lateinischen Wortlaut Spiritus Sanctus a Patre et Filio non factus nec creatus nec genitus sed procedens - nicht enthielt. Da nun das Misstrauen geweckt war, forderte der Zisterzienser den Mönch auf, seine Vorlage offenzulegen. Nach anfänglicher Weigerung und gleichsam seiner Schuld bewusst suchte dieser nach Ausflüchten, doch gelang es den beiden Zisterziensern schließlich, die Stelle im Original prüfen zu können: Dass das Filioque dort rechtmäßig zu finden war, bewies, dass der griechische Kopist mutwillig die Vorlage verändert und den betreffenden Wortlaut unterschlagen hatte. Bloßgestellt und herausgefordert rechtfertigte sich der griechische Mönch damit, dass er eifrig die häretischen Elemente seiner Vorlage hatte korrigieren wollen, denn es sei ja offensichtlich, dass nicht Athanasius selbst der Urheber einer solchen Blasphemie gewesen sein könne. Vor versammelter Menge erwiderten die Zisterzienser:

Immo tu es hereticus et falsarius librorum, qui ueritatem de libris auctenticis remouens nouum errorem in tuo libro ad libitum inseruisti! (TcG App. III, 64-66 (p. 163))

Vielmehr bist du der Häretiker und Fälscher von Büchern, der du die Wahrheit aus den authentischen Büchern entfernt und deinem Buch nach Belieben einen neuen Irrtum hinzugefügt hast!

Die Fälschung war von den Zisterziensern mit derartigem Nachdruck aufgedeckt worden, dass die Byzantiner selbst keine Möglichkeit mehr hatten, sie zu widerlegen. Sie hüllten daher den Mantel des Schweigens um diese Angelegenheit und entfernten die griechische Kopie als das corpus delicti aus der öffentlichen Aufmerksamkeit. Soweit der Bericht des Dominikaners, den er nach eigenen Angaben aus erster Hand von den Zisterziensern auf deren Rückweg von Nizäa erhalten hat. Inhaltliche Unterfütterung erhält der Fälschungsvorwurf durch den zusätzlichen Hinweis auf einen syrischen Mönch eines griechischen Klosters am Berg Sinai, der bestätigte, dass das Quicumque dort wortwörtlich gesprochen bzw. gebetet werde, wie es in der römischen Kirche üblich sei (uerbo ad uerbum, sicut in Romana ecclesia legitur et cantatur).

481 Quicumque/Athanasianum, ed. TURNER 1910, 401-411. 
Durch die illustrierende Darstellung dieser Fälschungsepisode betont der Dominikaner ein Zweifaches: erstens die Wichtigkeit dessen, mit den Quellen vertraut zu sein und damit entsprechend umgehen zu können; zweitens, dass der Leser bzw. der sich im Disput mit den Byzantinern Befindende auf der Hut sein müsse, weil sie zur Untermauerung „falscher Wahrheiten“ sogar zu Quellenfälschungen in der Lage und willens sind.

\subsubsection{Symbolum Nicaenum}

Inhaltlich stringent folgt auf den Fälschungsbericht das Symbolum als Teil IV des Appendix. Es handelt sich allerdings nicht um den Wortlaut des Quicumque, sondern um das grundlegende und allen Kirchen gemeinsame Symbolum Nicaenum „der 318 gottesfürchtigen Väter“ in einer gekürzten Version. Dies mag insofern überraschen, als das Nicaenum im dritten Artikel über den Heiligen Geist noch nicht mehr als den einen Satz „Et [credimus] in Spiritum Sanctum“ bekennt, dass sich also die Filioquedebatte gerade nicht am Nicaenum von 325, sondern erst am Wortlaut des Nicaeno-Constantinopolitanum von 381 entzündete. Die hier referierte Annotatio fidei enthält aber auch das Anathema gegen diejenigen, die die Lehre über den Sohn verfälschen. Von daher lässt sich hierin zwar nicht zwingend, aber ein Indiz zum Verständnis des Arguments finden, das der Autor mit Teil IV stark macht: Dass die trinitätsheologischen Debatten, denen sich das Konzil von Nizäa stellte und wogegen es mit dem Symbolum Nicaenum ankämpfte, im Kern bereits die Lehre des Filioque insofern enthielt, als die Wesensgleichheit von Vater und Sohn die Basis des immanenten Hervorgangs des Geistes aus dem Vater und dem Sohn ist.

\subsubsection{Die Exkommunikationen von 1054: Der Bericht des Pantaleo von Amalfi}

Teil V des Appendix trug zu beidem, zu Bekanntheit und Verwirrung in Bezug auf den Tractatus contra Graecos gleichermaßen bei. Erst im Zuge der Arbeiten zur kritischen Edition konnte gezeigt werden, dass es sich hierbei um das Werk des Pantaleo von Amalfi handelt, der sich - der griechischen Seite gegenüber kritisch eingestellt - mit den wechselseitigen Exkommunikationen von 1054 befasste. ${ }^{482}$ Da jene Version des Traktats, wie sie Aufnahme in die Patrologia Graeca gefunden hatte und der bisherigen Forschung als Bezugstext diente, eine verkürzte handschriftliche Überlieferung spiegelt, die diesen Teil V des Appendix als den letzten Text des Gesamttraktats erscheinen lässt, konnte einige Verwirrung hinsichtlich der Autorschaft des Tractatus contra Graecos entstehen. ${ }^{483}$

482 Vgl. Michel 1939, die Edition auf den Seiten 52-56 (= Exkurs II). Michel vergleicht die Druckversion des P. Stevartius mit einer zweiten Handschrift, die sich im Codex CPV 2177 der Österreichischen Nationalbibliothek auf den fol. 88-89 befindet und von W. Giesebrecht ediert wurde. Auf dieser Basis stellt Michel zwei (auch inhaltlich) verschiedene Rezensionen vor.

483 Für Details vgl. TcG introd., LVI-LIX und die Seiten 77-79 der vorliegenden Studie. 
Inhaltlich ist der Dominikaner mit der Aufnahme des Berichts des Pantaleo von Amalfi bei jenem Ereignis angelangt, das das erste kirchenrechtlich ausschlaggebende zur Begründung des Schismas ist: bei den gegenseitigen Exkommunikationen zwischen Humbert von Silva Candida auf lateinischer und Michael Kerullarios auf griechischer Seite aus dem Jahr 1054. Zum insgesamt dritten Mal also findet sich ein Motiv auf der Agenda des Autors, dem ansonsten in der neueren Forschung attestiert wird, dass seine Rezeption in den kontroverstheologischen Werken bis zum 15. Jahrhundert nur äußerst marginal stattfinde. ${ }^{484}$ Spannend ist dabei der Fokus, den der Dominikaner unter Bezugnahme auf Pantaleo von Amalfi setzt: Der Patriarch Michael Kerullarios wird als durch und durch unkluger und für die Kirche gefährlicher Akteur (actibus et intellectu stultissimus bzw. heresiarcha potius quam patriarcha) und als jemand diffamiert, der dem theologischen Diskurs in der Azymenfrage nicht gewachsen ist. Die Angemessenheit der Entscheidung der Legaten Leos IX. hingegen, die Bannbulle demonstrativ auf dem Altar der Sophien-Kathedrale zu platzieren, sei noch beginnend in der Kirche selbst durch ein Wunder demonstriert worden: Ein gewaltiges Erdbeben traf die Stadt, sodass die Byzantiner innerhalb weniger Tage einen Verlust von 60.000 Menschen zu beklagen hatten, während hingegen kein Fremder, das heißt nichtgriechischer Einwohner der Naturkatastrophe zum Opfer fiel. ${ }^{485}$

Mit dem Hinweis, dass es sich hierbei um einen Augenzeugenbericht des Pantaleo handle, schließt der kurze Text und reiht sich ein in jene Autoritäten, die der Dominikaner für kenntniswürdig und in der Debatte hilfreich hält.

\subsubsection{Die Sicht des 12. Jahrhunderts: Hugo Eterianus (De heresibus quas in Latinos Greci devolvunt) und Leo Tuscus (De heresibus et prevaricationibus Grecorum)}

Die beiden Texte an VI. Stelle sind dem 12. Jahrhundert gewidmet und weisen somit jener Epoche einen wichtigen Platz im Dossier zu, die hinsichtlich der lateinischgriechischen Kontroverse gerne als das vergleichsweise irenische, weil konsens-suchende bezeichnet wird. ${ }^{486}$ Zwei prominente Gelehrte stehen im Fokus, in deren Spuren der Dominikaner sich insofern bewegt, als diese beiden als die Experten im ost-westlichen Disput am Hof des byzantinischen Kaisers in der zweiten Hälfte des

484 Vgl. BAYER 2014 und die Anmerkung 430 auf Seite 116 der vorliegenden Studie.

485 Mox ipsi basilicam sancte Sophie ingredientes, super altare excommunicationis paginulam posuerunt. Exeuntes autem ab ecclesia, sublatis pedum sandaliis pauimenti marmora percutientes (liminari) puluerem proiecerunt, et hoc secundum Euangelii uocem egerunt dicentis: Quamcumque introieritis ciuitatem et non receperint uos etc. Preterea ipsis ab eadem ciuitate descendentibus stupendum ualde mil raculum actum est: Liminare namque marmoreum eiusdem ecclesie mire magnitudinis statim dissoluitur, et mox talis est clades subsecuta, ut diebus paucis elapsis sexaginta Grecorum milia morerentur, in quibus tamen nullus aliene gentis, quamuis multi essent inhabitantes urbem, interiit. Et per triduum inestimabiles coruscationes et tonitrua et ymbrium grandinumque ualitudines extiterunt. (TcG App. V, $22-35$ (p. 166-167))

486 Vgl. jüngst NeOCLEOUS 2019. 
12. Jahrhunderts gelten: (VI.1) Als ersten zieht der Dominikaner namentlich den byzantinischen Hofgelehrten und Laientheologen Hugo Eterianus heran; (VI.2) an zweiter Stelle konnte der Text, den der Dominikaner ebenfalls Hugo zuschreibt (was letztlich auf eine entsprechende Vorlage hindeutet), als aus der Feder von Hugos Bruder Leo Tuscus identifiziert werden. ${ }^{487}$

\section{Hugo Eterianus: De heresibus quas in Latinos Greci devolvunt}

Zunächst zu Hugo Eterianus bzw. zum Kontext, in dem ihm als Gelehrter und Berater des Kaisers eine wichtige Rolle zukommt: ${ }^{488}$ Um 1171 legte der byzantinische Gelehrte Andronikos Kamateros dem Kaiser Manuel Komnenos I. auf dessen Geheiß hin eine Kompilation an Texten als das klassische theologische Arsenal zur Verteidigung der Rechtgläubigkeit gegen die Lateiner und Armenier vor. ${ }^{489}$ Sein Zeitgenosse Hugo Eterianus, der ebenfalls am Hof des Kaisers tätig war und „unter den Griechen [als] einer der führenden lateinischen Kontroverstheologen“490 galt, verfasste als theologischer Berater in Unionsangelegenheiten am Hof des Kaisers ebenfalls gegen Ende des 12. Jahrhunderts ein dreibändiges Auftragswerk über den Ausgang des Heiligen Geistes: De sancto et immortali Deo (auf Griechisch und Latein, wobei die griechische Fassung verloren ist). ${ }^{491}$ In diesem Werk findet sich bereits die Methodik, die der Dominikaner einige Jahrzehnte später intensivieren und konsequenter anwenden wird: Hugo setzt sich mit den Meinungen seiner byzantinischen Zeitgenossen auseinander, indem er den westlichen Standpunkt vertritt und diesen jeweils mit Autoritäten nicht nur der griechischen Patristik, sondern auch seiner Gegenwart untermauert. ${ }^{492}$ Der Aufbau des Werkes spiegelt mehr eine mündlich geführte Debatte als einen klar strukturierten Text, was A. Dondaine zu seiner Wertung als „une oeuvre pesante, difficile, n’obéissant à aucun plan organisateur“493 veranlasst hat. Noch in der Mitte des 13. Jahrhunderts musste dieses Werk bzw. mussten die mit Hugo Eterianus in Verbindung gebrachten Schriften - zumindest im Osten - als Standardwerk gelten, wenn es um die inhaltliche Auseinandersetzung mit den Griechen ging. Dass es klare Bezugslinien zur Methodik des Tractatus contra Graecos gibt, unterstreicht das Gewicht, das der Dominikaner seinem Vorgänger des 12. Jahrhunderts nicht nur mit dessen namentlicher Nennung beimisst. Nun ist es aber nicht jenes berühmte

487 Vgl. Dondaine 1951, 362-366; vgl. KaPRIEv 2018 (und die Rezension von RIEdL 2019)

488 Vgl. generell JENSEN 2018.

489 Teilediert von Bucossi 2014.

490 Boshof 2007, 248.

491 Vgl. PL 202, col. 227-396. Alessandra Bucossi arbeitet derzeit gemeinsam mit Pietro Podolak und Anna Zago an einer kritischen Edition im Rahmen des von ihr initiierten internationalen Forschungsprojektes „The Eleventh and Twelfth Centuries as Forerunners of a United and Divided Europe: Dialogues and Disputes between the Byzantine East and the Latin West."

492 Vgl. Gemeinhardt 2002, 533-534 (bes. Anm. 72); vgl. PePPeRmüller 1991, 170. Zur Biografie des Hugo Eterianus vgl. Dondaine 1952, 67-134, hier: 69-97.

493 Dondaine 1952, 103. 
Hauptwerk des Hugo Eterianus, das der anonyme Autor zitiert, sondern Hugos lateinische Übersetzung einer griechischen antilateinischen Schrift: des berühmten und

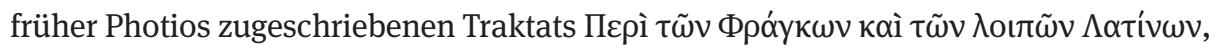
nun in der lateinischen Übersetzung Tractatus contra Francos bzw. De Francis et reliquis Latinis. ${ }^{494}$ Hugo widmet seine Übersetzung einem gewissen Kardinal Arduin ${ }^{495}$ auf dessen Bitte, dieses Werk in lateinischer Sprache zugänglich zu machen. ${ }^{496} \mathrm{Nach}$ Art eines Irrtumskatalogs listet die Übersetzung des Hugo Eterianus, wie sie im Appendix des Tractatus contra Graecos - vollständig mit Ausnahme der Widmung an den Kardinal - überliefert ist, der Reihe nach Vorwürfe der Griechen gegen die Lateiner auf: ${ }^{497}$ Obwohl am Rande auch klassische theologische Themen (Filioque, Azymen, Anrufung Mariens als Gottesmutter) angeführt sind, liegt der Schwerpunkt dennoch auf dem kirchlich-praktischen bzw. konkreter dem liturgisch-praktischen Bereich sowie auf einer allgemeinen Verhaltenskritik gegen Kleriker und Laien (Militärdienst von Klerikern; Fastengewohnheiten von Klerikern und Laien; Ikonographie und Kunst im Kirchengebäude; Geschlechterrollen in Liturgie und Kirchengebäude; Verhalten während des Gottesdienstes; liturgische Kleidung und Farben; Tauf- und Firmpraxis; liturgische Vorgaben hinsichtlich Sprache und Gesänge; Bestattungsgewohnheiten; Quantität der Eucharistiefeiern pro Priester und Tag; Verwandtschaftsgrad bei Eheschließungen; Zölibat; äußerliches Auftreten der Kleriker wie Bartrasur etc.; Assistenz von Laien beim Gottesdienst; Umgang mit der Krankenkommunion). Im Traktat des Dominikaners ist Hugos Übersetzung nicht kommentarlos angeführt, sondern zumindest mit einer kurzen Einleitung versehen, die an Schärfe die bisherigen Zuschreibungen an die Byzantiner übertrifft:

Sicut in proemio huius opusculi protestati sumus, Grecorum ecclesie decor, qui olim sua uenustate quam plurimos ad emulationem fidei prouocabat et morum, ita est nunc errorum caligine obfuscatus, quod sua feditate horrorem aspicientibus incutiat, ut iam non ecclesia fidelium, sed potius congregatio non immerito possit appellari heresiarcharum. Quod licet in iam dictis IIII articulis legentibus demonstretur, plenius adhuc tamen in hiis, que subiecta sunt, ostenditur. Que ex dictis magistri Hugonis Etheriani nuper extracta, huic operi necessario diximus inserenda. (TcG App. VI, 6-14 (p. 168))

Wie wir bereits im Proemium dieses Büchleins gezeigt haben, ist die Zierde der griechischen Kirche, die einst in ihrer Schönheit so Viele zum Streben nach Glaube und Sitten angeregt hat, nun derart von der Finsternis der Irrtümer vedunkelt, dass sie durch ihren Unrat den Hinsehenden das Grauen einjagt. Nicht mehr Kirche der Gläubigen verdient sie daher genannt zu werden,

494 Die Identifizierung gelang J. Hergenröther: Zum Tractatus contra Francos vgl. HERGENRÖTHER 1869a, 172-224. Die griechische Fassung des Traktats mit einer lateinischen Übersetzung findet sich bei HERGENRÖTHER 1869, 62-71; zu Hugo Eterianus als Übersetzer vgl. DondAINE 1952, 114-116.

495 Dondaine vermutet in ihm den Kardinal von Sainte-Croix in Jerusalem (vgl. DondAINE 1951, 364, Anm. 45).

496 Vgl. HERgEnRöther 1869, 62-71; vgl. außerdem die Teiledition in JUgIE 1926, 367-372; PG 140, col. 541 A-544 A.

497 Aus der Widmung an den Kardinal geht hervor, dass Hugo seine Übersetzung mit De heresibus quas in Latinos Graeci devolvunt neu betitelt hat. 
sondern vielmehr Versammlung der Häresiarchen. Was den Lesern bereits in den vier Artikeln nachgewiesen wurde, wird nun trotzdem noch ausführlicher im Folgenden gezeigt: Wir hielten es für notwendig, einiges, was wir kürzlich aus den Werken des Hugo Eterianus exzerpiert haben, diesem Werk einzuverleiben.

\section{Leo Tuscus: De heresibus et prevaricationibus Grecorum}

Der Appendix-Teil Nr. VI.2., den der Dominikaner übergangslos dem Werk des Hugo Eterianus zurechnet, konnte als der erste Teil eines Traktats des Leo Tuscus, des Bruders von Hugo Eterianus, identifiziert werden. Diese falsche Zuschreibung überrascht - abgesehen vom durchaus sehr verschiedenen Sprachstil der beiden Autoren insofern kaum, als sich Leos Text wie die Antwort auf die vorangegangenen referierten Vorwürfe gegen die Lateiner präsentiert: Leo Tuscus wendet sich nämlich seinerseits gegen Irrtümer und Fehltritte der Griechen - De haeresibus et praevaricationibus Graecorum $^{498}$-, womit eine mögliche Zusammengehörigkeit aus der Feder ein und desselben Autors auf den ersten Blick durchaus naheliegend ist. A. Dondaine geht davon aus, dass schon die Vorlage, die der anonyme Autor benutzt hat, Leo Tuscus nicht namentlich nennt, dass also auch der anonyme Dominikaner sie für das Werk Hugos gehalten hat: „De fait la partie reproduite ici [d.h. im Tractatus contra Graecos] de l'opuscule de Léon fait un digne pendant latin du Tractatus de Francis.“" ${ }^{“ 499}$ Leo Tuscus, der ebenfalls am Kaiserhof tätig war und vor allem Übersetzungstätigkeiten ausübte, beginnt seine Ausführungen geradezu klassisch mit dem Filioque und den Azymen: Er beschuldigt die Griechen unter anderem des Arianismus, weil die griechische Position eine Degradierung des Sohnes gegenüber dem Vater (Patre minor Filius) mit sich bringe(n müsse). Dass die Kraft, die die Wandlung bewirkt, nicht im Brot selbst, sondern im Wort liegt, führt er den Griechen wegen des ungesäuerten Brotes vor Augen und bezeichnet diesen liturgischen Brauch als „gegen die Anordnung Christi“" (contra instructionem Christi). Anschließend behandelt er in polemischem Ton eine Reihe von liturgischen Divergenzen, unter ihnen prominent die Wasserbeimischung, Fastengebote und -bräuche sowie Rechte und Pflichten des Klerus; er thematisiert Missstände, die in Kritik stehen, wie etwa finanzielle Misswirtschaft, moralische Verwerfungen, das Benehmen von Frauen, von monastisch lebenden Geistlichen und häusliche Gewohnheiten, um abschließend die Verwerflichkeit des Angeführten zu betonen und sich davon zu distanzieren, gleichzeitig aber auch den Griechen damit die Möglichkeit zu bieten, den besseren Weg erkennen und letztlich wählen zu können:

498 PG 140, col. 544 A-550B und Leo Tuscus imperialium epistolarum interpres: De heresibus et prevaricationibus Grecorum, in: BARMIN 2006, 566 - 613 (lat.-russ.). Barmin verwendet in seiner Edition den Stevart'schen Drucktext zum Vergleich im Apparat, weswegen sich bisweilen Ungenauigkeiten ergeben, die der Vorlage geschuldet sind.

499 Dondaine 1951, 346. 
Quod omnibus supradicitis abhominabilius et detestabilius iudico. Hoc mellitum lac inter ceteras Grecorum consuetudines repertum expressi, ut, cum eo ipsi pectora irrigauerint, tremularum cannarum baculis se adhuc inniti recognoscant. (TcG App. VI, 444-448 (p. 187))

Alles oben Angeführte beurteile ich als verabscheuens- und verachtenswert. Als honiggesüßte Milch, gefunden unter anderen Gewohnheiten der Griechen, habe ich dies alles herausgepresst, damit sie - nachdem sie selbst damit ihr Herz benetzt haben - neu erkennen, auf welch zitternden Stock aus Schilfrohr sie sich bisher gestützt haben.

Durch die Aufnahme der Werke des Hugo Eterianus und seines Bruders Leo Tuscus als einflussreiche Vorgänger auf dem literarischen Feld der Kontroverstheologie zeigt der anonyme Dominikaner besonders, dass er sich zum einen der Traditionslinie und der Quellen bewusst ist, denen er mit seinem eigenen Werk verpflichtet ist. Zum anderen zeigt die prominente Positionierung im Appendix, dass Hugo Eterianus, als dessen Werk der Traktat beide Texte präsentiert, zu den maßgeblichen Autoren und Hilfestellern in der lateinisch-griechischen Debatte seiner Tage zählt.

\subsubsection{Dominikanische Quellen: Die Syllogismen des Eustratios von Nikaia und refutationes der dominikanischen Autoren Nicolaus de Syria und lacobus Mediolanensis ${ }^{500}$}

Mit solchen für die Debatte mit den Griechen wichtigen zeitgenössischen Autoren und Theologen setzt die Anordnung des Appendix an VII. Stelle fort: Geboten werden drei aufeinander bezogene, aktuelle Werke unter dem Titel Sophismata Eustachii Greci contra Latinos et confutationes eorundem secundum fratrem Nicolaum quondam priorem provincialem in Syria 〈et secundum fratrem Iacobum Mediolanensem) de ordine fratrum predicatorum, das heißt: Die Syllogismen des Eustratios von Nikaia (den der Dominikaner als ,den Griechen Eustachios` bezeichnet) und die Antworten bzw. Widerlegungen zweier Dominikaner, des Nicolaus de Syria OP und und des Iacobus Mediolanensis OP. Gerade wegen der dominikanischen Texte erhält dieser AppendixTeil seine besondere Bedeutung hinsichtlich der Quellen zur Geschichte des Dominikanerordens, da sie Zeugnisse der Aktivitäten der Brüder in den kontroverstheologischen Debatten im Osten sind, die nicht nur fundierte Kenntnisse über den byzantinischen Osten voraussetzten, sondern auch entsprechende Griechischkenntnisse verlangten. Kurz sollen alle drei Texte behandelt werden:

Jener Text, auf den die beiden Dominikaner antworten und der somit (auch in der kompositionellen Anordnung der Handschriften und somit in der kritischen Edition) ${ }^{501}$ im Mittelpunkt dieses Appendix-Teiles steht, ist der Angriff auf das Filioque vonseiten des Metropoliten Eustratios von Nikaia († nach 1117) zu Beginn des 12. Jahrhunderts. Dem als Aristoteles-Kommentator und Kontroverstheologe gegen die

500 Zur Anordnung der drei Teile, d.h. zur Mittelstellung der Syllogismen des Eustratios, auf die sich die beiden lateinischen Texte beziehen, vgl. TcG introd., XLVIII (Anm. 141).

501 Vgl. ebd. 
Lateiner bekannten Autor wird hier ein Werk zugeschrieben, in dem er in insgesamt 16 Syllogismen die Lehre vom Ausgang des Heiligen Geistes aus dem Sohn kritisiert und widerlegt. A. Dondaine hat bereits auf ein Zweifaches hingewiesen: Dass dieser Text außerhalb des Appendix des Traktats nicht überliefert ist, und dass 14 der 16 Syllogismen Übernahmen aus dem klassischen Mystagogie-Repertoire des Photius sind. ${ }^{502}$

Nikolaus von Syrien OP ist, wie der Dominikaner vermerkt, der Autor der ersten refutatio der Eustratios'schen Syllogismen. In zwölf kurzen Punkten wiederholt er zunächst die griechische Position in eigenen Worten, um sie dann ebenso knapp zu widerlegen. Der Hauptertrag, den die Forschung aus diesem verhältnismäßig kurzen Text ziehen kann, ist der Autor selbst, der aus keinem anderen literarischen Kontext bekannt ist: Es handelt sich hier um den ehemaligen Provinzial der dominikanischen Provinz im Heiligen Land. ${ }^{503}$ Die Entstehungszeit dieses Dokuments kann insofern relativ genau bestimmt bzw. eingeschränkt werden, als die Bezeichnung der Provinz mit Syrien von der frühesten Zeit dieser Provinz zeugt, in der man sich ordensintern noch für keinen konkreten Namen (Heiliges Land, Jerusalem oder Syrien) entschieden hatte..$^{504}$

Der etwas besser bekannte Jakob von Mailand OP ist der Autor der zweiten, stilistisch originelleren refutatio. Zur ersten Dominikaner-Generation gehörend und ab 1227 als Lektor im Konvent von Genua tätig, zog es ihn später in den Osten, wo er zunächst in die griechische Provinz kam, dann nach Kreta und schließlich nach Candia, wo sich heute noch sein Grab befindet. ${ }^{505}$

\subsubsection{Konstantinopel: Bilinguales Brieffragment des Patriarchen Germanos II. und refutatio des anonymen Autors}

Mit zwei singulär in der Leithandschrift der kritischen Edition überlieferten Texten, die mit guten Gründen der Originalkomposition des Dominikaners zuzurechnen sind ${ }^{506}$, endet der Appendix zum Traktat. Beide Texte sind, was die Chronologie betrifft, am nähesten an der Wirkungszeit des Dominikaners angesiedelt, und beide gehören Kontexten an, die sie zu wertvollen Zeugen in der lateinisch-griechischen Debatte machen. Zunächst sei der Fokus auf Konstantinopel gerichtet:

Als VIII. Teil des Appendix überliefert ist ein zweisprachiges Brieffragment des Patriarchen Germanos II., auf das der Dominikaner in einer daran anschließenden ausführlichen refutatio inhaltlich reagiert, indem er zum Teil auf die inhaltsgleiche dritte distinctio des Tractatus maior zurückgreift bzw. -verweist. Das Brieffragment findet sich nicht unter der bislang edierten bzw. gedruckten Literatur des Patriar-

502 Vgl. Dondaine 1951, 373.

503 Vgl. ebd., 373-374.

$504 \mathrm{Zu}$ Quellenangaben und Thesen zur Person vgl. ebd.

505 Vgl. LOENERTz 1938, 274-284; vgl DondAine 1951, 375.

506 Vgl. TcG introd., LIX-LXIV. 
chen. ${ }^{507} \mathrm{~A}$. Dondaine hat mit guten Gründen argumentiert, dass es sich beim lateinischen Text, das heißt bei der lateinischen Übersetzung des Germanos-Briefes, um einen Autographen handelt ${ }^{508}$, womit diesem Appendixteil für die Argumente aus der handschriftlichen Tradition des Traktats besonderes Gewicht zukommt. ${ }^{509}$

Inhaltlich ist der Brief des Patriarchen (Amtszeit von 1222 bis 1240) der Azymenproblematik gewidmet. Der Dominikaner bietet Informationen über die Adressatin dieses Briefes: „Besagter Gotteslästerer schrieb also diesen Brief an eine noble Dame aus Konstantinopel [...]“ (scribens igitur dictus blasphemus epistolam cuidam nobili domine de Constantinopoli [...]). Es handelt sich um ein Fragment vom Schlussteil des Briefes, das erkennen lässt, dass Germanos im Teil davor seiner Adressatin die Gründe der Lateiner für die Verwendung des ungesäurten Brotes dargelegt hat. Der überlieferte Schlussteil hat drei Gründe zum Inhalt, warum die Byzantiner ihrerseits Abstand von den Azymen nehmen bzw. diese als die falsche Tradition verwerfen (tria sunt, que nos persuadent abstinere $a b e o$ ), und auf die der Dominikaner in seiner anschlieBenden refutatio Bezug nimmt. Am Ende fordert der Patriarch seine Leserin auf, ihr Leben lang dem Glauben ihrer Väter treu zu bleiben, ohne sich von den Gegnern der Wahrheit (a ueritatis inimicis) verunsichern zu lassen.

Das Brieffragment des Germanos II. im Kontext des Appendix ist ein schönes Beispiel dafür, dass die in der Sekundärliteratur lange erfolgte Methoden-Zuschreibung an jeweils Lateiner und Byzantiner aufgebrochen werden muss: Hat man den Byzantinern die Methode der patristischen Spurensuche, Untermauerung und Legitimierung zugedacht, standen die Lateiner für das Repertoire, das die neue bzw. sich weiterentwickelnde Scholastik im Westen geboten hat. Auch das nur kurze Brieffragment des Germanos II. zeigt, dass sich die beiden Kontrahenten methodisch durchaus verstanden und aufeinander (bzw. im Fall des Germanos auf die lateinischen Einwände) reagierten. ${ }^{510}$ Im Folgenden werden die drei überlieferten Einwände des Germanos präsentiert, denen jeweils - gemäß der Darstellungsweise der einzelnen distinctiones im Tractatus maior - die Antwort des Dominikaners als Paraphrase nachgestellt wird.

\section{Einwand 1 des Germanos: Sacerdos secundum ordinem Melchisedec oder: Die Propheten sind Zeugen des ungesäuerten Brotes}

Vnum quidem, quia Prophete Christum sacerdotem nominant secundum ordinem Melchisedec et non secundum ordinem Aaron. Melchisedec artos et uinum obtulit, Aaron uero post sacrificium animalium azimos etiam obtulit. Scriptum est enim: „Non ascendet artos fermentatus super altare meum." Igitur offerentes azima non credunt, quod uenerit Christus, qui secundum ordinem Mel-

507 Das Fragment findet sich nicht unter den edierten Texten in PG 140, col. 601-757 und PG 98, col. 221-290 sowie bei LAGOPATES 1913.

508 Vgl Dondaine 1951, 330-331.

509 Vgl. TcG introd., LXII.

510 Vgl. dazu ausführlicher die Seiten 8-10 der vorliegenden Studie. 
chisedec est sacerdos. Signum enim aduentus Christi et eius qui in ipso est sacerdotii, panis perfectus est et uinum, et propter fermentatum et azimum distinguitur Melchisedec ab Aaron. (TcG App. VIII, 58-61 (p. 198))

[Gründe gegen die Azymen] Zum einen, weil die Propheten Christus den Priester nach der Ordnung Melchisedeks nennen und nicht nach der Ordnung Aarons. Melchisedek brachte Brot und Wein dar, Aaron aber brachte nach dem Tieropfer auch Azymen dar. Es steht aber geschrieben: „Gesäuertes Brot soll nicht auf meinen Altar gelangen.“ Azymen darbringend glauben sie [die Lateiner] daher nicht, dass Christus kam als Priester gemäß der Ordnung Melchisedeks. Zeichen aber des Kommens Christi und seines Priestertums ist das vollkommene Brot und der Wein, und anhand des gesäuerten und des ungesäuerten Brotes unterscheiden sich Melchisedek und Aaron.

Dass Christus Priester nach der Ordnung des Melchisedek ist, wie es der Hebräerbrief basierend auf dem Alten Testament bezeugt, sei eine Tatsache, die niemand leugnen kann, so der Dominikaner. Man müsse aber genauer hinsehen und verstehen, warum diese Zuschreibung gilt: Nicht etwa, weil Melchisedek Abram gesäuertes Brot und Wein dargeboten hat, denn davon finde sich nichts in der Heiligen Schrift geschrieben. Es seien vielmehr - und aussagekräftiger - jene Analogien zu benennen, die Melchisedek in Allem als typus Christi ins Spiel bringen, als den König der Gerechtigkeit (rex iustitie) und in weiterer Folge als den König des Friedens (rex pacis), als ohne Anfang und ohne Ende (alpha et $\Omega$ [...] sine patre et sine matre), wie der Dominikaner mit exegetischem Geschick darlegt. Auch sei das Priestertum des Melchisedek dem des Aaron nicht vorangestellt bzw. mehr wert als dieses, denn auch Aaron ist - wie viele Väter des Alten Testaments - typus Christi. Dass der Grieche außerdem lügt, wenn er behauptet (sicut Grecus mendatio suo astruit), dass gesäuertes Brot als Opfer am Altar Gottes dargebracht wurde, zeigt der Dominikaner anhand eines sprachlichexegetischen Streifzugs durch das Alte Testament.

\title{
Einwand 2 des Germanos: Iudaicum pascha melius est sacrificio Latinorum oder: Sogar die Juden bevorzugen das Vollkommene vor dem Unvollkommenen
}

\begin{abstract}
Aliud, quia Iudei pecus perfectum et immaculatum accipiebant ad Pasche sollempnitatem. Latini autem inperfectum et reprehensibile offerunt in sacrificium, scilicet azimum. Sacrificium uero Pascha est: „Pascha autem nostrum immolatus est Christus“, inquit Apostolus, ergo Iudaicum Pascha melius est sacrificio Latinorum. (TcG App. VIII, 62-67 (p. 199))

Zum anderen, weil die Juden ein vollkommenes und makelloses Lamm für die Paschafeierlichkeiten nahmen. Die Lateiner aber bringen unvollkommenes, tadelnswertes Brot als Opfer dar, nämlich das ungesäuerte Brot. „Als unser Paschalamm ist Christus geopfert worden“, sagt der Apostel; deswegen ist das jüdische Pascha noch besser als das Opfer der Lateiner.
\end{abstract}

Umgekehrt - und bereits den letzten Einwand inhaltlich mit hinzunehmend - zeigt der Dominikaner auf der Pascha-Folie, dass gerade der Sauerteig das Brot verdirbt (quia fermentum corruptio quedam est uel Pascha corrupta). Der Sauerteig aber, das heißt die Verderbnis an sich, hat nicht die Kraft, dasjenige zu wandeln, dem er bzw. sie hinzugefügt wird. Vielmehr verdirbt, befleckt, zerstört und vernichtet er bzw. sie, wie 
Paulus in Analogie von der Sünde spricht. Es müsste, in dieser Argumentationslinie bleibend, vielmehr behauptet werden, dass die Eucharistie nicht mit gesäuertem Brot gefeiert werden dürfe, weil der Sauerteig von Gott verworfen sei (sed odibile Deo et non acceptum non potest consecrari, ergo fermentatum [...] consecrari non potest).

\section{Einwand 3 des Germanos: Quomodo potest sacrificari oder: Widerspricht das Neue dem Alten Testament?}

Tertium capitulum est, quod apud Vetus Testamentum et Iudaicam culturam infima et inperfecta non erant accepta Deo, sed hodibilia omnino. Infimum autem et inperfectum est azimum. Si dicet Latinus, quod sanctificatur et efficitur corpus Christi: Quomodo id, quod odibile est et repulsum apud Deum tamquam inutile, sacrificabitur? Si in Veteri Testamento infima et inperfecta refutabat Deus: Quomodo acceptabit nunc, quando gratie perfectio illuxit et sol iustitie umbram legis soluit et exterminauit? Preterea, quis sustinebit simul cum Iudeis sollempnizare? Etenim maior Iudaicarum festiuitatum fuit esus azimorum. (TcG App. VIII, 68-78 (p. 199))

Der dritte Passus ist, dass [die Azymen] im Alten Testament und in der jüdischen Kultur minderwertig, unvollkommen und von Gott nicht angenommen, sondern gänzlich verachtet waren. Das gesäuerte Brot ist daher minderwertig und unvollkommen. Wenn der Lateiner sagt, dass der Leib Christi geheiligt und gewandelt wird: Wie kann das geheiligt werden, was von Gott verachtet und verworfen wird wie etwas Unnützes? Wenn Gott im Alten Testament das Minderwertige und Unvollkommene verworfen hat: Wie kann es nun angenommen werden, wo die Vollkommenheit der Gnade erstrahlte und die Sonne der Gerechtigkeit den Schatten des Gesetzes löste und vertrieb? Außerdem: Wer wird es ertragen, gleichsam wie die Juden zu feiern? Denn ein Hauptfest der Juden war das Fest der ungesäuerten Brote [wörtich: das Mahl der Azymen].

Wenn das mit dem Judentum Gemeinsame verwerflich ist, so müssten von den Griechen konsequenterweise auch die meisten der liturgischen Elemente und Geräte, Vieles im Kalender des Kirchenjahres, Sprachgebrauch und Ämterstrukturen, wie auch das Kirchengebäude an sich, das ja der christliche Tempel ist, verworfen und verachtet werden. ${ }^{511}$ Mit einem wortreichen Hinweis auf den Papst und die römische Kirche als mater et magistra ecclesiarum und damit als diejenige Autorität, der und deren Beschlüssen zu folgen die Griechen vor derartigen Irrtümern bewahren würde, außerdem mit einem Hinweis auf den Tractatus maior für weitere und detailliertere Ausführungen, schließt der Dominikaner seine Reaktion auf Germanos II.

511 Vnde Grecis templum, quod naon uocant siue ecclesiam, altare, candelabra, sacrificium, cortine, sanctum scrisma, thumiama, thuribulum, aspersionis aqua, et uasa sancta, que sunt in ecclesia, siue ornamenta aut uestimenta sacerdotalia? Unde eis Pentecoste, Pascha siue Quadragesima? Unde eis pontifices et sacerdotes et leuite et reliqui ministeri altaris? Unde primitie et decime? Unde similiter uel quare puerpere obseruant dies purificationis? (TcG App. VIII, 320 - 326 (p. 206-207)) 


\subsubsection{Tiflis: Brieffragment der Dominikaner aus Georgien}

Der letzte Teil des Appendix ist inhaltlich den Azymen und dem Filioque gewidmet und bietet ein weiteres Zeugnis dominikanischer Schriftkultur der ersten Generation. Es handelt sich um ein Brieffragment der Dominikaner in Georgien, die im Kontext der lateinisch-griechischen Auseinandersetzungen an ihre Mitbrüder schreiben und ihnen jeweils ein griechisches Zeugnis für das Filioque und für die Konsekration mit ungesäuertem Brot bieten. A. Dondaine hat diesem Fragment in seiner Studie von 1951 bereits einigen Raum gewidmet: ${ }^{512}$

Dem Zeugnis des Humbert von Romans als Ordensmeister zufolge waren die Dominikaner seit 1238/1240 in Georgien präsent. ${ }^{513}$ Die Namen von acht Dominikanern sind überliefert, die zu Beginn des Jahres 1240 als päpstliche Delegation zum georgischen König Roussoudane gesandt wurden. Eine dominikanische Niederlassung in Tiflis ist daher spätestens seit diesem Jahr wahrscheinlich. Das undatierte Fragment ist als Quelle im Kontext der theologischen Kontroverse zweifach interessant: Zum einen zeugt es von der dominikanischen Kenntnis der georgisch-byzantinischen Liturgie und Literatur, indem es das georgische Pentecostarion für die Argumentation des Filioque und Exzerpte aus der Vita des Georg Hagiorites († 1066) zur Legitimierung der Azymen zitiert. ${ }^{514}$ Zum anderen bietet allein schon die Korrespondenz einen Einblick in die kontroverstheologische Arbeitsweise bzw. Quellen- und Literaturbeschaffung innerhalb des dominikanischen Netzwerkes.

\subsection{Analyse der Argumentation und Veranschaulichung anhand des Motives des Kirchenbildes im Tractatus contra Graecos}

Als Basis der Argumentation des Tractatus contra Graecos kann der Anspruch des Autors gelten, den Werk-Fundus der autoritativen griechischen Väter und der kirchlich-konziliaren Tradition zur Untermauerung der lateinischen Positionen heranzuziehen. Darauf aufbauend verfolgt er für jede Thematik, der er sich in seinem Dossier widmet, verschiedene und unterschiedlich gewichtete Argumentationsstrategien, die im Folgenden anhand des Motivs des Kirchenbildes veranschaulicht werden sollen, dessen Koordinaten in der Einleitung detailliert vorgestellt wurden. ${ }^{515}$ Die Untersuchung des Kirchenbildes, wie es entweder vorausgesetzt ist bzw. präsentiert wird, sofern es die eigene Kirche betrifft, oder wie es auf der Basis des Wissens und der Beobachtungen über die andere oder gar fremde Kirche dargestellt wird, soll damit als

512 Vgl. Dondaine 1951, 378-384.

513 Fratres nostri magnae auctoritatis et mirabilium viri virtutum, qui iam inter Georgianos, in remotissimis partibus orientis, XVIII annis et amplius vitam asperissimam duxerunt. Der Brief des Humbert datiert in das Jahr 1256. (Mon. OP hist. V, 40, zitiert nach DondaINE 1951, 378).

514 Für weiterführende Angaben vgl. DondAINE 1951, 378.

515 Vgl. dazu ausführlicher die Seiten 11-14 der vorliegenden Studie. 
thematischer Aufhänger im Zentrum stehen und die Basis legen für einen Vergleich der im Fokus stehenden Werke.

\subsubsection{Basis der Argumentation: Die Väterzitate im Tractatus contra Graecos}

Der Dominikaner geht von der normativen und fraglosen Autorität der lateinischen wie griechischen Kirchenväter - der sancti doctores - für die Tradition der Kirche aus. Dass in seinem Traktat beinahe ausschließlich griechische Kirchenväter zu Wort kommen und die Stimmen der lateinischen Patristik zwar nicht ausgespart, aber zumindest als Bezugsquellen - deutlich reduziert werden, hat zunächst methodische Gründe: Dem Zweck des Autors, die Byzantiner von der Richtigkeit der lateinischen Tradition zu überzeugen, dient die Argumentation mit den griechischen Quellen, wie oben gezeigt wurde. Darüber hinaus wäre es redundant oder gar kontraproduktiv, auch die lateinischen Väter anzuführen, weil der Autor für dieses Verfahren erstens auf Werke anderer lateinischer Theologen und Zeitgenossen verweisen kann, wie er es im Prolog tut, und weil er zweitens - implizit - ohnehin die lateinische Vätertradition wiedergibt, die es ja zu verteidigen gilt und die er mit den griechischen Zitaten untermauert. An mehreren Stellen seines Werkes zieht er den Schluss, dass eine Leugnung - ja, eine Ablehnung - der lateinischen Tradition, wie er sie den Greci moderni unterstellt, deswegen unhaltbar und geradezu frevlerisch sei, weil ihre Wahrheit und Richtigkeit mit dem eigenen Maßstab der Griechen, nämlich mit deren patristischer Tradition, nachgewiesen werden konnte.

Dementsprechend ist es konsequent, wenn der Dominikaner - zunächst einmal in Bezug auf die Formalia seiner Arbeit - sehr präzise vorgeht: Es muss für den Leser leicht möglich sein, die zitierten Quellen der griechischen Patristik zu finden und auf ihre Richtigkeit hin nachzuprüfen. Der Autor ist daher darauf bedacht, klare Quellenangaben zu liefern: Autor, Werktitel oder Beginn des entsprechenden Textes, bisweilen Kapitelangaben oder Bibelstelle, auf die sich die entsprechende Textpassage bezieht, gelegentlich konkretisiert anhand zusätzlicher Findhilfen wie parum ante finem, in fine, paulo ante medium, circa medium sermonis usw. Da es sich bei den Zitaten um die lateinische Übersetzung der griechischen Originale handelt, ist dieses Verfahren für beide potentiellen Leserschaften - in erster Linie Lateiner, aber zumindest theoretisch auch Byzantiner - von Vorteil, weil ohne diese Präzision auch vom Leser entsprechende Fremdsprachenkenntnisse verlangt wären, die in der Form mit großer Wahrscheinlichkeit nicht gegeben waren. In dieser formalen Vorgehensweise spiegelt sich außerdem nicht nur die Intention des Dominikaners, sondern auch sein gewandter Umgang mit den patristischen Quellen, die den entsprechenden Zugang und seine wissenschaftlichen Fähigkeiten sowie das ,Übersetzungs-Know-how voraussetzen. Das Neue und Bemerkenswerte an diesem Vorgehen ist das Streben nach Transparenz insofern, als die Überprüfbarkeit dessen, was der scholastisch geschulte Gelehrte erarbeitet, zum Qualitätskriterium seiner Arbeit (gemacht) wird. 
In Bezug auf die Zitation von Schriftstellen im Verhältnis zu den Kirchenvätern wurde bereits angesprochen, dass der Autor den Schriftbeweis in der Regel nicht in einfacher Form anwendet, sondern eine biblische Belegstelle in Verbindung mit der entsprechenden patristischen Kommentierung anführt. Er bedient sich dabei der im 13. Jahrhundert weithin üblichen Methode scholastischer Schriftauslegung, die sich so in den Schriftkommentaren findet und auch in anderen theologischen Werken und Kontexten angewendet wird: Diese Methodik bringt zum Ausdruck, dass ,die Väter als die Lehrer der Kirche und Übermittler der wahren Lehre die autoritativen Ausleger der Schrift sind und die richtige Schriftauslegung eben nur in Treue zu den Vätern möglich ist, ja dass Schrifttreue und Vätertreue sich gegenseitig bedingen“516. Indem der anonyme Autor den Griechen ihr eigenes patristisches Fundament vor Augen führt und gleichzeitig belegt, dass dieses Fundament die lateinischen Positionen in den genannten Konfliktpunkten stützt, fordert, ja erzwingt er geradezu das Eingeständnis der Byzantiner, dass sich hier autoritative Schriftauslegung ereignet, die somit die wahre Lehre der Kirche stützt.

\subsubsection{Das Kirchenbild des Tractatus contra Graecos}

\subsubsection{Kirchenbild des Autors: Gegenstand der Verteidigung}

Vor dem Hintergrund der in den Vorbemerkungen angeführten Koordinaten des Kirchenbildes ${ }^{517}$ kann zunächst die vierte distinctio des Tractatus maior über den Primat Roms als Leitfaden für das Grundgerüst des Kirchenbildes des Tractatus contra Graecos dienen: Der Garant für die Treue zur Offenbarung und zur apostolischkirchlichen Tradition, aber auch für das institutionelle Funktionieren der einen Kirche ist das eine Oberhaupt, der römische Papst. Er ist das Haupt der Gesamtkirche und damit implizit das Haupt aller Kirchen, womit ihm das Vorsteheramt über alle Gläubigen (praelatio omnium fidelium) übertragen ist. Er ist als Nachfolger Petri der Stellvertreter Christi, Vater der Väter und höchster Pontifex (vicarius Christi, pater patrum, summus pontifex). Er verfügt über die Fülle der Macht (plenitudo potestatis), während die Bischöfe und Vorsteher anderer Kirchen nur in Teilverantwortung (in partem sollicitudinis) berufen sind. Aus dieser Machtfülle resultieren konsequent die Prärogativen der Würde (praerogativa dignitatis) - beides Zuschreibungen, die das Verhältnis des Papstes zu den übrigen Bischöfen, in diesem Fall konkret zu den Patriarchen des christlichen Ostens bestimmen. Der Papst ist des Weiteren nicht nur pater in der Nachfolge des Petrus (Petro successit in potestate clavium), sondern auch magister in der Nachfolge des Paulus (Paulo successit in consideratione et discussione causarum), womit beide Elemente einer interessanten Unterscheidung des Primats Autorität und Kompetenz - angesprochen sind. Weniger auf die Person und das Amt

516 RIEBE 2005, 137.

517 Vgl. dazu die dritte Vorbemerkung auf den Seiten 11-14 der vorliegenden Studie. 
des Papstes, sondern mehr auf die universale im Verhältnis zur lokalen Autorität der Kirche zielt der „Topos von den apostolischen Sitzen“518, den sedes apostolice: Sowohl in Fragen des Glaubens als auch in Fragen der Kirchenadministration bildet Rom das normative Zentrum, den „Orientierungspunkt“519 der Kirchen. Es stellt gleichsam, so die Ausführungen und Belege des Dominikaners, immer schon die juridische Letztinstanz dar, die konziliare Entscheidungen durchlaufen müssen, um Gültigkeit beanspruchen zu können. Um schließlich auch in weltlichen Belangen die päpstliche Souveränität bzw. deren weitere Ausbildung rechtlich zu begründen, wird die Konstantinische Schenkung als Bürge und Referenzpunkt herangezogen.

Weil Rom der Orientierungspunkt für alle Kirchen ist, gilt das, was es lehramtlich oder disziplinär festlegt, für seinen gesamten Zuständigkeitsbereich, sprich für alle Kirchen. Von daher definiert Rom, wo die Grenzen zwischen Rechtgläubigkeit und Häresie zu ziehen sind, die den Maßstab für die Kirchenzugehörigkeit zur einen Kirche Jesu Christi bilden. In einem der drei großen Konfliktpunkte Filioque, Purgatorium und Azymen sieht der Tractatus contra Graecos diese Grenze zur Häresie expressis verbis strapaziert, wenn nicht gar überschritten, während in den beiden anderen Punkten etwas gemäßigter die Rede von einer falschen Auffassung oder einem zu korrigierenden Irrtum ist: Die Nicht-Anerkennung des lateinischen Filioque als theologische Wahrheit und der Lehre nach richtige und notwendige Erläuterung trinitätstheologischen Gehalts stellt eine so gewichtige Verfehlung dar, dass sie einen Ausschluss aus der kirchlichen Gemeinschaft zur Folge haben muss, wie es der Tractatus contra Graecos scharf zum Ausdruck bringt:

Illos uero qui dicunt, quod Spiritus Sanctus procedit quidem a Patre sed non a Filio, uel 〈quod〉 aliter aut plus a Patre procedit quam a Filio, aut prius a Patre, postmodum a Filio, et similia recte fidei aduersantia, et hoc asserendo credunt, predicant et scribunt, sicut iam dudum diffinitum est a sanctis patribus, tamquam hereticos a catholica ecclesia abicimus, uitamus, maledicimus et reprobamus. (TcG I, 1127-1134 (p. 54))

Jene aber, die sagen, dass der Heilige Geist nur vom Vater und nicht vom Sohn ausgeht, oder dass er auf andere Weise oder mehr aus dem Vater als aus dem Sohn ausgeht, oder früher aus dem Vater und später aus dem Sohn und ähnliche Dinge, die dem rechten Glauben widersprechen, und die dies alles bekräftigend glauben, verkündigen und schreiben als das, was schon längst von den heiligen Vätern festgeschrieben wurde, diese wollen wir wie Häretiker aus der ecclesia catholica werfen, sie meiden, sie schmähen und verwerfen.

Umgekehrt würde die Anerkennung des lateinischen Filioque von Seiten der Byzantiner allerdings keineswegs seine Übernahme für die griechische Tradition verlangen, sondern lediglich das Zugeständnis und damit die prinzipielle Annahme seiner Rechtmäßigkeit - nicht mehr und nicht weniger. Ein ähnliches Verfahren, allerdings nicht mit dem Schweregrad der Häresie behaftet, gilt für die Verwendung des gesäuerten oder ungesäuerten Brotes für die Eucharistiefeier: Beide Formen stehen

518 BEINERT 1995a, 73.

519 Ebd. 
gleichberechtigt nebeneinander, was umgekehrt zur Folge hat, dass keine der beiden - als solche gewachsenen - Traditionen als die allein richtige und damit innerhalb der gesamten Kirche allein normative angesehen werden darf. Die Verwendung der Azymen auf lateinischer Seite ist demnach keine ausschließliche, sondern eine gleichberechtigte Verwendung, die in diesem Sinne von der ganzen Kirche zu akzeptieren ist. ${ }^{520}$ Dass es - den eschatologischen Konfliktpunkt betreffend - Aufenthaltsorte der Seelen nach dem Tod bis zum Jüngsten Gericht gibt, deren einer das Purgatorium ist, steht ebenso fest wie die vor-endgerichtliche Aufnahme bestimmter Seelen in das Paradies oder in die Unterwelt. Da der Tractatus contra Graecos in diesem Punkt auf einen vergleichsweise nur kleinen Fundus (moderner) griechischer Lehrmeinungen zurückgreifen kann, ja für das male sentire der griechischen Zeitgenossen hinsichtlich dieses Punktes nur wenige Quellen zur Verantwortung zieht, beschränkt sich der Traktat darauf, diese Lehre auf einen konkreten und namentlich genannten Häresiarchen - Andreas von Caesarea ${ }^{521}$ - zurückzuführen, sie als demnach falsch $\mathrm{zu}$ bezeichnen und ihr die korrekte lateinische Variante gegenüberzustellen.

Um auf die Ausgangsfrage nach den Grenzen und dem Spielraum des im Text transportierten Kirchenbildes zurückzukommen, kann in einem ersten Resümee Folgendes festgehalten werden: Die deutliche Grenze hinsichtlich der Zugehörigkeit zur einen und wahren Kirche Jesu Christi manifestiert sich in der Anerkennung der päpstlichen Vollmacht als und über die Gesamtkirche. Der Autor belässt dieses Postulat interessanterweise in der Theorie und gibt nirgends konkrete Handlungsanweisungen wie etwa die einheitsbezeugende Nennung des Papstes in den Diptychen der Liturgie oder die konkrete Notwendigkeit einer päpstlichen Bestätigung, wenn es um die Besetzung kirchlicher Ämter geht. Gemäß der westlichen Entwicklung der Primatsidee stellt der Autor - auf dem Boden der biblisch-theologischen Fundierung die päpstliche Vollmacht kontinuierlich ausgehend von der Rolle Roms bei den sieben Generalkonzilien bis hin zur interpretativen Zuspitzung der Päpste Gregor VII. und Innozenz III. unter dem Stichwort plenitudo potestatis und vicarius Christi dar, wobei interessanterweise schon das Erste Ökumenische Konzil von Nizäa (325) zur Untermauerung und Referenz der päpstlichen bzw. römischen Vorrangstellung dient. ${ }^{522}$ Der

520 Si igitur diuinum uerbum transmutat proposita dona in corpus et sanguinem Iesu Christi, superfluum est contendere, siue ex azimis siue ex fermentatis fuerit, uel album siue rubeum forsan uinum, et huiusmodi quasdam stultas curiositates de metuendis et tremendis misteriis perscrutari. (TcG III, 344-348 (p. 84))

521 Andreas von Caesarea taucht auf der Liste der klassischen patristischen Belegstellen für den Zwischenzustand nicht auf; vgl. MERKT 2005 mit den entsprechenden Literaturangaben; vgl. RIEDL 2014.

522 Que cuncta, si diligens lector discutere uoluerit, inueniet illa tria, que in principio istius quarte partis quesita fuerant, esse soluta, uidelicet quo tempore Romana ecclesia habuerit istam potestatem, uel a quo, et utrum super omnes uniuersaliter an particulariter super aliquos. Quod tamen iterum breuiter repetentes, dicimus quod auctoritatem habet ecclesia a Christo mediante Petro, cui cura ouium spiritualium specialiter et singulariter fuit commissa; Executionem tamen potestatis uel auctoritatis sue habet ecclesia 
Mitvollzug dieser Entwicklung ist es, den der Dominikaner von den Byzantinern als ihre Schuldigkeit und Verpflichtung fordert. Damit einhergehend zählt der mit dem Filioque verbundene Themenkomplex zu den Grenzen des Kirchenbildes, das der Tractatus contra Graecos vertritt: Es gehe nicht an, dass diese Kirche, die die wahre Kirche Jesu Christi ist und die apostolische Tradition als ihre Trägerin durch die Zeit hindurch bewahrt hat, in einem so gewichtigen Punkt wie dem gemeinsamen Bekenntnis jemals geirrt habe. In der Verteidigung des dogmatischen wie liturgischen Lehrgebäudes, das hinter dem Filioque steht, stellt der Dominikaner klar den Papst als den rechtmäßig handelnden Entscheidungsträger dar, womit die Verbindungslinie zum magisterium des Papstes - nämlich hier in seiner Funktion als Repräsentant der lateinischen Filioque-Tradition - deutlich wird:

Quod cum negare Greci non possint nisi forsan scripta sua et sanctos patres uelint condempnare, necesse habent nobiscum et ipsi fatendo dicere Romanum pontificem propter additionem factam in symbolo, quam ueram esse nullus sanctorum dubitauit, non esse excommunicatum uel hereticum, sed pium doctorem et catholicum et fidelem dispensatorem, quem Dominus super familiam suam, id est super uniuersalem ecclesiam constituit, ut det illis cibum fidei in tempore oportuno. (TcG I, 883891 (p. 43))

Weil die Griechen dies [i.e. das Filioque] nicht leugnen können, außer sie möchten vielleicht ihre eigenen Schriften und die heiligen Väter verdammen, müssen sie notwendigerweise selbst und mit uns bekennend sagen, dass der römische Papst wegen der geschehenen Hinzufügung im Glaubensbekenntnis - deren Wahrheitsgehalt niemand der Heiligen bezweifelte - nicht exkommuniziert oder häretisch ist, sondern gottesfürchtiger Gelehrter, rechtlgäubiger und zuverlässiger Schatzmeister, den der Herr für seine Familie, das heißt für die Universalkirche eingesetzt hat, damit er ihnen das Brot des Glaubens gebe zur rechten Zeit.

Was den Spielraum des Kirchenbildes angeht, so wird dieser deutlich in der Haltung gegenüber dem, was mit consuetudines - Gewohnheiten bzw. Gepflogenheiten bezeichnet werden kann. Dazu zählen sowohl Fragen des Ritus am Beispiel der Verwendung des eucharistischen Brotes als auch Angelegenheiten des kirchlichen Lebens und der Pastoral wie (Priester-)Ehe und Ehescheidung, Fasten- und Reinheitsgebote und Geschlechterrollenzuschreibungen in der Liturgie, die in den jeweiligen Canones geregelt sind und von daher per se einer Auslegung bzw. Erklärung bedürfen. Ein Spielraum ist hier insofern erkennbar, als die westliche Kirche in der Darstellung des Tractatus contra Graecos durchaus zu Zugeständnissen zugunsten der griechischen Kirche bereit ist, umgekehrt allerdings dieselbe Haltung von den Byzantinern einfordert: Liturgische Gepflogenheiten, Fastengebote und dergleichen müssen nicht angepasst werden - so lautet gleichermaßen das Zugeständnis und die Forderung des Westens. Zwar verteidigt der Dominikaner westliche, von den Griechen angegriffene consuetudines, indem er die (gemeinsamen!) Canones entsprechend interpretiert, doch scheint das Ziel des Autors hier mehr das Aufzeigen der Interpretationsmög-

a primo concilio Nicee celebrato, in quo unaqueque sedes, secundum quod plus et minus honoris ab Apostolis receperat, magis et minus fuit priuilegiata et exaltata. (TcG IV, 513-523 (p. 108)) 
lichkeiten der Canones bzw. ihrer dezidiert falschen Auslegung von byzantinischer Seite als eine Überzeugung der Byzantiner von den lateinischen Bräuchen insofern zu sein, als sie diese übernehmen müssten. Dafür spricht nicht zuletzt die Tatsache, dass der Autor die consuetudines und die Besprechung der Canones in den Appendix und nicht in den Hauptteil seines Werkes setzt, dass er diese also nicht zu den ausschlaggebenden und korrekturbedürftigen Irrwegen (deviationes) der Byzantiner zählt.

\subsubsection{Argumentationsstrategien}

Die vierte distinctio über die Stellung des römischen Papstes ist - wie gezeigt ${ }^{523}$ - die einzige, in der es der Autor unterlässt, die Gegenargumente der Byzantiner als programmatischen Leitfaden voranzustellen und daran die lateinische Position zu entfalten. Sie stellt sich vielmehr als eine beinahe eigenständige Abhandlung dar, die die Notwendigkeit der römischen Obödienz mit einem ganzen Set an Argumentationen zwingend vor Augen führen will. Die Analyse dieses Sets von Argumentationsstrategien, die der Dominikaner zur Darlegung seiner Ekklesiologie heranzieht, soll nun im Folgenden in zwei Schritten erfolgen: Zunächst werden in einem ersten Schritt die in der vierten distinctio impliziten Provokationen von Seiten der Byzantiner als Themenblöcke herausgearbeitet. Da es die Intention des anonymen Autors ist, seinen Leser möglichst gut und detailliert auf den Disput mit den Griechen vorzubereiten und ihm die entsprechenden Argumente zur Hand zu geben, können durch seine Gewichtung der einzelnen Themenblöcke die Haupteinwände der Griechen bzw. ihre impliziten Anfragen an den römischen Primat herausgefiltert werden. ${ }^{524}$ Die vier nachfolgenden Themenbündelungen („Gleichheit der Apostel versus Vorrang des Petrus“, „Autorität der Apostel versus Autorität des Petrus“, „Pentarchie versus päpstlicher Absolutheitsanspruch“, „Primat von Konstantinopel versus Primat von Rom“) sind keine Kategorien, die der Traktat selbst einführt, sondern stellen eine Einteilung von außen dar, die der besseren Darstellung dienen soll. In einem zweiten Schritt wird das Argumentationsverfahren des anonymen Autors, auf das seine Reaktion schließen lässt, dargestellt. Vorweggenommen sei dazu, dass zu diesem Zweck die Argumentationsstrategien zu drei Kategorien zusammengefasst und überblicksartig vorgestellt werden:525 Den eindeutig größten und prominentesten Raum nehmen die historischen und (biblisch-)theologischen Argumente ein, gefolgt von quellenkritischen und sprachlich-etymologischen Beweisführungen, die als sekundäre Stütze theologischer oder historischer Argumente dienen.

523 Vgl. dazu ausführlicher die Seiten 123-128 der vorliegenden Studie

524 Vgl. dazu auch Milton 2001, 1-119 (VIII).

525 Vgl. die Herangehensweise von RieBE 2005, 130 - 197 (unter dem Stichwort „Die Verteidigung der Kirchenunion“: politisch-pragmatisch; historisch; theologisch) und AvVAKUMOv 2002, 303 - 334 (unter dem Stichwort „Reflexion der Lateiner“: ekklesiologisch; sakramentaltheologisch; kirchengeschichtlich). 


\section{Implizite Anfragen an den römischen Primat Gleichheit der Apostel versus Vorrang des Petrus}

Dass der Bischof von Rom der Nachfolger des Apostels Petrus ist, bildet das Fundament, über das bei Lateinern und Byzantinern Einigkeit besteht. Erst mit der Frage, ob und welche Privilegien dem Papst damit zukommen und in welchem Verhältnis er zu den übrigen Patriarchen steht, die ja jeweils Nachfolger der Apostel sind, unterscheiden sich die Positionen von Lateinern und Byzantinern grundlegend: Unter Berufung auf Mt 23,8-9 insistieren die Byzantiner, dass keiner der Apostel höhergestellt war als die anderen, dass alle zwölf gleichen Ranges und Brüder (pares et fratres) waren und dass dieses ekklesiologische Konzept der Kirche in Gegenwart und Zukunft normativ sein müsse. Diese Gleichheit der Apostel stellt eine tragende Säule des Pentarchiemodells dar, jener Theorie einer Bruderschaft der fünf Kirchenzentren Rom, Konstantinopel, Alexandrien, Antiochien und Jerusalem -, die „vor allem in Byzanz zu einer eigentlichen ekklesiologischen Wertvorstellung geworden“ ${ }^{\text {“526 }}$ war. Rom hingegen betont, wie im Tractatus contra Graecos dargestellt, die Vorrangstellung des Petrus unter den Aposteln, die ihre Grundlage in dessen Bekenntnis hat, dass Jesus der Messias und Sohn Gottes ist. Dieses Bekenntnis zieht eine Reihe von Konsequenzen nach sich, die bis in die Gegenwart des Dominikaners als Privilegien und Verpflichtungen des Nachfolgers Petri einzuhalten seien, wenn die Tradition der Kirche gewahrt werden soll.

Die Darstellung des Tractatus contra Graecos zum Themenblock „Gleichheit der Apostel versus Vorrangstellung des Petrus“, die ja letztlich auch die Frage nach dem Verhältnis von Papst und ökumenischem Konzil berührt, zielt vor allem darauf, das griechische Gleichheitskonzept der Apostel(-nachfolger) aufzubrechen. Aus Sicht der griechischen Kirche stellt das ökumenische Konzil diejenige Instanz dar, die über der Autorität eines einzelnen Patriarchen und damit - dem Gleichheitskonzept entsprechend - auch über der Autorität des Papstes steht. Besonders in Fragen des Glaubens der Kirche sei daher das Konzil das einzig gültige Entscheidungsforum. Vor diesem Hintergrund spielt es eine nicht unwesentliche Rolle, dass auf lateinischer Seite der Traktat den Vorrang Roms nicht nur feststellt, sondern detailliert entfaltet, welche Kompetenzen dem Papst, darunter auch in Glaubensfragen, zukommen: Er ist es, der mit seiner Zustimmung den Konzilsbeschlüssen erst ihre Gültigkeit, ihre Kraft (robur firmitatis) verleiht. Umgekehrt heißt dies, dass ohne die Bestätigung des Papstes die Beschlüsse des Konzils nicht letztgültig sind, dass der Papst damit letztlich über den übrigen Kirchenoberhäuptern, ja über der Autorität des Konzils steht. Auch die Verleihung der patriarchalen Würde obliegt dem Papst, womit sein Vorrang vor den Patriarchen der Ostkirchen einmal mehr zum Ausdruck kommt. Dass die Patriarchenwürde insofern an den Papst gebunden ist, als sie der päpstlichen Bestätigung bzw. Verleihung bedarf, ist Gegenstand einer zweiten Anfrage an den römischen Primat, mit der sich der anonyme Autor auseinandersetzt:

526 CongourdeAu 2010, 294-314, hier: 298. 


\section{Autorität der Apostel versus Autorität des Petrus}

In enger Verbindung mit der erstgenannten Anfrage an den römischen Primat steht der zweite Konfliktpunkt, der die Frage nach dem Existenzrecht der patriarchalen Sitze stellt: Wessen Autorität war in apostolischer Zeit ausschlaggebend für die Gründung der großen kirchlichen Zentren, und wessen Autorität bildet daher gegenwärtig, das heißt zur Zeit des Dominikaners, die Grundlage des Existenzrechtes der Patriarchate? Die griechische Position macht sich für ein personengebundenes Modell stark, das die Autorität desjenigen Apostels hervorhebt, der jeweils als der Gründungsvater der Patriarchate verehrt wird und als dessen Nachfolger sich die Patriarchen verstehen. Dieses Modell steht in direktem Zusammenhang mit der griechischen Auffassung über die Gleichheit der Apostel: Die Autorität jedes Patriarchates leitet sich unmittelbar ab von der Autorität der Apostel, die diese in Gemeinschaft und ohne strukturelle Vorrangstellung eines einzelnen unter ihnen ausübten. Die lateinische Sichtweise hingegen betont Petrus als den Dreh- und Angelpunkt der Ausbreitung der frühen Kirche und damit der Gründung von kirchlichen Leitungszentren: Mit Ausnahme von Konstantinopel und Jerusalem waren sie jeweils Gründungen von Petrus selbst, indem er entweder persönlich vor Ort war (wie in Antiochien) oder einen Stellvertreter sandte (wie in Alexandrien). Daraus folge zum einen, dass die gegenwärtigen Patriarchate ihre Existenz der Gründung und damit dem Beschluss des Petrus verdanken, und zum anderen, dass die - im apostolischen Modell bereits vorgezeichnete - Rolle des Nachfolgers Petri auch gegenwärtig zur Wahrung der Tradition beibehalten und respektiert werden müsse. Während Jerusalem als Ort des Leidens und der Auferstehung des Herrn eine ekklesiologische Sonderstellung innehat und deswegen auch ohne die Vermittlung des Apostels Petrus den Status eines Patriarchats genießt, bedarf die Begründung des Konstantinopler Patriarchats - die implizit die dritte Anfrage der Griechen an den römischen Primat, nämlich das Pentarchiemodell, thematisiert größerer Aufmerksamkeit des Dominikaners, wie im nächsten Punkt darzustellen ist:

\section{Pentarchie versus päpstlicher Absolutheitsanspruch}

Ein in der byzantinischen Ekklesiologie altes und weit verbreitetes Bild für die Kirche Jesu Christi, genauer für ihre Struktur und Handlungsfähigkeit, ist das Bild der fünf Sinne des menschlichen Körpers. ${ }^{527}$ Mit dieser Metapher, die im Übrigen im Umkreis des Konzils von Ferrara-Florenz lebhaft in die Diskussion eingebracht wurde, ${ }^{528}$ soll die griechische ekklesiologische Position - kurz zusammengefasst im PentarchieModell - adäquat ins Bild gebracht werden: Die fünf Sinne der Kirche als der Leib Christi sind die fünf Patriarchate, die jeweils für ihren eigenen Zuständigkeitsbereich verantwortlich sind, dabei aber immer in Übereinstimmung mit den anderen handeln

527 Vgl. dazu Milton 2001, 55-56; Congourdeau 2010, 298-299; vgl. PRInZING/Todt 1993, 17851789, hier: 1786; zum Pentarchiemodell allgemein vgl. GAHBAUER 1993.

528 Vgl. Laurent 1962, 5-60, hier: 50. Vgl. Congourdeau 2010, 298. 
müssen, um überhaupt handlungsfähig zu sein und zu bleiben. ${ }^{529}$ Nur so - in kollegialer Übereinstimmung - bilden die fünf Patriarchate gemeinsam „die oberste Gewalt in der Kirche“530, die in dieser Form die Bedingung und das Forum für konziliare Beschlüsse sein muss und die einzig Christus als dem Haupt des Leibes unterworfen ist. ${ }^{531}$ Während die Byzantiner das Pentarchiemodell als den einzig gangbaren Weg einer Zusammenarbeit der kirchlichen Zentren ansehen und darin dem Patriarchat von Rom zwar eine Ehrenvorrangstellung, allerdings nicht auf apostolischer, sondern auf konziliarer Basis zuerkennen, ist der Dominikaner bestrebt, dieses Modell einer brüderlichen und ebenbürtigen kirchlichen Vernetzung zugunsten eines Modells der römischen Obödienz aufzubrechen. Zu diesem Zweck dekonstruiert er zunächst die Legitimität des Konstantinopler Patriarchats: Dass Konstantinopel überhaupt im Rang eines Patriarchats stehe, sei dem unrechtmäßigen, weil ohne Zustimmung des Papstes geschehenen Vorgehen auf den Konzilien von Konstantinopel 381 und Chalcedon 451 zu verdanken: Ohne päpstlichen Rückhalt und damit ohne Beschlusskraft wurde Konstantinopel in den Rang eines Patriarchates erhoben und zudem auf den zweiten Platz in der Rangfolge nach Rom gereiht, womit Alexandrien, Antiochien und Jerusalem unverschuldet und grundlos nach hinten gedrängt worden waren. Abgesehen von dieser nicht zu befürwortenden Handlungsweise, durch die Beleidigung Anderer die eigene Position zu stärken, könne auch die postulierte Ebenbürtigkeit der fünf Patriarchate nicht aufrechterhalten werden: Wären die Patriarchate im Allgemeinen ohne die autorisierende Beteiligung des Petrus entstanden, wie die Byzantiner behaupten, dann müsste eine weit größere Zahl an kirchlichen Leitungszentren existieren, da die Zahl der Apostel größer als fünf gewesen sei. Über das Verhältnis Roms zum Patriarchat von Konstantinopel schreibt der anonyme Autor schließlich ausführlicher und thematisiert damit die vierte Anfrage an den römischen Primat, die aus griechischer Perspektive den Primat Konstantinopels mit historischer Begründung ins Feld führt und die singuläre Stellung Roms damit in Frage stellt:

\section{Primat von Konstantinopel versus Primat von Rom}

Aus griechischer Sicht ist es folgerichtig, dass mit der Verlegung der Hauptstadt des Imperiums auch die kirchliche Leitungszentrale ihren Sitz wechselte: Die Entscheidung für Konstantinopel als neue Reichshauptstadt, die Mitte des 4. Jahrhunderts gefallen war, sei demnach nicht nur für die Politik, sondern auch für neue kirchliche

529 In der lateinischen Tradition wurde das Bild von den fünf Sinnen schon früh um eine entscheidende Nuance verändert: Zwar ist Christus das Haupt des Leibes, der mit den fünf Sinnen ausgestattet ist, aber der Sehsinn, der Rom repräsentiert, dominiert die anderen vier Sinne und ist somit höhergestellt als diese; vgl. dazu v. a. die Literaturangaben bei Milton 2001, 105 (Anm. 217).

530 Prinzing/Todt 1993, 1786; vgl. Biedermann 1993, 1874.

531 Milton formuliert die Prinzipien bzw. Prämissen des Pentarchiemodelles folgendermaßen: „The equality and independence of all five patriarchates were cardinal features of patriarchal theory [...].“ (Milton 2001, 57). 
Strukturen als richtungsweisend anzusehen. ${ }^{532}$ Diese Sichtweise impliziert erstens, dass der kirchliche Primat an die weltliche Herrschaft gebunden, ja dass er sogar von ihr abhängig ist, und zweitens, dass Konstantinopel ab dem 4. Jahrhundert konsequenterweise jenen Primat innehaben sollte, dessen sich Rom bis dahin gerühmt hatte. Der Dominikaner verzichtet an dieser Stelle auf theologische Beweisführungen und antwortet auf diese Positionsbekundung der Griechen, indem er ihnen - in beinahe klassisch gewordener Argumentationsweise - die Konstantinische Schenkung vor Augen führt: Mit der Nennung des Privilegium Constantini, das zum Textcorpus der sogenannten Konstantinischen Schenkung zählt, ${ }^{533}$ verweist er auf jene schon im 13. Jahrhundert in der neu entstehenden Disziplin der kirchlichen Kanonistik an den Universitäten stark diskutierte Autorität, die die weltlichen Machtansprüche des Papsttums rechtfertigt und in der mittelalterlichen Vorstellung „die erste Schenkungsurkunde eines christlichen Kaisers für die römische Kirche“534 war, mit der Kaiser Konstantin I. Papst Silvester I. sowie sämtlichen Nachfolgern ohne zeitliche Begrenzung kaiserliche Privilegien zuerkannte.

\section{Argumentationsverfahren des anonymen Autors \\ Historische Argumente}

Die immer wieder eingeflochtene rhetorische, d.h. in diesem Fall den Argumentationsgang vorantreibende Frage, welche Gründe denn seine griechischen Zeitgenossen gegen die römische Obödienz anführen können, verwendet der Autor zunächst als Fingerzeig auf die gemeinsame kirchengeschichtliche Vergangenheit, die sich von der apostolisch-biblischen Zeit über die gemeinsamen Konzilien bis hin zu den ersten Brüchen - angefangen bei Karl dem Großen als westliches Pendant zum (byzantinischen) Kaiser des römischen Reiches bis zu den aus seiner Sicht zerstörerischen Aktivitäten des Patriarchen Photius gegen Ende des 9. Jahrhunderts - erstreckt. Nach der biblisch-theologischen Grundlegung der Vorrangstellung Roms in Gestalt des Apostelfürsten Petrus ruft der Autor im historischen Rückblick die Rolle des Papstes in Erinnerung, die dieser entsprechend der theologischen Grundlegung innehatte und die ihm nicht nur von Seiten der Westkirche, sondern auch und besonders von Seiten der östlichen Patriarchate zuerkannt wurde. Dies belegt er großzügig mit ost-westlicher konzilsbezogener Briefkorrespondenz und mit einem ausführlichen Rekurs auf die Legitimation der jeweiligen Patriarchate, wobei bei letzterem theologische und historische Argumente zum Teil zusammenfallen. Den einzig nachvollziehbaren Grund bzw. die einzig vorstellbare Rechtfertigung (excusatio), dass die Byzantiner dem

532, „[... [ for it seemed only logical that the ruler of the entire inhabited world, as the Byzantine emperor never ceased to regard himself, should have the major Church of Christendom over which to preside.“ (Milton 2001, 57)

533 Für weiterführende Literaturangaben zur Konstantinischen Schenkung vgl. die Anmerkung 451 auf Seite 127 der vorliegenden Studie.

534 FuHRMANn 1966, 64. 
Papst den Gehorsam verweigern können, sieht der Autor bezeichnenderweise in einem Sachverhalt, der keinerlei inhaltsbezogene Dimensionen aufweist: Einzig die lange Zeit (longiturnitas temporis), die seit Beginn des Auseinanderdriftens von Ost und West verronnen ist und die diesen unheilvollen Zustand in gewisser Weise verfestigt und buchstäblich zur Gewohnheit gemacht hat, wie es später bei Johannes XI. Bekkos $^{535}$ heißen wird, könne eine nachvollziehbare Erklärung für das Verhalten der Byzantiner bieten.

Die historische Argumentation des Autors berücksichtigt schließlich die jüngsten kirchenpolitischen Angelegenheiten in Bezug auf das Filioque als zweiten Grund für die Abweichung (deviatio) der Byzantiner neben dem Grund der verweigerten römischen Obödienz. Der Dominikaner nimmt dafür Bezug auf die Beschlüsse des Vierten Laterankonzils (1215), dessen Agenda die Frage nach dem Umgang mit der griechischen Kirche unter Innozenz III. enthielt. Da das IV. Lateranum die entscheidende Station für die lehramtliche Verbindlichkeit des Filioque darstellte ${ }^{536}$, wirft der Autor die Erinnerung daran am Ende seines chronologischen Durchgangs durch die Geschichte des Filioque in der Kirche mit gewichtigen Gründen in die Waagschale. ${ }^{537}$ Hinsichtlich der Rezeption aktueller kirchenpolitischer Gegebenheiten in der historischen Argumentation erscheint es auffällig, dass im Tractatus contra Graecos das Lateinische Kaiserreich in Konstantinopel mit keinem Wort Erwähnung findet, wie dies beispielsweise später bei Humbert von Romans der Fall ist. Die Entstehungshintergründe des Traktats würden vermuten lassen, dass die veränderten kirchenpolitischen Gegebenheiten in Konstantinopel, aber auch die wechselseitigen Kommunikations- und Verständigungsbemühungen eine deutliche Prägung im Umgang miteinander offenbaren, die allerdings im Tractatus contra Graecos nicht explizit zu finden ist. Zwar erscheint die alles umfassende Absicht des anonymen Autors, nämlich die Byzantiner von der römischen Obödienz zu überzeugen und somit das Schisma zwischen den Kirchen zu heilen, als direkte Maßnahme im Engagement zugunsten der Kircheneinheit. Aber sie lässt sich nicht - zumindest nicht explizit einordnen in die Entwicklungen, die aus der Sicht Roms mit der Etablierung des Lateinischen Kaiserreichs und vor allem Patriarchats in Konstantinopel nach der Eroberung durch die Kreuzfahrer begonnen worden waren und aus verschiedenen Gründen einer Fortführung bedurften. ${ }^{538}$ Was sich nach 1204 praktisch im kirchlichen Bereich vollzogen hatte - Einsetzung und, wenn auch nachträgliche, päpstliche Bestätigung eines lateinischen Patriarchen, der selbst dem Papst unterstellt war, dem

535 RIEBE 2005, 154.

536 Vgl. OBERDORFER 2001, 193.

537 Sed et Innocentius papa tertius in editione, quam fecit catholice fidei temporibus nostris, presidens in generali concilio Laterani celebrato, et dicens Patrem a nullo, Filium a Patre solo, Spiritum Sanctum pariter ab utroque, omnem excommunicauit et anathematizauit heresim extollentem se aduersus eam, quam exposuit, sanctam orthodoxam et catholicam fidem. Sed Grecus manifeste se erigit contra articulum de Spiritu Sancto, ergo etc. (TcG I, 1101-1108 (p. 53))

538 Zur Haltung von Papst Innozenz III. vgl. die Seiten 18-20 der vorliegenden Studie. 
wiederum der gesamte lateinische wie griechische Klerus untergeordnet war -, sollte nun vor dem Hintergrund bisheriger Erfahrungen mit der griechischen Kirche und ihrem Widerstand auch theoretisch nachhaltig gefestigt werden. Im Kontext der dominikanischen Tradition in der Provinz Graecia muss schließlich noch auf den Umstand hingewiesen werden, dass nach bisheriger Kenntnis keines der Werke des ausgehenden 13. und beginnenden 14. Jahrhunderts das Lateinische Kaiserreich explizit und argumentativ erwähnt.

\section{Theologische Argumente}

Wenn von der theologischen Argumentation des Kirchenbildes die Rede ist, dann sind damit mehrere Bereiche angesprochen, die unterschiedlichen theologischen Disziplinen zuzuordnen sind: Zunächst geht es bei der theologischen Argumentation, wie sie der Tractatus contra Graecos zugunsten seines Kirchenbildes anwendet, um die Frage nach der richtigen, autoritativen Schriftauslegung, die in der Tradition der Kirche gewährleistet ist. Solange sich die Kirche in den Spuren der Tradition bewegt, die sich wiederum in Person und Werk der Kirchenväter der Universalkirche sowie in den gemeinsamen konziliaren Beschlüssen manifestiert, geht sie in ihrer Lehre und ihrem Leben nicht fehl. Das Nennen patristischer und konziliarer Belegstellen, das ja als das methodische Grundgerüst des gesamten Traktats bezeichnet werden kann, dient demnach klar der Absteckung dieses Traditionsweges, an den sich die Kirche in Vergangenheit, Gegenwart und Zukunft bindet. Aus der Schrift heraus und vermittelt durch die autoritative Auslegung der Väter und Konzilien lassen sich die Grundkonstanten des Kirchenbildes des Traktats lesen. Die zweite Komponente der theologischen Argumentation ist die liturgisch-theologische Ebene insofern, als der Autor die Liturgie bzw. die Form der gottesdienstlichen Feier in unmittelbarem Zusammenhang zur Dogmatik sieht und von daher reziproke Rückschlüsse zieht: Was in der Liturgie gebetet bzw. gesungen, zum Teil auch an liturgischer Kunst betrachtet wird, das ist auch die Lehre der Kirche, und - umgekehrt - was die Kirche lehrt, das kommt auch in ihrer Liturgie und Ikonographie zum Ausdruck. Die liturgischen Texte sind von daher eine reiche Quelle für das Lehrgebäude der griechischen Kirche, das sich der anonyme Autor - und in noch größerem Umfang der Revisor des Traktats im Jahr 1305, Bartholomeus Constantinopolitanus ${ }^{539}$ - in derselben Weise wie die griechischen patristischen Quellen als Fundus seiner eigenen Argumentation zunutze macht. Zur theologischen Argumentation des Kirchenbildes zählt schließlich auch die Art und Weise, wie der Dominikaner das Schisma versteht: Im fünften Teil des Tractatus maior legt er den Byzantinern vier Gründe des Schismas (de quatuor causis schismatis) ${ }^{540}$ als ausschlaggebend für den Bruch zwischen Ost- und Westkirche in den Mund, wobei

$539 \mathrm{Zu}$ Bartholomeus Constantinopolitanus vgl. ausführlicher die Seiten 200 - 208 der vorliegenden Studie.

540 Vgl. TcG V, 1-55 (p. 112-114). 
alle vier Gründe im weitesten Sinn den Stempel der Kirchenpolitik tragen: Karl der Große als westliches Pendant zum (ost-)römischen Kaiser; die Nicht-Einbindung der Griechen in den Entscheidungsfindungsprozess bzgl. des Filioque; das als überheblich wahrgenommene Auftreten lateinischer Gesandter; und schließlich die als Provokation empfundene Absetzung des Patriarchen Photius. Da der Dominikaner diese vier Gründe am Ende seiner Aufzählung als nicht ausreichend und wohl kaum zwingend für ein Aufrechterhalten des Schismas bewertet, müssen die wahren Gründe, die notwendigerweise und zugunsten der Kircheneinheit einer Aufarbeitung bedürfen, im theologischen Bereich gesucht werden. Von daher ist die Argumentation des Kirchenbildes, das letztlich mit der Vorstellung der Kircheneinheit konform geht, von Grund auf theologisch angelegt.

\section{Quellenkritik und sprachliche Argumente}

Dass der Dominikaner die griechische Sprache beherrscht und damit Zugang zu den griechischen patristischen Quellen hat, dass er somit nicht auf die Wiedergabe der Meinungen griechischer Zeitgenossen aus dem mündlichen Diskurs beschränkt bleiben muss, sondern zum einen die Richtigkeit ihrer Angaben prüfen und zum anderen selbst Belegstellen anführen kann, die für seine Zwecke dienlich sind, darüber informiert er den Leser mehrfach mehr oder weniger explizit. Er stellt es andererseits in gewisser Weise auch zur Schau, indem er quellenkritische Argumente zu seinen Gunsten bringt und sprachlich-grammatikalische Missverständnisse in der lateinischgriechischen Kommunikation benennt. Aus Sicht des Autors und im Blick auf die griechischen Meinungen beinhaltet dies zudem Hinweise auf bewusste Quellenfälschungen und -manipulationen ${ }^{541}$ sowie auf falsche inhaltliche Ableitungen auf Basis fehlerhafter Übersetzungen oder Herleitungen ${ }^{542}$, wie der Dominikaner sie vor allem in der Azymen-Thematik mehrfach aufzeigt. ${ }^{543}$ Bemerkenswerterweise tut der Dominikaner damit genau das, was von vielen an den Unionsverhandlungen theologisch oder diplomatisch Beteiligten vor und besonders nach der Entstehung des Tractatus contra Graecos als unabdingbar angemahnt und eingefordert wird, um die Verständigung zunächst realisieren und dann vorantreiben zu können: die Sprachbarriere zu entschärfen. Dass gerade die mangelnden oder fehlenden Sprachkenntnisse eines der Haupthindernisse der gegenseitigen Verständigung darstellen, ist ein im lateinischen Kontext häufig anzutreffendes Argument vor allem im Kontext der dominikanischen, speziell auf die Mission ausgerichteten Bildungsstrukturen: ${ }^{544}$ Im Vorfeld des II. Kon-

541 Vgl. etwa TcG App. III, 1-92 (p. 163-165); TcG IV, 61-78 (p. 88-89); TcG App. II, 117-138 (p. 141142); TcG App. II, 141-150 (p. 142-143).

542 Vgl. etwa TcG III, 349-360 (p. 84) und die darauffolgenden Beweisgänge; vgl. zudem mehrere verstreute Einwürfe im ganzen Text.

543 Vgl. dazu vor allem die dritte Distinctio und die Widerlegung des Brieffragments des Patriarchen Germanos II. (TcG III, 1-384 (p. 69-85) und TcG App. VIII, 1- 498 (p. 199-211)).

544 Vgl. dazu auch GARZYA 2004, 143-152. 
zils von Lyon betont Humbert von Romans in seiner Funktion als fünfter magister generalis des noch jungen Dominikanerordens die Wichtigkeit des Sprachstudiums und setzt somit strategisch eine Anforderung um, die der anonyme Dominikaner bereits zwanzig Jahre vor der Amtszeit Humberts an die dominikanischen Missionare gestellt hatte. Auf Basis der Handschriftentradition, die gerade im Umfeld des Konzils von Basel/Ferrara-Florenz die meisten Abschriften des Tractatus contra Graecos bezeugt, kann davon ausgegangen werden, dass die Sprachkompetenz des anonymen Autors und seine Fähigkeit, mit ihr zu argumentieren, wesentlich zur Verbreitung der als Handreichung konzipierten Schrift beigetragen und diese gleichsam als Bonus gegenüber anderen Informationsquellen ausgezeichnet haben. ${ }^{545}$

\subsubsection{Konsequenz: Das Bild des Autors von der griechischen Kirche}

Für den Autor ist es eindeutig, dass es die griechische Kirche ist, die sich im Laufe der Jahrhunderte - ausgehend von der Zeit des Patriarchen Photius am Ende des 9. Jahrhunderts - von der einen, wahren Kirche Jesu Christi wegbewegt hat. Der Vorgang des Wegbewegens manifestiere sich zum einen in der aktiven Annahme widersprechender Lehren (z. B. die Lehre über den Zustand der Seelen), zum anderen im passiven Beharren auf der Exklusivität kirchlicher Traditionselemente (z. B. die Verwendung gesäuerten Brotes in der Liturgie), insgesamt aber darin, dass die Griechen die Autorität Roms missachten oder geringschätzen, wenn sie die theologische Richtigkeit der lateinischen Tradition (Filioque) anfechten und damit generell die Position der römischen Kirche und des römischen Papstes als ihr Oberhaupt anzweifeln bzw. aktiv leugnen. Die griechische Kirche, die der Autor für die Zeit vor dem photianischen Schisma als amica bezeichnet ${ }^{546}$, bildet ebenso wie die lateinische das Corpus der Gesamtkirche. Sie bewegen sich beide - mit ihren jeweiligen liturgischen und kulturellen Eigenheiten - in den Spuren der Apostel und der Kirchenväter und damit der kirchlichen Tradition, deren Träger und Hüter das römische Papsttum ist. Da die griechische Kirche aber

innumeris et diuersis errorum offuscata turbinibus in eadem caligine suarum opinionum diuisa a sacrosancta Romana ecclesia et ceca perseuerat (TcG Prol., 8-10 (p. 3))

blind und getrübt von unzähligen und unsteten Stürmen der Irrtümer in demselben Nebel ihrer Meinungen getrennt von der hochheiligen römischen Kirche verharrt,

ist es nun die Aufgabe des päpstlichen Hüters und seiner Beauftragten, sie zum größeren Nutzen der Kirche zur Wahrheit zurückzuführen.

545 Zur Vorbereitung der lateinischen Konzilsakteure auf die Diskussionen mit den Byzantinern sowie zu weiterführender Literatur vgl. RIEDL 2020.

546 TcG V, 35 (p. 113). 